LA-8403-PR

Progress Report

C.3

CIC-14 REPORT COLLECTION

REPRODUCTION

COPY
Reactor Technology

January-March 1980

ర0

$\frac{\gtrsim}{\infty}$

$\frac{5}{1}$

$\frac{\text { I }}{2}$

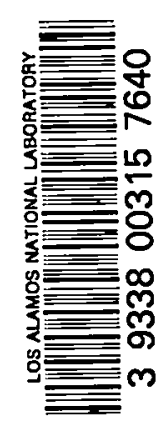

'L 
The four most recent reports in this series, unclassified, are LA-7878-PR, LA-7992-PR, LA-8160-PR, and LA-8259-PR.

This report was not edited by the Technical Information staff.

This work was supported by the US Department of Energy, Offices of Military Application and Laser Fusion, and Divisions of Advanced Systems and Materials Production, Reactor Research and Technology, Basic Energy Sciences, and Fossil Energy Power Systems; Hanford Engineering Development Laboratory; and the National Aeronautics and Space Administration.

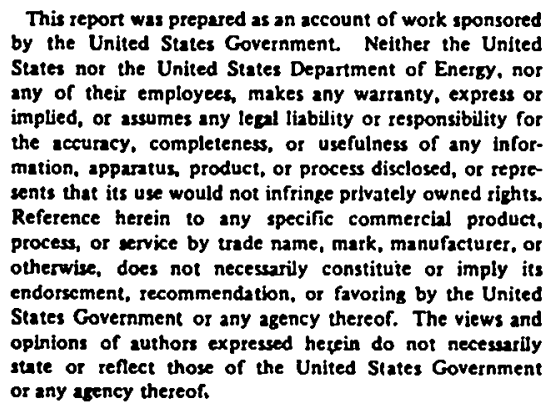

UNITED STATES DEPARTMENT OF ENEROY Contract w-7aos-ene. 36 
LA-8403-PR

Progress Report

UC-80

Issued: June 1980

\title{
Reactor Technology
}

\section{January - March 1980}

\author{
Prepared by \\ Energy Technology Office \\ Energy Division \\ C. R. Emigh \\ Associate Division Leader \\ Edited by \\ Michael Breslow \\ Sally Sullivan
}


3
1
0

,

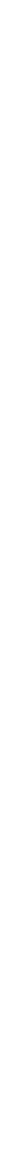




\section{CONTENTS}

ABSTRACT. . . . . . . . . . . . . . . . . . . . . I 1

I. SPACE REACTOR (SPAR) ELECTRIC POWER SUPPLY. ......... 3

A. Executive Summary. ................ 3

B. Program Overview ............... 3

C. Mission Requirements.............. 3

D. Power Plant System Analyses. . . . . . . . . . 8

E. Core Heat Pipe Development . . . . . . . . . . 17

F. Thermoelectric Module Development. .......... 24

G. Radiator Development ............... 27

H. $\mathrm{NO}_{2}$ Fuel Fabrication ............... 44

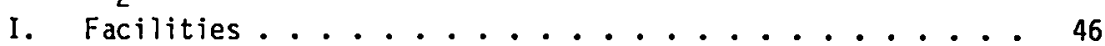

REFERENCES. ..................... 47

II. REACTOR SAFETY: GAS-COOLED FAST REACTOR SAFETY EXPERIMENTS. . . 48

A. Executive Summary. ............... 48

B. Program Planning............... 48

C. Analysis................... 48

D. Design ........................ 51

E. Procurement and Fabrication............. 51

F. Assembly, Installation, and Checkout ......... 52

G. Testing. ................. 52

III. REACTOR SAFETY: STRUCTURAL ANALYSIS . . . . . . . . . 54

A. Executive Summary. ............... 54

B. HTGR Structural Evaluation ............ 54

C. Structural Margins to Failure. ............ 55

D. Zion and Indian Point Study. ............ 56

REFERENCES. .................. 58

IV. HEAT PIPE TECHNOLOGY DEVELOPMENT. .............. 59

A. Executive Summary. . . . . . . . . . . . . 59

B. Ceranic Heat Pipe Technology Development Program ..... 59

C. Heat Pipe Engineering. .............. 64

v. NUCLEAR CRITICALITY EXPERIMENTS AND SAFETY. ......... 68

A. Executive Summary............... 68

B. Nuclear Criticality Safety ............ 68

C. Honeycomb Assembly................ 69

D. Godiva IV. . ................ 70

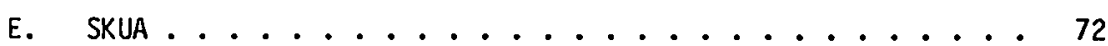

F. Cockcroft-Walton Accelerator . ........... 73

G. "INRAD" Measurements of LASL Weapons ............ 74

H. Sandia Shipping Cask Evaluation. . . . . . . . . 75

Publications. ..................... 75

REFERENCES. .................... 75 


\section{FIGURES}

1. Power plant mass as a function of shield half angles and converter efficiencies.................... 4

2. Gamma shielding for shutdown mode . . . . . . . . . . 7

3. Gamma activities as a function of time. . . . . . . . . 7

4. Maintainability with permanent gamma shield . . . . . . . 8

5. Auxiliary shield inside power plant radiator. . . . . . . . 9

6. Maximum payload vs mission time using various thruster subsystems..................... 10

7. Microscopic examination of tab and tube contact regions.... 11

8. Neutron fluence at payload vs shield mass . . . . . . . . 13

9. Minimum shield mass vs radiator half cone angle . . . . . . 13

10. Shish Kebab module. ........................... 14

11. Maximum fin temperatures for worst interior case. . . . . . 14

12. SPAR mockup in honeycomb critical assembly (quarter section). Modules are $7.62 \mathrm{~cm}$ square............... 15

13. Polyethylene reactivity worth in SPAR Honeycomb mockup. . . . 16

14. System lifetime distribution function analys is flow process... 16

15. SPAR-1 heat pipe. ......................... 18

16. SPAR-1 pore size as a function of power at $55^{\circ}$ tilt and

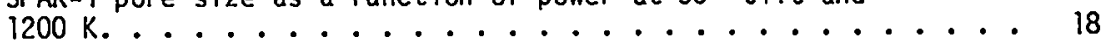

17. SPAR 1 performance with $46 \mu \mathrm{m}$ pore size ........... 19

18. As-received, stress relieved Mo tubing. . . . . . . . . 21

19. Annealed molybdenum tubing. ................ 21

20. Annealed molybdenum tubing (4)............... 22

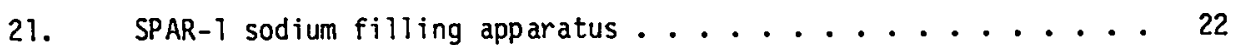

22. Free energies of formation for oxides expected in SPAR core heat pipes.................... 24

23. P-type SiGe thermoelectric properties . . . . . . . . 25

24. SPAR thermoelectric module. . . . . . . . . . . 26

25. Finite element model of bonded thermoelectric module. . . . . 27

26. Radiator mass vs meteoroid mass for various numbers

of stringer heat pipes................. 28

27. Radiator mass vs cone half angle for various thermoelectric. .29

28. Stringer heat pipe length vs cone half angle for various thermoelectric efficiencies.............. 29

29. Wicking height geometry . . . . . . . . . . . . . 29

30. RAD-2, a completed 2-m-long titanium heat pipe........ 31

31. Assembly and welding fixture for titanium radiator heat pipes showing PCGTA welding head in place............ 32 
32. End cap with EB welded fill tube. ............. 33

33. End view of a titanium heat pipe showing a laser

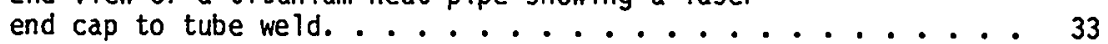

34. RAD-2 and heater in the vacuum chamber ready for testing. . . . 35

35. Zinc orthotitanate emissivity coatings on pure titanium

(a) as-received and (b) after one cycle to $775 \mathrm{~K} . \ldots 35$

36. D-111 emissivity coating on pure titanium

(a) as-received and (b) after one cycle to $775 \mathrm{~K}$. . . . . 36

37. Arrehnius plot of total layer growth. . . . . . . . . 37

38. Arrehnius plot of $\mathrm{Be}_{2} \mathrm{Ni}_{5}$ layer growth. . . . . . . . 37

39. Arrehnius plot of BeNi layer growth ............. 38

40. Sabot plates and target from shot 78........... 40

41. Portion of oscilloscope record showing typical cut off of second laser beam by projectile and other material launched by gun. The passage of the projectile can be identified as the short downward spike. ..............40 40

42. Typical record of muzzle flash from light gas gun ....... 41

43. Radiograph of a sabot carrying a copper projectile, from shot 88.41

44. Relationship between volume of the crater in the mold steel SP

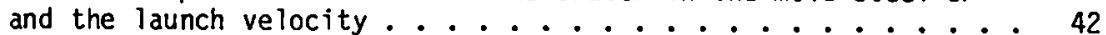

45. Crater made by 0.5 -mm glass bead in shot $82 \ldots 43$

46. Crater made by copper projectile in shot $89 . \ldots 43$

47. Three frames selected from $8 \& W 300$ record from shot 95 , showing projectile prior to impact, bulge in rear target surface, and

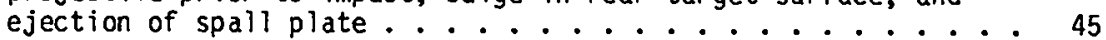

48. Sketch of reactor core with $\mathrm{U0}_{2}$ tiles . . . . . . . . . 4 45

49. Rotatable mirror calorimeter design . . . . . . . . . 46

50. Center hole circumferential stress. . . . . . . . . . 49

51. GCM model ......................... 50

52. Results for Case 1 at 2 h .............. 50

53. Results for Case 1 at 64 h. ............... 50

54. Heat losses in GCM experiment ............... 51

55. The FLS3 circuit. ................ 52

56. Concrete cube with four tendons and one-dimensional

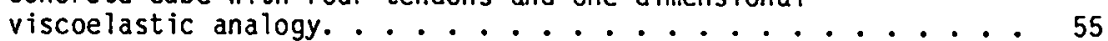

57. Decay of tendon preload because of concrete creep . . . . . 55

58. Views of the finite element mesh for the Zion

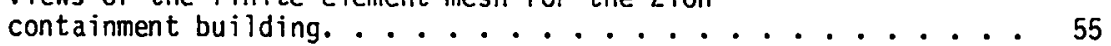

59. Results from static pressure loads.............. 57

60. Pressure-moment interaction curve at cylinder-ring intersection . 58

61. Longitudinal section through tungsten coated silicon carbide heat pipe and end-plug which was brazed at $1300-14000$

with Palco and Paloro................. 
62. Cross section of thermally cycled $\left(1500^{\circ} \mathrm{C}\right)$ molybdenum tube plated with tungsten and silicon carbide ........ 62

63. Heat pipe recuperator arrangement . . . . . . . . . . 63

64. Crossflow plate-fin heat exchanger construction ....... 63

65. Ceramic recuperator design concept - glass furnace. . . . . . 65

66. BES4 heat pipe schematic. . . . . . . . . . . 66

67. Heat pipe performance for methanol working fluid. . . . . . 66

68. Heat pipe performance for water working fluid . . . . . . . 67

69. Heat pipe performance for toulene working fluid . . . . . . 67

70. Quarter section of Honeycomb SPAR mockup. . . . . . . . 70

71. Polyethylene reactivity in Honeycomb SPAR mockup. . . . . . 70

72. Collimator for fission distribution measurements. . . . . . 73

73. Table for moving fissile sample by remote control . . . . . 73

74. Polyethylene effectiveness in Skua flux trap. . . . . . . . 74

75. Thermal neutron flux in Skua cavity . . . . . . . . . . 74

76. Automatic linear positioning system for radiation detectors . • 76

77. Boro-silicone cask cover "A" after exposure . . . . . . . . 77

78. Borated beechwood cask cover "D". . . . . . . . . . . 79

79. Boro-silicone cover "H" in mockup shipping cask . . . . . . 80

TABLES

I. $100 \mathrm{~kW}$ POWER PLANT . . . . . . . . . . . . . . . 4

II. TYPICAL DESIGN PARAMETERS FOR $100-k W_{e}$ POWER PLANT . . . . . . 4

III. CLASSIFICATION OF POTENTIAL MISSIONS. . . . . . . . . . 5

IV. MANNED OPERATIONS IN VICINITY OF SPACE REACTOR. . . . . . . 8

v. GAMMA SHIELD MASS AS A FUNCTION OF SHIELD LOCATION. . . . . . 9

VI. RING TENSILE TESTS ON MOLYBDENUM TUBING ............. 20

VII. RADIATOR CHARACTERISTICS AT $100 \mathrm{~kW}$. . . . . . . . . . 28

VIII. CALCULATED AND OBSERVED WICKING HEIGHTS FOR RIGHT ANGLE

IX. OBSERVED WICKING HEIGHTS FOR PYRAMIDAL EMBOSSED SURFACES. . . . 30

X. OBSERVED WICKING HEIGHTS FOR STEEL SHOT-BLASTED TITANIUM. . . . 30

XI. PREDICTED POTASSIUM WICKING HEIGHT AT $775 \mathrm{~K}$

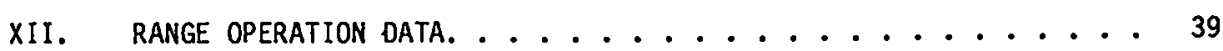

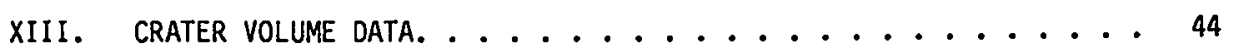

XIV. CALCULATIONS OF CRATER PARAMETERS ................... 44

XV. SUMMARY OF STATIC RESPONSE. . . . . . . . . . . . 57

XVI. CERAMIC HEAT PIPE RECUPERATOR DESIGN CONDITIONS . . . . . . 63 
XVII. HEAT PIPE RECUPERATOR PRELIMINARY DESIGNS . . . . . . . . . . 63

XVIII. COST SUMMARY FOR CERAMIC HEAT PIPE SYSTEMS (\$) . . . . . . . . 64

XIX. 1984 COST SAVINGS (1979 DOLLARS) . . . . . . . . . . 65

XX. 1984 SIMPLE PAYBACK PERIOD (YEARS). . . . . . . . . . . 65

XXI. DC RESPONSE OF SCINTILLATION NEUTRON DETECTORS. . . . . . . . 72

XXII. SANDIA CASK ATTENUATION FACTORS ............... 78

XXIII. MEASURED DOSE RATES FOR SANDIA SHIPPING CASK COVERS NEUTRON \& GAMMA ...................... 78 


\section{REACTOR TECHNOLOGY}

JANUARY - MARCH 1980

Prepared by

Energy Technology Office, Energy Division

C. R. Emigh, Assoc. Div. Leader

Edited by

Michael Breslow

Sally Sullivan

\section{ABSTRACT}

Significant progress is reported in the Space Reactor (SPAR) Electric Power Supply Program. Power plant analysis, where converter efficiency and shield half angle were-varied to determine the effect on system mass, indicated that for a converter efficiency of $9 \%$ and shield half angle of 300 the mass is less than our $1910 \mathrm{~kg} \mathrm{goal}$; if the efficiency drops to $8 \%$, the shield half angle would need to be less than $26^{\circ}$ to stay under $1910 \mathrm{~kg}$, and for $7 \%$ less than $18^{\circ}$. SPAR-1, the first 2-m-long molybdenum heat pipe, was fabricated and is undergoing test. Impact data on titanium at elevated temperatures show the armor requirements for the radiator are $40 \%$ less than anticipated. Incorporating this finding into the design led to a radiator mass reduction of about 25\%; however, more detailed studies on shield designs at the higher cone half angles tend to hold the power plant weight around $1750 \mathrm{~kg}$. A $2-\mathrm{m}-$ long $\mathrm{Ti} / \mathrm{K}$ heat pipe was constructed and operated at $825 \mathrm{~K}$, representing a major advance in fabrication and testing development.

The Gas-Cooled Fast Reactor Safety Experiments Program reports that SMART I, because of funding limitations, will not be assembled this year. Design work will be completed, however, and the FLS-3 test performed. Cooling of the GCM pressure vessel was analyzed and found acceptable as were the results of an analysis on the effects of enlarging the diameter of the central hole in the upper GCM pressure vessel cover. In the FLS-3 current design, the diameter of the lower pipe and the valve have been reduced, and the horizontal pipes have been lengthened to increase flexural compliance to thermal distortion. Only a moderate amount of effort remains to complete the SMART I design. Most of the hardware required for the FLS-3 has been received. A significant number of SMART I parts is on hand and many are on order, but no new orders are being placed because of funding limitations. Instrumentation wiring between the test cell and the data acquisition system is now installed, bringing the system capacity up to 210 channels. Testing is underway to determine the cause of variations in the measurements of graphite heater rod resistance. Experimental work is continuing to determine feasibility of $x$-ray diagnostics, and arrangements have been made to try this technique on the FLS-3 test.

In the Reactor Safety/Structural Analysis Program, work has continued on the NONSAP-C code development task with major progress being the addition of a tendon element to the element library of the code. A study of the vulnerability of the 7.ion and Indian Point containments to steam explosions and hydrogen explosions was completed. In the former, the possibility of generating large missiles was found to be remote, and in the latter case, a containment static failure pressure of 154 psig was determined while dynamic loading with a peak pressure of 200 psig was found to cause structural collapse.

The Heat Pipe Technology Development Program continues its investigation of envelope, closure, and working fluid materials for the ceramic heat pipe program and the analysis of the economics of ceramic recuperator application in the steel, glass, and aluminum industries. The investigation of limiting conditions in gravity assisted heat pipes has continued with fluid inventory and operating angle as basic parameters. 
Nuclear Criticality Experiments and Safety reports the nanosecond pulsing system installed on the Cockcroft-Walton accelerator is now undergoing tests. When

operational, it will provide a time-of-flight capability for neutron spectroscopy experiments. Uranium fuel rings for the Godiva IV burst machine have been aluminumion plated in preparation for experiments at the PHERMEX Facility to measure neutron multiplication in a dynamic subcritical system. Preliminary measurements of the reactivity worth of hydrogen in the space reactor, SPAR, mockup have been made. The results will be used to evaluate the criticality hazard of flooding the reactor with water. Intrinsic radiation measurements are continuing on the B6 1-3 Inrad Unit and preparation made to examine the W80 InRad Unit inside a Navy Tomahawk missile to ver ify predictions satisfying military characteristics for the system. Measurements of the degradation of radiation attenuation factors have been completed for several materials proposed by the Sandia Laboratory for spent-fuel shipping casks. The mockup cask covers had been subjected to design-basis accident exposures. 
I. SPACE REACTOR (SPAR) ELECTRIC POWER SUPPLY

A. Executive Summary (D. Buden, Q-DO/ET)

Components for a 10 -to- $100 \mathrm{~kW}_{\mathrm{e}}$ space nuclear reactor electrical power plant are being designed, fabricated, and tested. Such a power plant will consist of: (1) a nuclear reactor for generating heat, including heat pipes for transferring the energy from the reactor to the power conversion equipment; (2) a radiation shield to attenuate radiation to an acceptable level for the payload;

(3) thermoelectric (TE) converters to convert heat to electricity; and (4) a radiator for rejecting waste heat to space. The components being designed and tested, when incorporated into a power plant, will provide a relatively inexpensive, compact power source for large, earth orbiting satellites that the Department of Defense is evaluating for communications and surveillance.

Significant progress was made in the design and experimental program, including:

- Power plant analysis assuming different converter efficiencies shows that for a converter efficiency of $9 \%$ and shield half angle of $30^{\circ}$ the mass is less than our $1910 \mathrm{~kg} \mathrm{goal;}$ if the efficiency drops to $8 \%$, the shield half angle would need to be less than $26^{\circ}$ to stay under $1910 \mathrm{~kg}$, and for $7 \%$ less than $18^{\circ}$.

- SPAR-1, the first 2-m-1ong molybdenum heat pipe was completed and is now being tested. The first test series in a quartz vacuum tube was performed at $1400 \mathrm{~K}$. The heat pipe was tilted up to $60^{\circ}$ to demonstrate performance against gravity.

- Thermoelectric module rings of the compression design were mated to a molybdenum heat pipe for the first time and are now being tested. A preliminary thermoelectric module bonded design has been completed.

- Impact data on titanium at elevated temperatures indicate that the armor requirements for the radiator are $40 \%$ less than was anticipated. Incorporating the impact data into the radiator design leads to a radiator mass reduction of about $25 \%$. More detailed studies on shield designs at the higher cone half angles tend to hold the power plant weight around $1750 \mathrm{~kg}$.

- A 2-m-long $T i / K$ heat pipe was constructed and operated at $775 \mathrm{~K}$. Although the arteries did not work as designed, this represents a major advance in fabrication and testing development. B. Program Overview (D. Buden, Q-DO/ET)

During this quarter, significant progress was made in shielding analysis and in the radiator design. Originally, we based our designs on a $12^{\circ}$ cone half angle shield. Mission studies had indicated that this was a reasonable assumption. However, considerations of Shuttle volume packaging and potential use of SPAR with electric ion propulsion has led us to consider shield half angles to $30^{\circ}$. The larger shield half angles led to investigating more optimum shield shapes. These studies are now completed. Also, the meteoroid impact data studies reported under radiator design indicate significant reduction in armor thickness is possible. In the area of thermoelectric module design, we are learning more of what must be accomplished to reach $9 \%$ efficiency. The $9 \%$ goal appears to be feasible, but the effect of not reaching that goal has been evaluated along with the new shield and radiator calculations. The analysis is summarized in Table I and Fig. 1. It shows that we can stay within our mass goal for all shield cone half angles to $30^{\circ}$ with $9 \%$ efficiency TE converters; with $8 \%$ converters the shield angle would be less than $26^{\circ}$, and $7 \%$ converters less than $18^{\circ}$.

A set of typical design parameters for the $100-\mathrm{kW}_{\mathrm{e}}$ system is shown in Table II. A $25^{\circ}$ shield half angle is chosen because it utilizes less than a fourth of the Shuttle and would reach full Shuttle diameter at the same location as a $30^{\circ}$ shield with ion thrusters incorporated in the design. Electric propulsion so relieves the constraints on mass to geosynchronous orbit that additional shielding can be easily handled.

C. Mission Requirements (D. Buden, Q-DO/ET)

At its Feb. 26 meeting, the NASA (OAST)/Air Force (AFSC) Interdependency Working Group endorsed an approach to establishing a space reactor power system technology plan. The plan calls for an Interagency Steering Committee of DoD, NASA, and $D O E$ to provide technical management and approval towards establishing technology readiness in the 1980 s to meet the 1990 s mission requirements and a Working Group to determine mission 
TABLE I

$100 \mathrm{kH}_{e}$ POWER PLANT

SHIELC HALF ANGLE (Dëg.)

Efficiency $(x)$

Reac tor power $\left(K H_{t}\right)$

Core heat pipe temperature ( $K$ )

Radiator temperature (K)

Radiator power $\left(k W_{t}\right)$

Length of power $p$ lant to shuttle dianeter ( $m$ )

Overall length of power plant (m)

Power plant mass $(\mathrm{kg})$

Reactor and heat pipe to thermoelectrics $(\mathrm{kg})$

Shield (kg)

Thermoe lec tr ic converters $(\mathrm{kg})$

Radiator ( $\mathrm{kg}$ )

Structure $(\mathrm{kg})$

\begin{tabular}{lll}
\multicolumn{3}{l}{15} \\
\hline 7 & 8 & 9 \\
1430 & 1250 & 1110 \\
1400 & 1400 & 1400 \\
775 & 775 & 775 \\
1330 & 1150 & 1010 \\
7.5 & 7.5 & 7.5 \\
10.3 & 9.2 & 8.5 \\
1835 & 1650 & 1530 \\
430 & 410 & 400 \\
300 & 290 & 290 \\
365 & 320 & 285 \\
575 & 480 & 415 \\
165 & 150 & 140
\end{tabular}

\begin{tabular}{lll}
\multicolumn{3}{l}{20} \\
\hline 7 & 8 & 9 \\
1430 & 1250 & 1110 \\
1400 & 1400 & 1400 \\
775 & 775 & 775 \\
1330 & 1150 & 1010 \\
5.5 & 5.5 & 5.5 \\
9.1 & 8.1 & 7.4 \\
1950 & 1765 & 1645 \\
430 & 410 & 400 \\
430 & 415 & 410 \\
365 & 320 & 285 \\
555 & 460 & 400 \\
170 & 160 & 150
\end{tabular}

\begin{tabular}{lllllll}
\multicolumn{3}{c}{25} & & \multicolumn{3}{c}{30} \\
\cline { 1 - 4 } \cline { 5 - 7 } & 8 & 9 & & 7 & 8 & 9 \\
1430 & 1250 & 1110 & & 1430 & 1250 & 1110 \\
1400 & 1400 & 1400 & & 1400 & 1400 & 1400 \\
775 & 775 & 775 & & 775 & 775 & 775 \\
1330 & 1150 & 1010 & & 1330 & 1150 & 1010 \\
4.3 & 4.3 & 4.3 & & 3.5 & 3.5 & 3.5 \\
8.4 & 7.4 & 6.7 & & 7.9 & 6.9 & 6.2 \\
2045 & 1855 & 1730 & & 2165 & 1980 & 1860 \\
430 & 410 & 400 & & 430 & 410 & 400 \\
520 & 505 & 500 & & 640 & 625 & 620 \\
365 & 320 & 285 & & 365 & 320 & 285 \\
545 & 450 & 390 & & 535 & 445 & 385 \\
185 & 170 & 155 & & 195 & 180 & 170
\end{tabular}

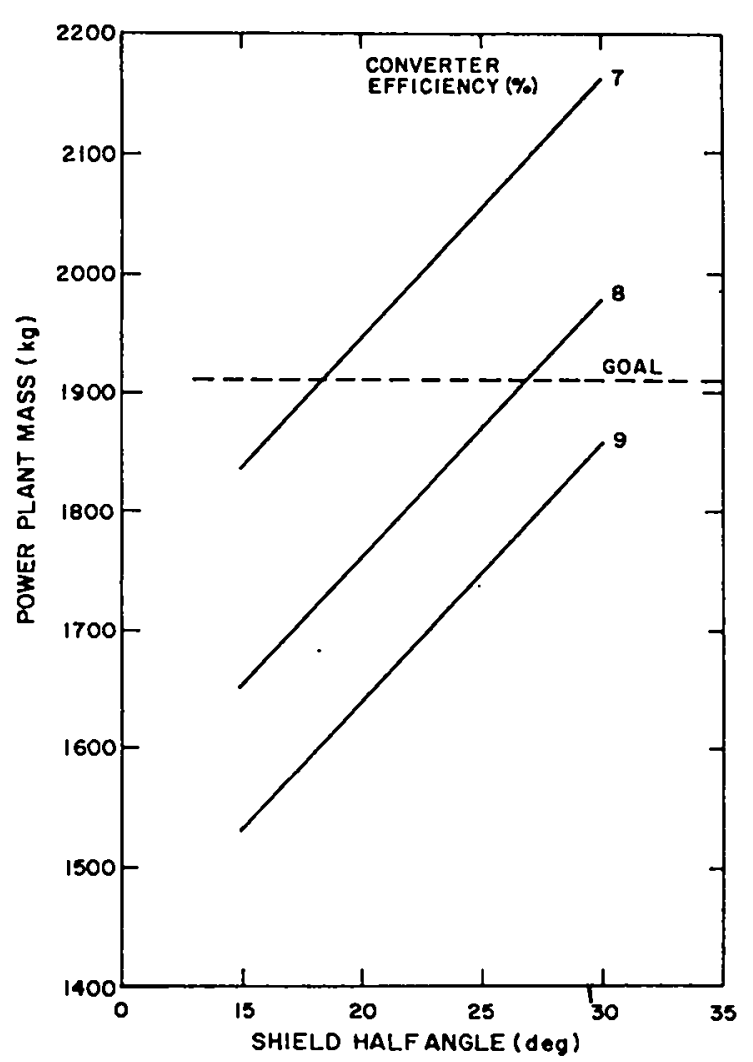

Fig. 1. Power plant mass as a function of shield half angles and converter efficiencies. $\left(100 \mathrm{~kW}_{\mathrm{e}}\right)$.
TABLE II

TYPICAL DESIGN PARAMETERS FOR $100-\mathrm{kH}$ e POHER PLANT Reactor power $\left(k W_{t}\right)$

Core heat pipe temperature $(K)$

Number of core heat pipes

Fuel swelling (x)

Burn fraction of ${ }^{235} U(x)$

Thermoelectric efficiency $(x)$

Radiator power $\left(\mathrm{kW}_{\mathrm{t}}\right)$

Reactor diameter $(\mathrm{m})$

Reactor length ( $m$ )

Radiator area $\left(\mathrm{m}^{2}\right)$

Overall power plant length ( $m$ )

Shuttle bay length exclusion of full diameter (m) 4.3

Power plant mass ( $\mathrm{kg}$ )

Reactor

400

Fuel region

Reflector

125

Heat pipes

Control system

Support structure

Shield ( $25^{\circ}$ half angle)

Thermoe lec tric converters

Radiator

500

285

390

Structure
1110

1400

90

3

9

1010

0.52

0.50

64

6.7

1730 
requirements and to reconcile differences and to prepare a detailed development plan.

Candidate missions for a space nuclear power plant have been catalogued and evaluated. A number of $f$ actors are weighed in deciding whether SPAR is a prime candidate for particular missions. For example, the power required for the sensors results in other sources of power becoming uneconomical, or the energy required for transportation and station keeping would be excessive for other power sources. Also, there may be special considerations such as survivability in case of enemy attack or the need for a compact power source for spacecraft stability and maneuverability.

The various potential missions have been categorized based on whether they could be the driving prospects or "best prospect" for developing SPAR, on whether SPAR would be a "good candidate" to be included in the mission if it is fielded, or on whether SPAR is a potential subsystem once it is developed. Table III summarizes our opinions on various mission prospects. The "best prospects" are those that have a high probability of being fielded and SPAR is an enabling technology or offers significant advantages. These will probably be the decisive missions that determine whether SPAR is developed. The "good candidates" may be enabled by having SPAR, but insufficient work is being done to use these missions as a primary selling point for developing SPAR. The "potential user" category includes those systems that could benefit from the existence of SPAR, but are unlikely to be decisive in gaining a commitment for SPAR development.

of the many existing potential missions that could benefit from a space nuclear electric power plant, the number of prime missions that will govern the decision as to whether SPAR is deveToped centers on the following:

TABLE III

CLASSIFICATION OF POTENTIAL. MISSIONS

\section{Best Prospects}

Defense: Space-based radar

Scientific: Planetary exploration

Iransportation: Earth orbit transfer stage

\section{Good Candidates}

$\begin{array}{ll}\text { Defense: } & \begin{array}{l}\text { Advanced strategic } \\ \text { survellance sensor } \\ \text { (infrared) }\end{array} \\ \text { Space-based weapon } \\ \text { systems } \\ \text { Deep space backup } \\ \text { surveillance } \\ \text { DSCS-X } \\ \text { G.I. - personal } \\ \text { communications } \\ \text { Deep space comand } \\ \text { post }\end{array}$

Defense: Global logistics information system

Navigation grid

Far-term RPV control readout

Civilian: Disaster cormunications set

Urban/police wrist radto

Personal communications wrist radio

Electronic mail transmission

Advanced T.V. broadcast

Voting/polling wrist set

National information service

3-D holographic

teleconferencing

Vehic le/package locator

Border surveillance

Fire detection

Burgular alarm/intrusion detection

Energy monitor

Nuclear waste disposal

Lunar Power station for

Colony: 12 men 
1. Surveillance mission space-based radar technology is being developed by DARPA and is scheduled to become an Air Force Space Division program in 1981. Currently, a technology road map is being prepared to lead to an operational system by the end of this decade. If a geosynchronous orbit is selected, nuclear power will probably be required.

2. It is becoming apparent that a large capacity transfer vehicle is going to be needed for moving satellites from low Earth orbit to geosynchronous orbit. The Space Shuttle can transport $29500 \mathrm{~kg}$ to low orbit but with the chemical stages now being developed, only $3000 \mathrm{~kg}$ can be transported to geosynchronous orbit. Electric ion thrusters, such as the 30-cm-diam thruster, are already highly developed but no power source is available to take advantage of their capability. However, with a SPAR nuclear electric power source, $10000 \mathrm{~kg}$ could be transported to geosynchronous orbit using the ion thrusters.

3. Planetary missions will eventually require nuclear electric propulsion and, in fact, NASA has had a continuing technology program in this area for several years. SPAR would provide a significant capability for comet, asteroids, Uranus, and Neptune missions with an upgraded version for missions to Pluto. The main shortcoming in designing systems for planetary missions is getting the Government to commit and maintain a time table for their execution.

Most other potential DoD missions are too ill defined at this time to provide a sound basis for SPAR development. Space weapon systems could potentialty be an application but, again, insufficient work is underway in the power systems area and schedules are too elastic to provide a firm base for SPAR development.

Many potential civilian applications exist that should require power levels and orbits where SPAR would be a potential candidate. However, these missions are not well defined and will probably be sized for whatever technology is available. Therefore, the near-earth civilian applications do not appear to offer a mission basis for developing SPAR.
Some thoughts are presented here on maintaining a satellite with a nuclear power source. Sensors and other components within the satellite are protected from the reactor radiation field by means of a radiation attenuation shield. This shield usually takes the form of a low atomic density material to attenuate the neutrons and a high atomic density material to attenuate gamma rays. Rather than surrounding the entire reactor with a shield, to minimize weight, shielding is located at only one section of the reactor. The satelitite components are located within the shadow cone angle of this section. Usually, sufficient shielding is placed on the satellite for electronic components. However, man is about $10^{4}$ times more vulnerable to radiation than electronic components. For manned operation in the vicinity of a space reactor, safety 1 imits have been set at 35 rem/13 weeks. With the usual unmanned shield, people cannot safely approach within $2.5 \mathrm{~km}$ of an operating reactor within the shadow shield cone and $12.8 \mathrm{~km}$ outside this cone; for a shutdown reactor these distances decrease to $0.5 \mathrm{~km}$ and $1.2 \mathrm{~km}$, respectively. To meet the criteria of no more than $10^{7}$ RADS gammas and no more than $10^{13}$ nut neutrons at the payload over the 7 year mission 1 ife requires an attenuation in the shadow shield of a factor of 5 for gammas as compared with a factor of 10,000 for neutrons. Thus inside the shadow shield cone the biological dose rate from gammas (reactor operating) is about a factor of 400 greater than from neutrons compared with a factor of about 1/5 outside the cone. This accounts for the relatively small improvement in approach distance between being outside and inside the shadow shield cone. It should be noted that this does not cause problems to other satellites that might be located in the vicinity of the nuclear powered satellite because they are usually $1-2^{0}$ or over $600 \mathrm{~km}$ apart.

It is postulated that there would be no desire to maintain a satellite with the reactor operating, so our discussion will concentrate on the shutdown case.

Figure 2 provides shielding thickness requirements for a person at $10 \mathrm{~m}$ from a shutdown reactor using $U, W$, or $\mathrm{Pb}$ as the shielding material. It should be pointed out that gamma radiation is the dominant radiation during shutdown (see Fig. 3 ). 


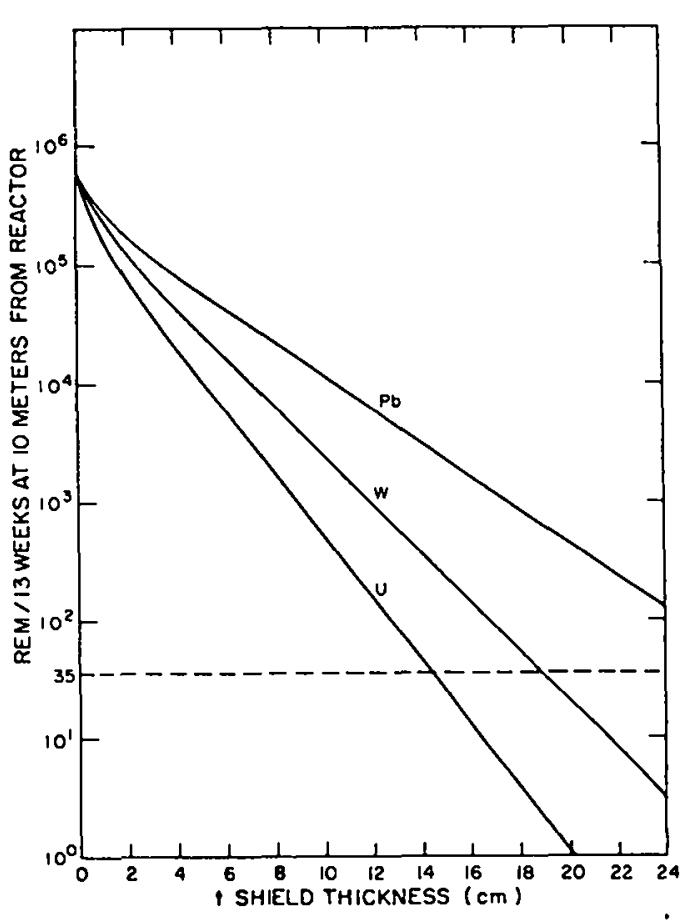

Fig. 2. Gamma shielding for shutdown mode.

Table.IV gives some representative values for shield thickness for various assumed requirements. There are two approaches to consider in arriving at a personnel shield--either a permanent shield that is included as part of the satellite or a mobile shield that is temporarily emplaced on the satellite only during the maintenance operations.
The permanent shield would add a dense material between the reactor and the current lithium hydride shadow shield (see Fig. 4). The thickness of the shield would depend on the location of the nearest component to be maintained directly by personnel. Thus, if the nearest personnel location is to be $10 \mathrm{~m}$ from the reactor, a i layer 19 $\mathrm{cm}$ thick would be located at the reactor. It is possible to approach closer than $10 \mathrm{~m}$ for a limited period of time. Also, since personnel would move well away from the reactor during rest and sleep periods, the radiation exposure is expected to be much less than the limits used. The $W$ layer would be in a region populated by heat pipes. It is anticipated that the $W$ can be installed by canning the region of interest and inserting powdered or small beads of $W$. If the shadow shield angle is $0^{\circ}$, the quantity of $W$ for a $19 \mathrm{~cm}$ thick layer is $720 \mathrm{~kg}$, while for a $30^{\circ}$ half angle shield, the quantity increases to 2440 $\mathrm{kg}$.

The permanent addition of a gamma shield is the lightest weight shield for an individual satellite, but it must be included as part of the original satellite. An alternate approach is to deploy a maintenance spacecraft that would be used to service all satellites. We would envision a craft that would use nuclear electric propulsion to move the maintenance vehicle from low to high orbit, that would include shielding, a storm cellar, and other permanent items for maintenance.

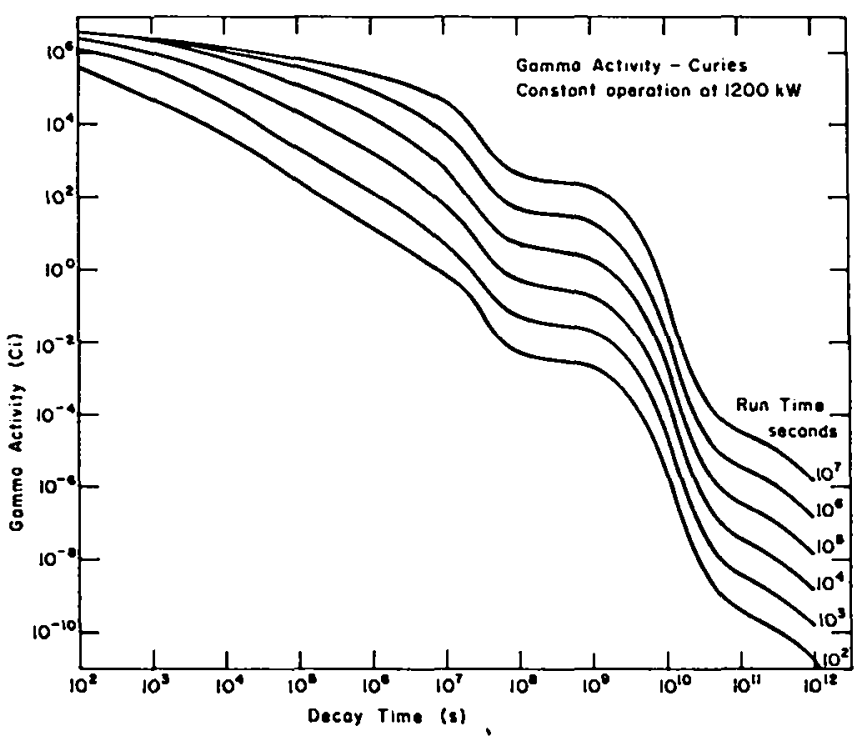

Fig. 3. Gamma activities as a function of time. 
TABLE IV

MANNED OPERATIONS IN VICINITY OF SPACE REACTOR (1.2 MW $\left._{t}\right)$

(35 REM/13 WEEKS DOSE RATE LIMIT)

Full power operation

One day after shutdown

Distance from reactor

full power operation

One day after shutdown

After the vicinity of geosynchronous orbit is reached, the reactor power plant would be disposed of and chemical propulsion used to rendezvous with the satellite to be maintained. The maintenance craft would be moved to the vicinity of this satellite and then a manned, chemically-powered transfer module that includes expendables and replacement $p$ arts would be launched from low earth orbit and rendezvous with the maintenance spacecraft. The two crafts will dock and then be moved into final position for performing maintenance. A number of concepts can be used to protect personne] during maintenance. Figure 5 shows that an auxiliary shield can be placed inside the power plant radiator (Concept 1). This shield would probably be easiest to install if a shielded central hub is supplied as part of the original power plant through which the electric and control cables pass. The shield then would be installed on the hub or a bladder could be supplied as part

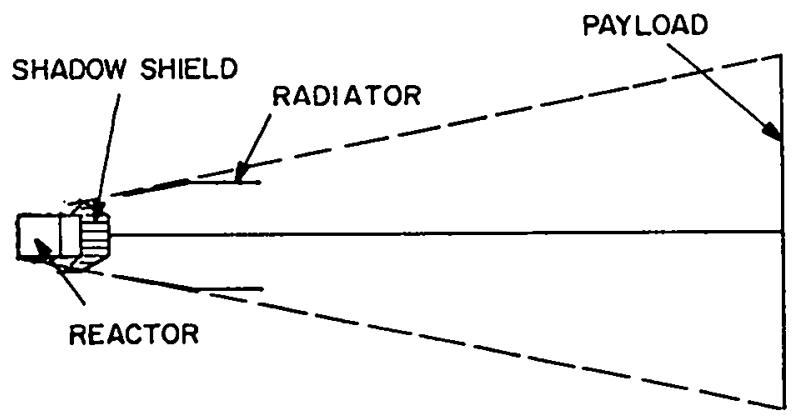

Fig. 4. Maintainability with permanent gamma shieid.
Distance from reactor with no personnel shield

Within shadow of Outside shadow of payload shield payload shleld

$\begin{array}{lr}2.5 \mathrm{~km} & 14.1 \mathrm{~km} \\ 0.5 \mathrm{~km} & 1.2 \mathrm{~km}\end{array}$

Personnel shielding thickness for maintenance outside shadow of payload shield

\begin{tabular}{|c|c|c|}
\hline $10 \mathrm{~m}$ & $25 \mathrm{~m}$ & $100 \mathrm{~m}$ \\
\hline $\begin{array}{l}1.17 \mathrm{~m} \mathrm{LiH} \\
+0.36 \mathrm{~m} \mathrm{~Pb}\end{array}$ & $\begin{array}{l}1.05 \mathrm{~m} \mathrm{L1H} \\
+0.32 \mathrm{~m} \mathrm{~Pb}\end{array}$ & $\begin{array}{r}0.85 \mathrm{~m} \mathrm{LiH} \\
+0.23 \mathrm{~m} \mathrm{~Pb}\end{array}$ \\
\hline $\begin{array}{l}0.19 \mathrm{~m} \mathrm{~W} \\
0.28 \mathrm{~m} \mathrm{~Pb} \\
0.14 \mathrm{~m} \mathrm{U}\end{array}$ & $\begin{aligned} & 0.15 \mathrm{~m} \mathrm{~W} \\
& \text { or } 0.22 \mathrm{~m} \mathrm{~Pb} \\
& \text { or } 0.11 \mathrm{~m} \mathrm{U}\end{aligned}$ & $\begin{array}{l}0.09 \mathrm{~m} \mathrm{~W} \\
0.14 \mathrm{mb} \\
0.07 \mathrm{~m} \mathrm{U}\end{array}$ \\
\hline
\end{tabular}

of the nuclear power plant and a dense material pumped into the bladder for shielding. Another alternative is to place the shield aft of the radiator (Concept 2). This has the advantage of ease of installation, but the disadvantage of being significantly heavier. A third location for auxiliary shielding is to use the maintenance vehicle as a shield (Concept 3 ). This permits work in localized areas of the satellite but could be quite awkward. The maintenance spacecraft might also be used to install a shield on the sides of the reactor away from the payload if extensive renovation is to be done in order to allow complete freedom of movement (Concept 4). Estimated weights for mass of various shields are shown in Table $V$. Once maintenance is complete, the temporary shield would be removed for use on other satellites.

One feature of the maintenance depot is that it can be used as a storm cellar during solar flares. Another, is that it can be made quite heavy and use nuclear electric propulsion to move it to high orbit. Time would not be a factor so that a year or possibly two years can be used to make the transfer. Studies indicate a vehicle of some $15000 \mathrm{~kg}$ is feasible to consider (see Fig. 6).

D. Power Plant System Analyses

These studies will define the system in sufficient detail to identify materials and components requirements. Continuing refinements will be made in the design in order to incorporate the results of analyses and experiments as well as 
TABLE $V$

GAMMA SHIELO MASS AS A FUNCTION OF SHIELD LOCATION

\begin{tabular}{|c|c|c|c|c|c|}
\hline Concept & Dist. (m) & Radius (cm) & Thickness $(\mathrm{cm})$ & Mass (kg) & Angle $\left({ }^{0}\right)$ \\
\hline 1 & 2 & 80 & 20 & 7450 & 15 \\
\hline 1 & 2 & 140 & 20 & 22800 & 30 \\
\hline 2 & 7.5 & 225 & 15.5 & 4560 & 15 \\
\hline 2 & 6.3 & 400 & 16 & 150000 & 30 \\
\hline 3 & 10 & 150 & 14 & 18000 & \\
\hline 3 & 25 & 150 & 11 & 14000 & \\
\hline 3 & 100 & 150 & 7 & 9000 & \\
\hline 4 & 10 & $25+47$ & 22 & 7610 & \\
\hline 4 & 25 & $25 \rightarrow 44$ & 19 & 6100 & \\
\hline 4 & 100 & $25+40$ & 15 & 4340 & \\
\hline
\end{tabular}

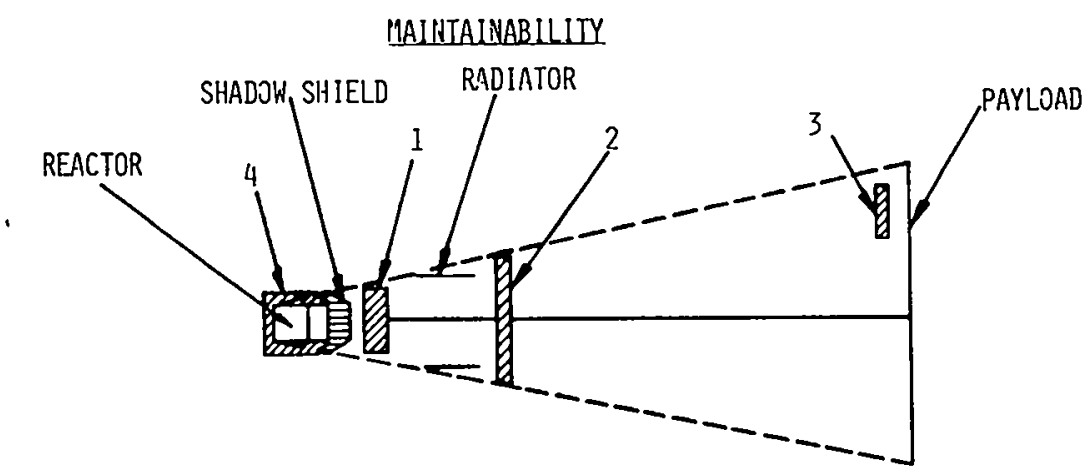

CONCEPT 1: AUXILIARY SHIELD INSIDE RADIATOR (SOLID OR BLADDER)A

2: AUXILIARY SHIELD BEYOND RADIATORA

3: LOCAL SHIELD

4: REACTOR $4 \pi$ SHIELD

A SPACECRAFT DESIGN INCORPORATES SHIELD HUB FOR ATTACHING AUXILIARY SHIELD.

Fig. 5. Auxiliary shield inside power plant radiator.

revisions in program objectives and requirements. Reliability analysis will be used to maximize the usefulness of the experimental program. The system analyses will be augmented with experiments using critical assemblies, models for examining assembly procedures, materials evaluation, and component designs and tests.

1. Configuration Analysis (Karl L. Meier, Q-15). Core fins were made of HT molybdenum. The fins were recrystallized at $2000 \mathrm{~K}$ for $1 \mathrm{~h}$ and preformed successfully at $500 \mathrm{~K}$. The fins were stress relieved at $1250 \mathrm{~K}$ and pressed over the 3-tube core heat pipe mockup. The circumferential fin contact around the heat pipe tubes was very good. Figure 7 shows circumferential contact arcs between two typical tabs and tube. An intense light source was placed below the contact arc to illuminate points of poor contact. The lower contact arc has almost complete contact between $f$ in and tube. The upper arc has about $95 \%$ contact. The small gap is highlighted in the figure. Microscopic examination of tab and tube contact regions was performed at the points where slots are cut in the fin. These regions, which are delineated in Fig. 7, were examined to determine the thickness of the contact arcs in the axial direction. Several approximate measurements were made and showed considerable variation. Contact arc thickness varied from $0.2 \mathrm{~mm}$ to $0.4 \mathrm{~mm}$ and averaged $0.3 \mathrm{~mm}$. This is $60 \%$ of the $0.5 \mathrm{~mm}$ thickness. These preliminary measurements show that over $50 \%$ of the fin cross-sectional area is in contact with the heat pipe surface. 


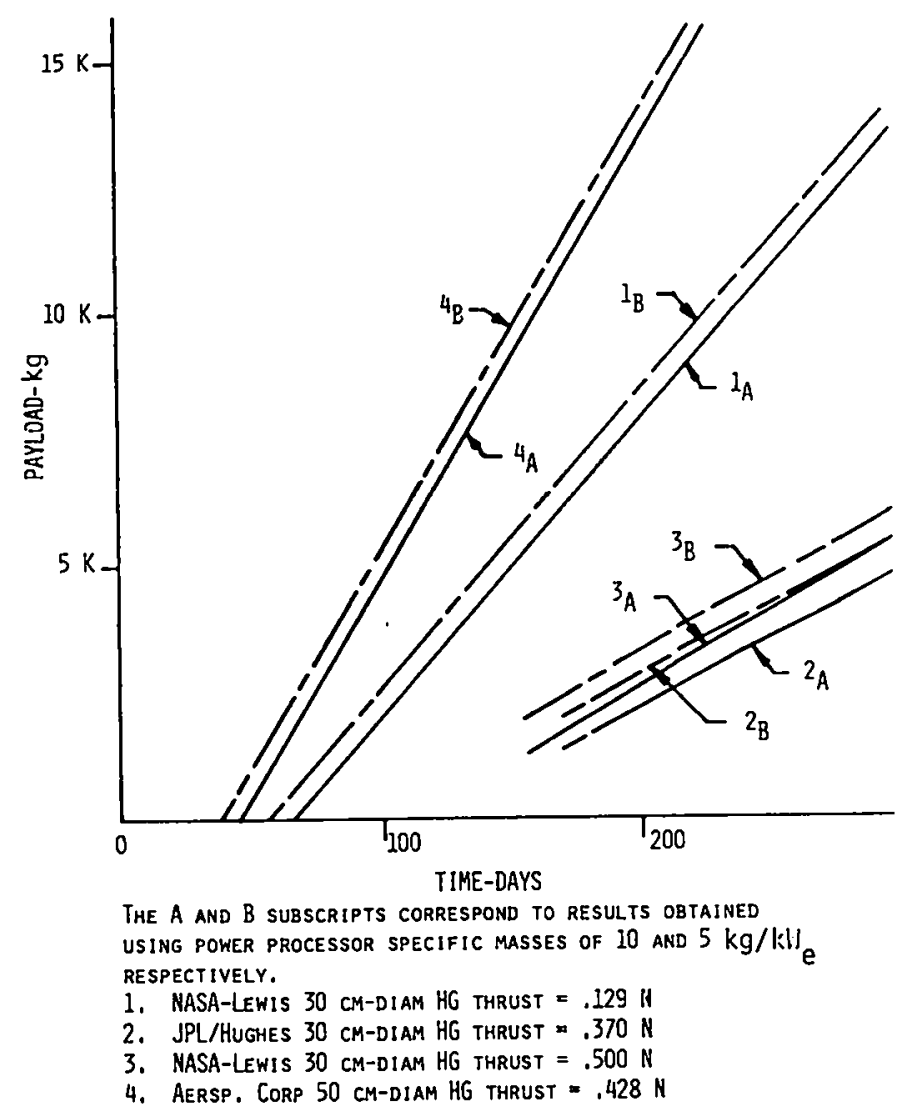

Fig. 6. Maximum payload vs mission time using various thruster subsystems.

These experiments have shown that recrystallization, stress relief, and preforming must be done on the HT molybdenum fins at elevated temperatures. This can be accomplished relatively easily on 300-mm-diam 0.5-mm-thick fins. Elevated temperatures are not required for final assembly of the fins in the core. It is very important that final assembly of the fins around the 90, 2-m-long core heat pipes and between thousands of uranium dioxide fuel tiles be performed at room temperature.

Fins have also been fabricated of Amax $C L-100$ molybdenum. This high-purity powder metallurgy molybdenum was successfully preformed at $361 \mathrm{~K}$ in the as-received condition; no recrystallization was necessary. Photographic and microscopic examination has begun. The contact between tube and fin initially appears to be similar to that of the HT molybdenum.

In choosing fabrication techniques for the 3-hole fin experiments, it was deemed necessary to use techniques that could eventually be used on 300-mm-diam, 90-hole fins. The hole spacing must be maintained to small tolerances. The diameter of the holes determines the height and amount that the tabs will bend up along the heat pipe axis. This diameter also has a closer tolerance, and it was desired to try several different diameters throughout the course of the experiments. All the holes were bored on a multiple jig bore to the desired size. This method can be used to bore many holes in these sheets to close tolerances.

Three methods of slot forming were considered: milling, broaching, and electric discharge machining (EDM). The first method is good for 3-hole fins, but could prove expensive and time consuming for a large number of 90-hole fins. The broaching method could prove to be the best and cheapest for a large number of identical 90-hole fins. However, the fabrication of different broaches for different sized holes, different slot depths, and different numbers of siots would be expensive. The EDM method was attempted because of minimum cost and probable relevancy to 


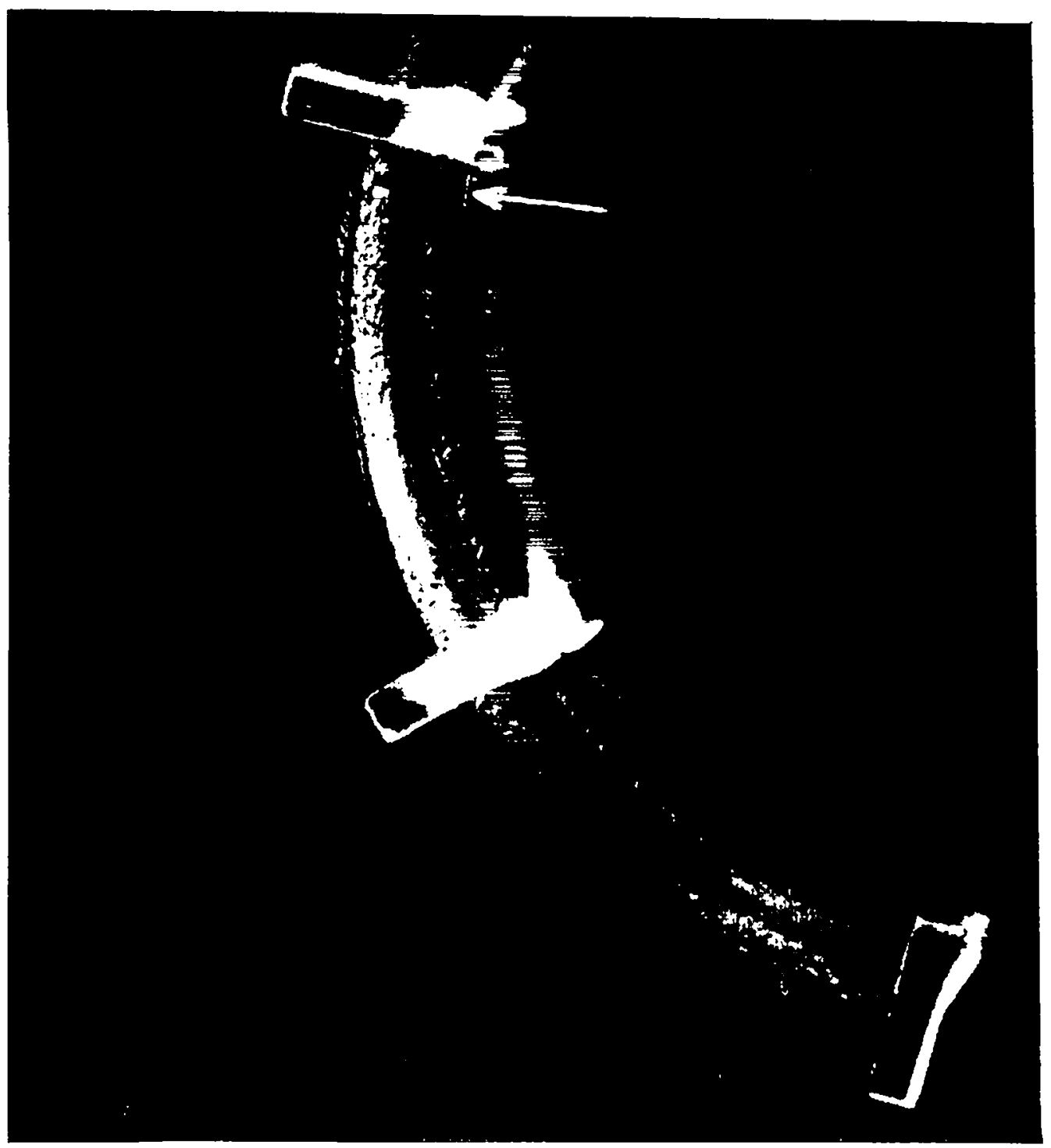

Fig. 7. Microscopic examination of tab and tube contact regions.

a 90-hole pattern. It is possible that the EDM method produces an undesirable local embrittlement of the molytdenum fin surface. If so, it appears that this effect is eliminated by recrystallization and stress relief in HT molybdenum, and by preforming at elevated temperature in Amax $\mathrm{CL}-100$. When hole size, slot depth, number of slots, and material has been selected, the broaching technique will be evaluated for reduced fabrication costs and less severe material degradation.

2. Neutron Shielding (R. G. Palmer, Q-15; L. M. Carruthers, $Q-13$ ). It is obvious from geometric considerations that the greater the cone angle of the shield, the larger will be the mass of shielding required. The function and construction of the radiator is such that as the cone angle is decreased its mass increases and it becomes more difficult to place the thermoelectric modules into a single circumferential ring. If the diameter of this ring were to be kept constant by moving the thermoelectrics and radiator further from the reactor as the cone angle is reduced, the length of the adiabatic section of the core heat pipes would become prohibitively large.

For neutronic calculations, the geometric arrangement of the reactor, radiator, and shield is too complex for analytical or finite element methods. A stochastic Monte Carlo technique, the LASL 
MCNP2 code (1) was therefore used for the shielding studies. This is a general purpose code that $c$ an be used for neutron, photon, or coupled neutron-photon transport. The code treats an arbitrary three-dimensional configuration of materials in geometric cells bounded by first- and second-degree surfaces ( $p$ lanes, cones, etc.). Pointwise cross-section data are used. A number of standard features are available to improve computational efficiency, such as geometry splitting, Russian roulette, and source biasing.

In the SPAR neutron shielding studies, ENDF/B-IV cross sections were used. Separate two-dimensional neutron transport calculations were made on the SPAR reactor to obtain the magnitude and the energy spectrum of the neutrons leaking from the reflector. This was converted to an equivalent volume source over the whole reactor for the MCNP calculations. It is well known that lithium hydride is the best neutron shielding material for space applications, so this was used as the basis of the shield with 25 weight percent stainless steel being added to account for structural needs.

Four parametric quantities were varied in the neutron shielding studies: $\theta$ the half-cone angle of the radiator, $\psi$ the angle of the "trailing wing" of the shield, $L$ the axial length of the shield at its center, and the mass of the shield. These parametric variabies are illustrated in Fig. 8. A number of scoping studies showed that for a certain constraint on the fluence at the payload, the shield mass decreased as $\psi$ was reduced from $90^{\circ}$, but leveled off as $\psi$ approached $30^{\circ}$. Furthermore, a broad minimum in shield mass was found around $L=70 \mathrm{~cm}$. Based on the results of these scoping studies, a series of MCNP2 runs was made with $L$ and $\psi$ fixed at $70 \mathrm{~cm}$ and $30^{\circ}$ respectively, with $\theta$ varying between $15^{\circ}$ and $30^{\circ}$ and with shield masses in the range $200 \mathrm{~kg}$ to 1100 $\mathrm{kg}$.

The calculated neutron fluences at the payload for $7 y$ operation are shown in Fig. 8 as a function of shield mass for various $\theta$ values. From these curves are extracted the data for Fig. 9 which shows the minimum shield masses as a function of $\theta$ for fluence constraints of $5 \times 10^{13}, 1$ $\times 10^{13}$, and $2 \times 10^{12}$ nvt, respectively. It can be seen that there is a considerable mass advantage in reducing $\theta$ from $30^{\circ}$ to $15^{\circ}--350 \mathrm{~kg}$ for the $1 \times 10^{13}$ nvt constraint.

In performing the shielding studies, it was noticed that about $60 \%$ of the neutrons reaching the payload had energies about $1 \mathrm{MeV}$. Special MCNP2 runs, in which the reactor leakage neutrons were made monoenergetic, showed that the attenuation through the shielding was strongly energy dependent. Attenuation for $1 \mathrm{MeV}$ neutrons was a factor of 1000 greater than for $10 \mathrm{MeV}$ neutrons. This suggested that if the spectrum of neutrons leaving the reactor could be softened considerably at the high MeV range, then a substantial reduction in shield mass might be possible.

The best nuclear mechanism for reducing the energy of neutrons at high energies is the inelastic scattering process for absorbed neutrons to produce a compound nucleus and re-emitted a very short time later at reduced energies. Elastic ("billiard ball") scattering is not so effective at high energies because the scattering is predominantly in the forward direction with little energy degradation. Low atomic mass materials, like the beryllium of the SPAR reflector, are good elastic scatterers but have virtually no inelastic scattering. Medium atomic mass materials, such as nickel, have good inelastic scattering properties.

Calculations were made for the SPAR core with nickel oxide reflectors. In terms of critical size, $9 \mathrm{~cm}$ of nickel oxide was found to be as effective as $10 \mathrm{~cm}$ of beryllium. There was also a significant reduction (about a factor of 3 ) in the high energy component of the neutron leakage spectrum and when this was used in the shielding calculations, a significant reduction in shield mass resulted. However, in the best case with a radiator cone angle of $30^{\circ}$, a reduction in shield mass of $150 \mathrm{~kg}$ did not compensate for the increase in reflector mass resulting from a factor of 4 density difference between nickel oxide and beryllium. Attempts to optimize the situation by using a beryllium inner reflector and a nickel oxide outer reflector and other combinations of the two, showed no improvement. Other good inelastic scattering materials were studied, but no system mass reduction could be realized. 


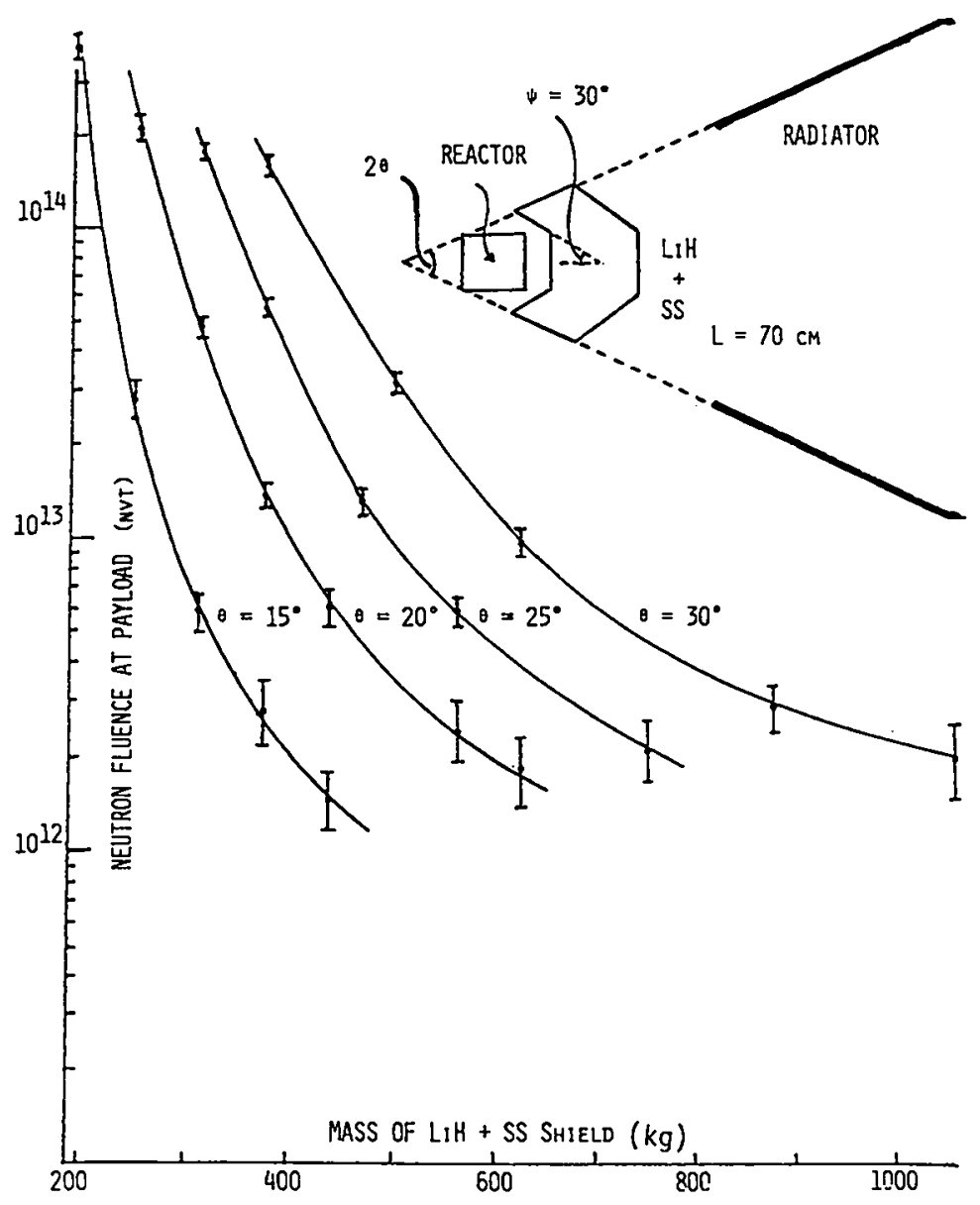

Fig. 8. Neutron fluence at payload vs shield mass.

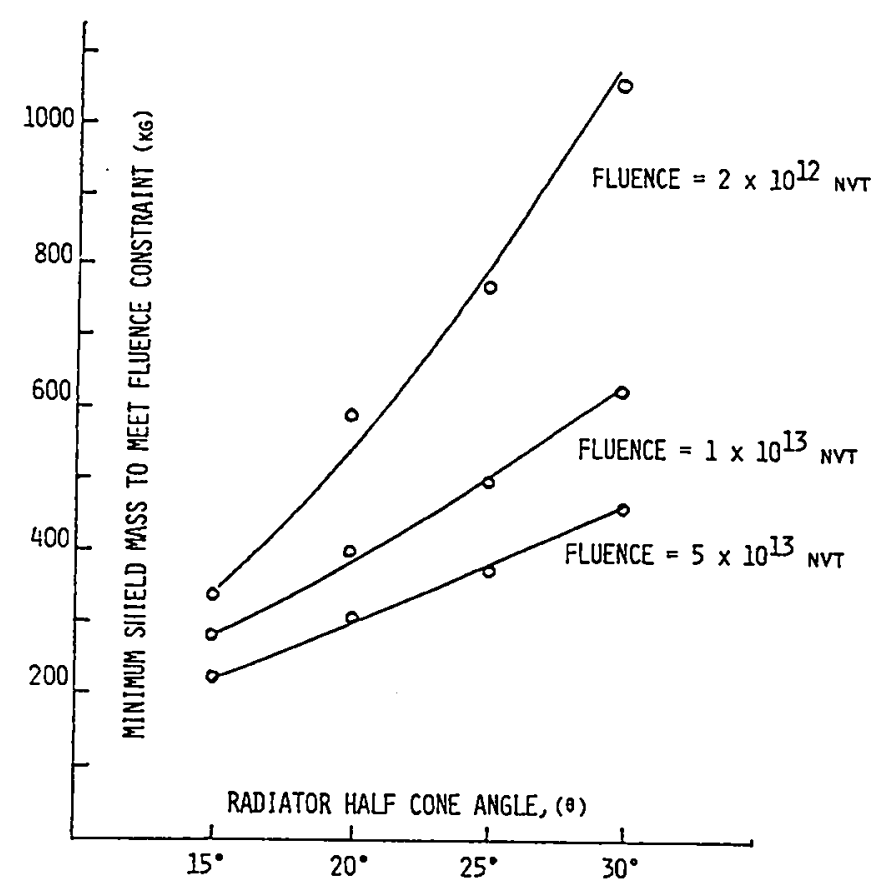

Fig. 9. Minimum shield mass vs radiator half cone angle. 
3. Heat Transfer Analysis (K. Cooper, Q-13). The current core design has layers of molybdenum sheets alternating with uranium dioxide fuel. The molybdenum sheets act as fins to conduct heat from the uranium dioxide to the heat pipes. In normal operation, the fins conduct this heat to the nearest heat pipe. In case of a failed heat pipe, the fins conduct heat away from the failed heat pipe to the neighboring heat pipes. The Shish Kebab design is similar to the current design except that it is composed of modules. Each heat pipe and $i$ ts surrounding fins and uranium dioxide form a module (Fig. 10), and there is no continuous heat conduction path between modules. In case of a heat pipe failure, the heat will cross. the gaps between modules by a combination of three mechanisms:

1) Thermal radiation;

2) Heat of vaporization of uranium dioxide; and,

3) Thermal conduction through redeposited uranium dioxide.

Initial results from a computer analysis of the worst interior Shish Kebob case shows that there are two thermal transients involved in the fuel time-temperature relationship in the vicinity of a failed heat pipe:

1) A short transient lasts about three minutes, where the heat produced in the vicinity of a failed heat pipe is at first converted by heat capacity into a temperature rise rate of about 20 $\mathrm{K} / \mathrm{s}$. This rate decreases as thermal radiation

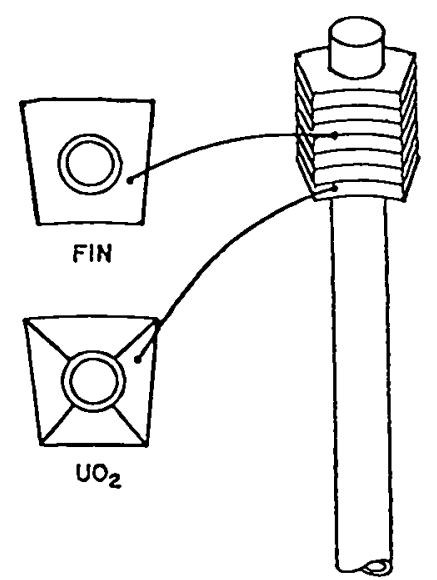

Fig. 10. Shish Kebab module. transports heat across the gap, until a pseudoequilibrium is reached. This short transient rajses the maximum fin temperature from $1660 \mathrm{~K}$ to $2580 \mathrm{~K}$. This temperature is well below the melting point of molybdenum $(2900 \mathrm{~K})$ and uranium dioxide $(3100 \mathrm{~K})$, so there is no immediate concern.

2) At the high temperatures incurred, the uranium dioxide vaporization rate increases to an appreciable value, and the uranium dioxide from the hot side of the gap gradually vaporizes and redeposits on the colder side. This redeposited uranium dioxide bridges the gap and transports more and more of the heat, and the temperature drops to $2070 \mathrm{~K}$ in about one day. This equilibrium temperature is about $120 \mathrm{~K}$ hotter than the corresponding temperature in the current design $(1950 \mathrm{~K})$, and does not seem to present a long-term problem.

These molybdenum fin temperatures are shown in Fig. 11 for the case where heat pipes are interconnected outside the core and remain at $1400 \mathrm{~K}$ even after one heat pipe fails.

The vaporization rate is slow enough so that heat transport by heat of vaporization is insignificant compared to thermal radiation and uranium dioxide conduction.

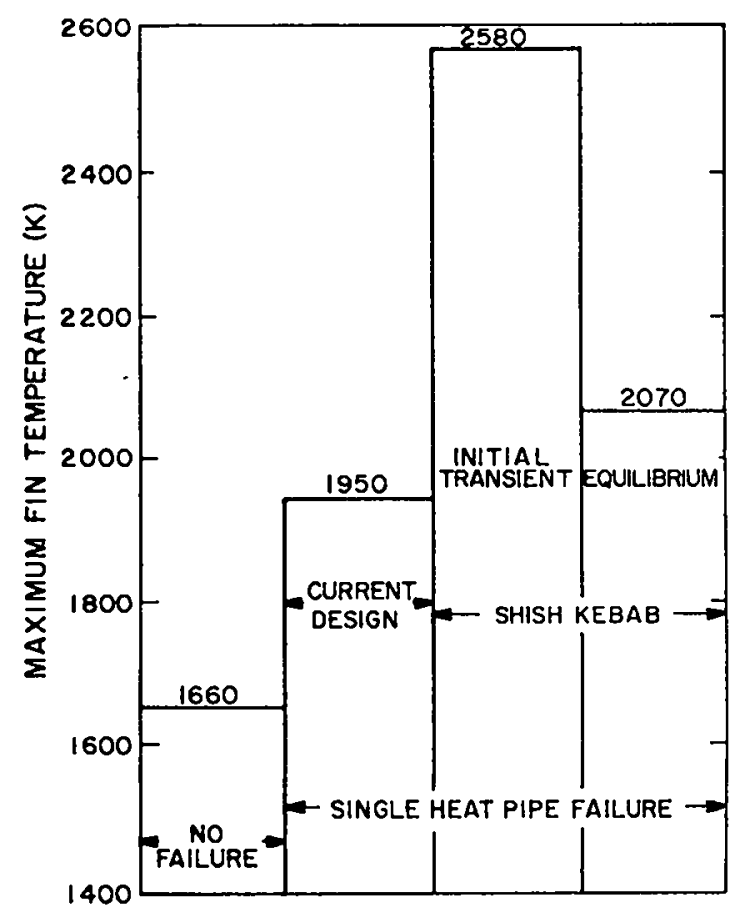

Fig. 11. Maximum fin temperatures for worst interior case. 
More work will be done on refining the computer model, and experimental work is needed to get characteristics of redeposited uranium dioxide.

4. Hydrogen Reactivity Worth in SPAR Space Reactor Mockup Core (E. A. Plassmann, T. P. McLaughlin, T. F. Wimett, B. Pena, Q-14). A series of experiments are being performed to corroborate criticality safety calculations of the SPAR reactor under water flooding conditions.

The reactivity worth of hydrogen in the core of the Honeycomb mockup of the SPAR space reactor $c$ an be found by adding core-length (30.5-cm-long) threads of polyethylene into convenient voids between core materials. A diagram of the present configuration is drawn in Fig. 12. With the control rod fully inserted and no polyethylene in the assembly, i.e., the base loading, the configuration is supercritical and we observe a $10.7 \mathrm{~s}$ e-folding period for leakage neutron generation. Eight strands of polyethylene, weighing a total of $6.72 \mathrm{~g}$, are then added at the center. By measuring the resulting change in positive period, we can infer the reactivity worth of polyethylene at that position. The measurement is then repeated with the polyethylene inserted at other radial locations.

Our preliminary results are shown in Fig. 13 where the reactivity worth per gram of polyethylene is plotted against radial position in the core. To be precise, these data should be corrected for the relatively small effect of carbon to yield the reactivity coefficient for the hydrogen alone. The carbon measurements have not yet been made.

5. Failure Modes and Effects Critical Analysis (FMECA) (R. Bartholomew, Q-15). The state-space method of reliability analys is has been formulated conceptualiy in flow diagram form and is shown in Fig. 14. The portion enclosed in the dashed block corresponds to a set of component or initiator Fault Tree Analyses (FTAs) with the initiator dependent minimum cut sets (MCS ${ }_{0}$ ) produced. The vector $\lambda_{0}$ represents a vector composed of the hazard functions (failure rates)

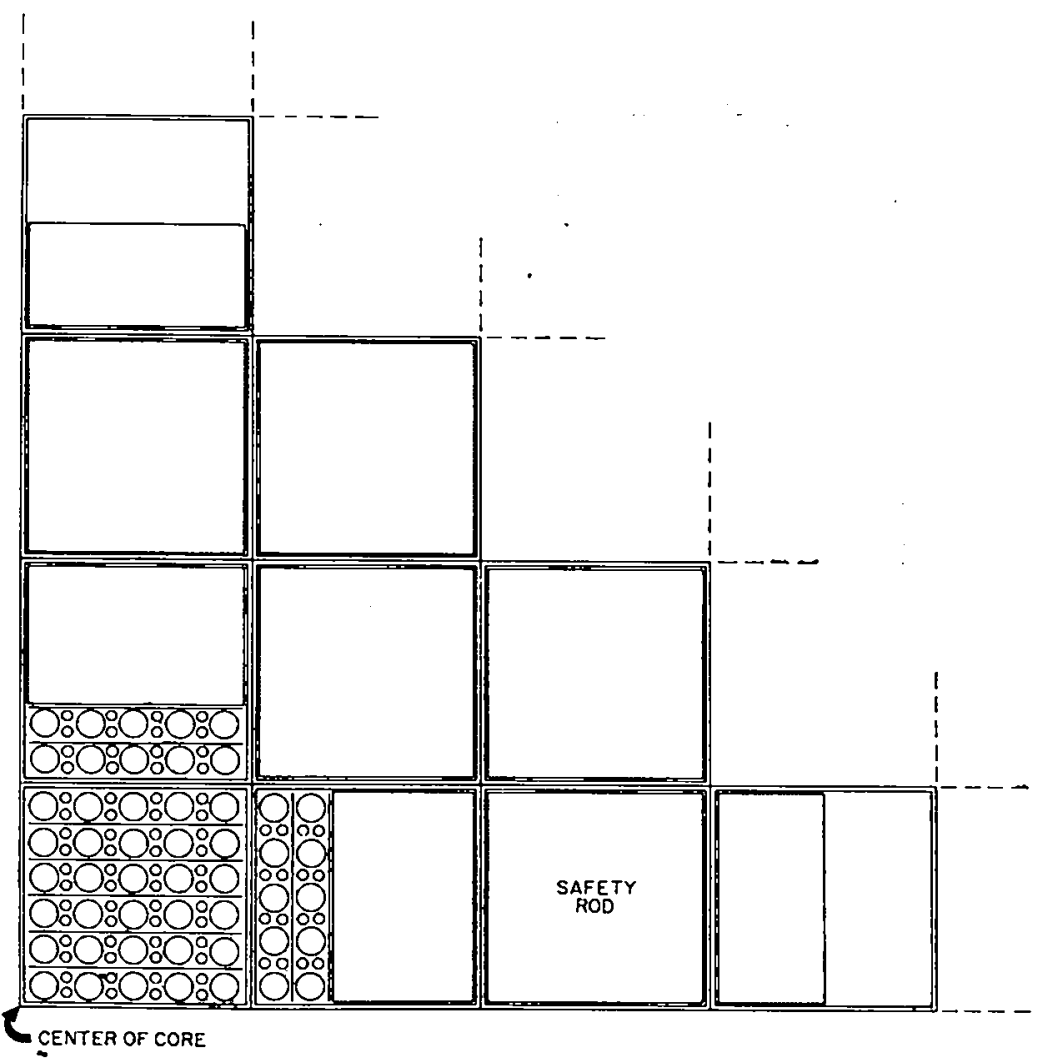

Fig. 12. SPAR mockup in honeycomb critical assembly (quarter section). Modules are $7.62 \mathrm{~cm}$ square. 


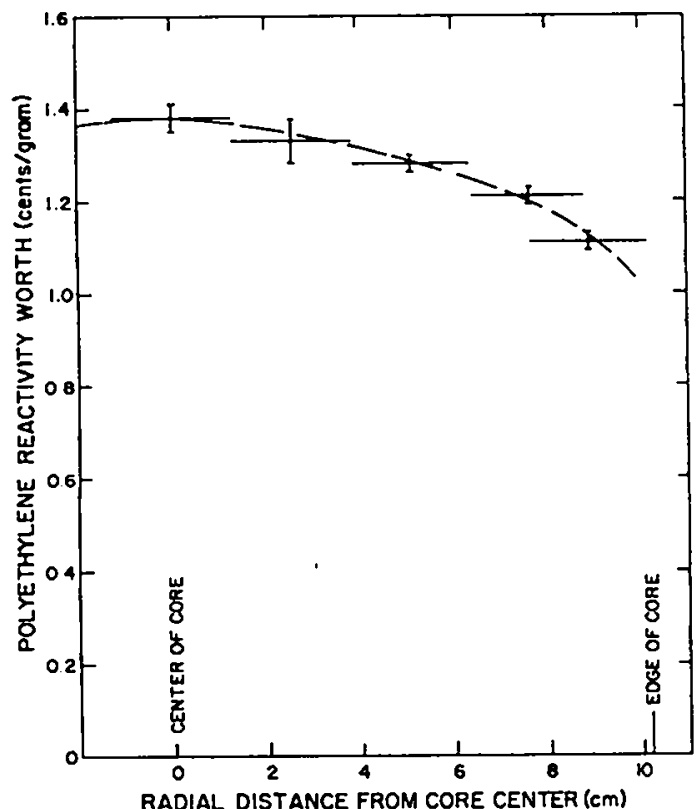

Fig. 13. Polyethylene reactivity worth in SPAR Honeycomb mockup.

corresponding to each of the MCS 0 derived from combinatorial mathematics for each of the initiators and the "AND" or "OR" logic in the individual component fault trees. The block designated $S$ corresponds to the system lifetime distribution model. The system differential equations solved are:

$$
\underline{F}=\underline{A} \underline{F}+\underline{B} \underline{U}(t)
$$

and

$$
\underline{I}=\underline{C} \underline{F}+\underline{D} \underline{U}
$$

where

$\underline{F}=$ SPAR system state vector comprising all of the component failure modes as elements in the vector $\underline{F}$.

$\underline{A}=$ Matrix of hazard functions and component interdependencies relating failure mode to rate of failure.

$\underline{B}=$ SPAR system initiator hazard function matrix relating initiator events and sequences to rate of failure.

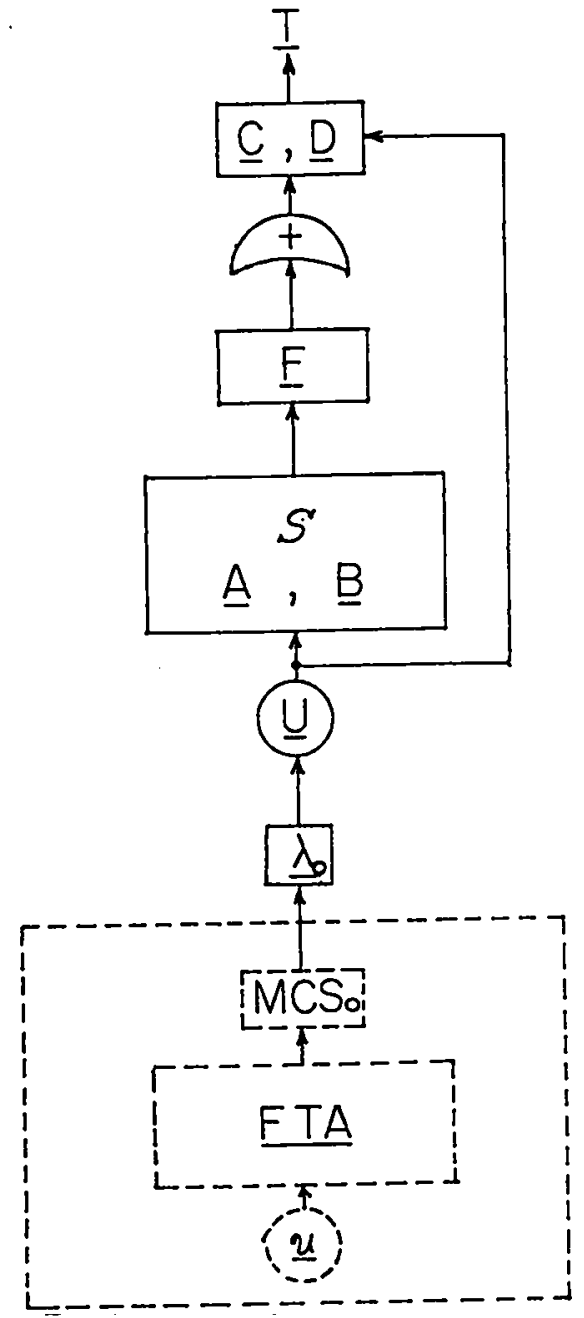

Fig. 14. System iffetime distribution function analysis flow process.

\footnotetext{
$\underline{c}=$ Matrix of influence coefficients relating component failure modes to system or subsystem failure represented by the vector of top events I.

$\underline{D}=$ Direct consequence influence coefficients between initiators and the vector of system or subsystem top events $\mathrm{I}$.
} 
Since Eq. (2) contains the effects of serial or parallel combinations of components (from the standpoint of reliability), the matrix $\underline{D}$ contains the influence of such combinations of initiators $\underline{U}$ as would have first order reliability effects on the top events $\underline{I}$. The matrix $\underline{C}$ always contains the various linear combination part of the failure modes $F$ leading to the top events $I$. The resulting "output" vector of time profiles of the system or subsystem top event failures $I(t)$ are the system lifetime distribution functions for the SPAR power unit. The particular top event failure $T_{i}(t)$ that has the shortest lifetime effect will be the dominant hardware related failure in the system. If this $T_{j}(t)$ is within the SPAR reliability goal, we may consider that the SPAR power unit has been designed with sufficient reliability. However, if $T_{i}(t)$ is not satisfactory, we may

(1) re-allocate component reliability,

(2) add redundancy where required,

in order to bring $T_{j}(t)$ into line. We must be careful to account for interdependencies in $\underline{A}$ and additional combinational effects in $\underline{D}$ when we do this in order that we do not shorten some other top event lifetime $T_{j}(t)$.

The implication is clear that we need to de velop a digital computer program that has the necessary features in order to perform systematized analyses for SPAR. Such a program directly suitable to SPAR is not in existence as a general reliability analys is tool. The reason for the need is that the system of equations (1) will be in the hundreds, if not thousands, and their solution is totally beyond the capacity of individual calculation capabilities.

E. Core Heat Pipe Development

A development program is underway on core heat pipes for extracting energy from the reactor. Questions to be answered include such items as grade of materials, fabrication methods, types of wick structure, methods of bending, material transport and effects of impurities. These investigations will lead to prototype units.
1. Heat Pipe Analys is (F. C. Prenger, Q-13). A 2-m-long molybdenum heat pipe has been fabricated using a porous tube for separation of the liquid and vapor flow paths. Sodium was vapor distilled into the heat pipe as the working fluid. After the annular liquid flow passage was filled, a sodium pool of $320 \mathrm{~mm}$ remained at one end. Since this heat pipe, referred to as SPAR 1, will be operated with a negative $5^{0}$ tilt (evaporator up) the liquid pool will be at the end of the condenser and will reduce the effective condenser length to $330 \mathrm{~mm}$. The evaporator length is $300 \mathrm{~mm}$ and is shifted $50 \mathrm{~mm}$ from the end of the heat pipe leaving a 1.0-m adiabatic section. The heat pipe is shown schematically in Fig. 15 .

Preliminary testing of the heat pipe without the calorimeter attached was conducted. The heat pipe was operated at $1400 \mathrm{~K}$ horizontally. To evaluate the degree of wetting by the working fluid, the condition of the porous tube, and the amount, if any, of noncondensible gas in the heat pipe, the test procedure was to increase the tilt of the heat pipe (evaporator up) during operation until a dryout was encountered. By knowing the maximum tilt angle and the heat load, an effective pore size for the porous tube can be obtained using the heat pipe computer code HTPIPE. The maximum tilt angle was $55^{\circ}$ and the heat pipe operating temperature was $1200 \mathrm{~K}$. Since the radiating areas was $6.6 \times 10^{4} \mathrm{~mm}^{2}$, the heat rejection and therefore the heat load was $785 \mathrm{~W}$, assuming a surface emissivity of 0.1 . Figure 16 shows the pore size as a function of heat pipe load for a tilt angle of $55^{\circ}$ and an operating temperature of $1200 \mathrm{~K}$. For a heat load of $785 \mathrm{~W}$, the pore size is $47 \mu \mathrm{m}$.

Measurements on a sample of the porous tube showed a pore size of $34 \mathrm{\mu m}$. Aside from the possibility of mechanical damage to the porous tube during or after installation in the heat pipe, the larger pore size can result from an imperfection in the tube if the imperfection location is in the evaporator, where the maximum pressure differential occurs. Other possibilities exist for explaining the reduced performance in the preliminary test. They include, 


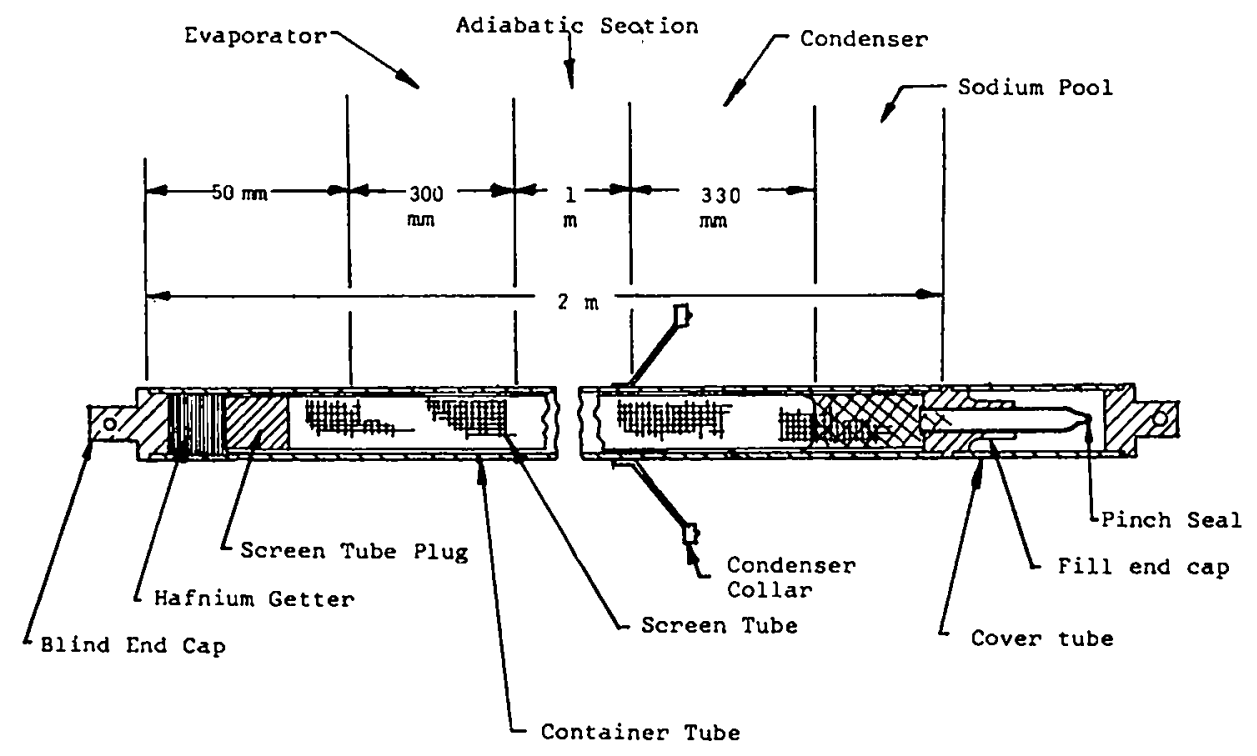

Fig. 15. SPAR-1 heat pipe.

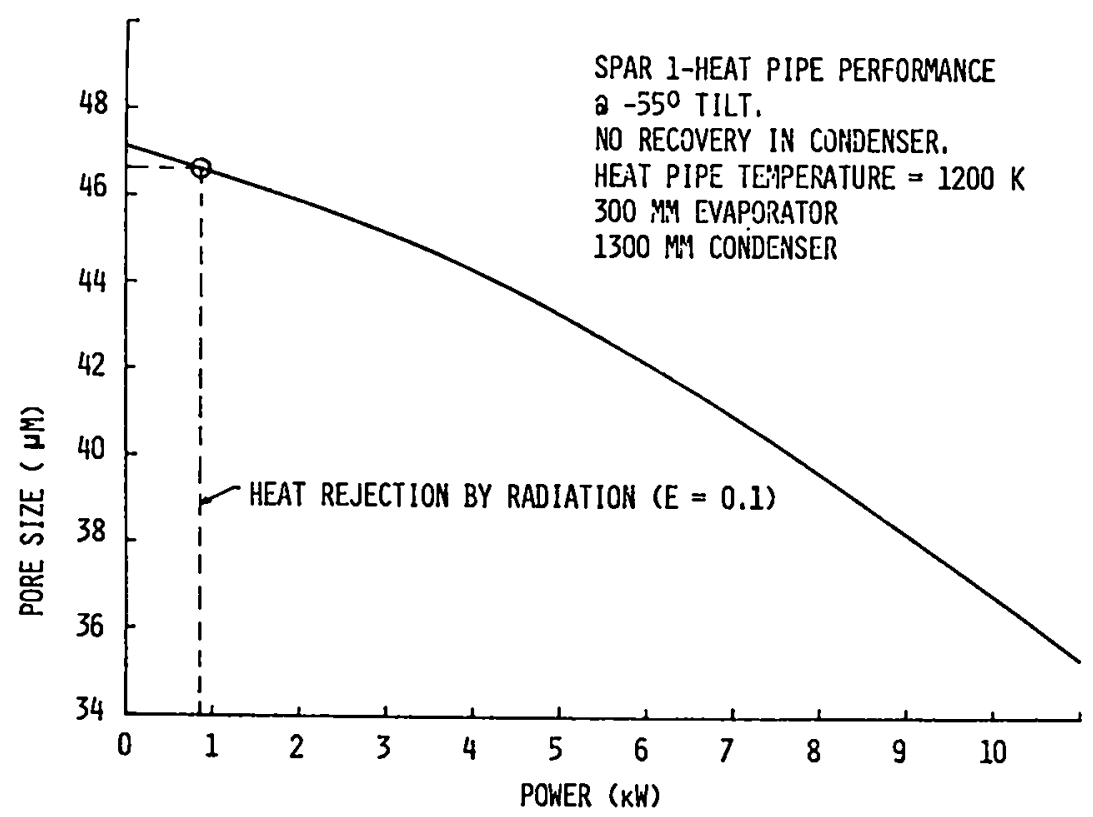

Fig. 16. SPAR-1 pore size as a function of power at $55^{\circ}$ tilt and $1200 \mathrm{~K}$.

1) Increased wetting angle of the working fluid due to impurities (oxygen).

2) Reduced surface tension due to impurities.

3) Higher radiant heat rejection than assumed (higher emissivity).
Further testing of SPAR 1 may indicate which mechanism is responsible for the performance degradation.

Using a pore size of $47 \mu \mathrm{m}$, a test prediction for SPAR 1 was calculated. Figure 17 shows the sonic and wicking limits for both laminar and turbulent flow. At $1200 \mathrm{~K}$, the wicking 1 imit is 


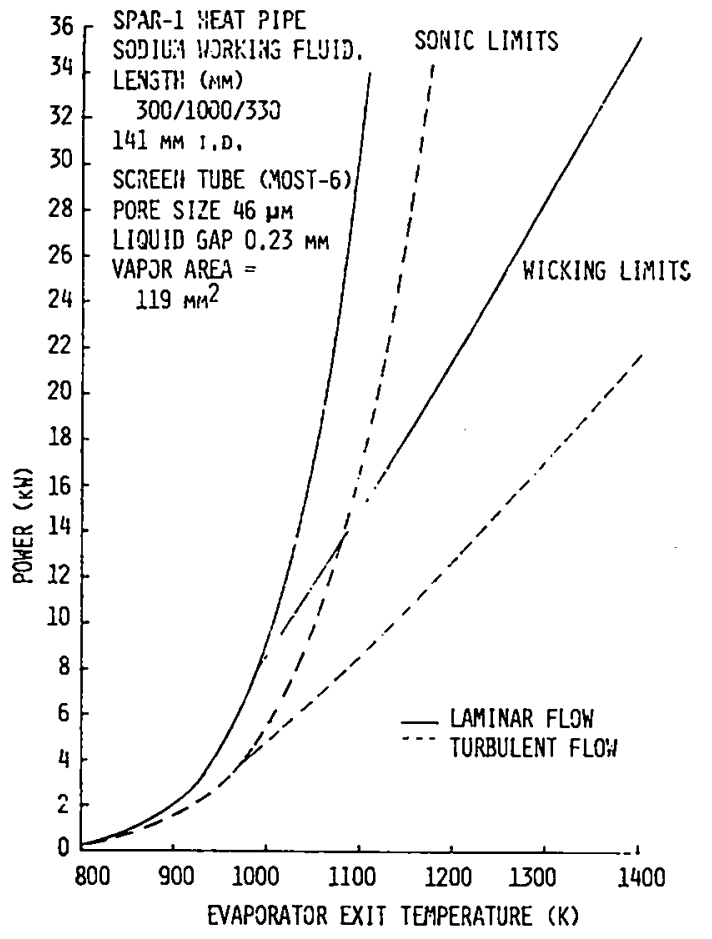

Fig. 17. SPAR 1 performance with $46 \mu \mathrm{m}$ pore size.

reduced by $2500 \mathrm{~W}$ (turbulent flow case). Further testing of SPAR 1 will enable detailed comparisons with the heat pipe model and aid in understanding the effects of long adiabatic sections.

2. Heat Pipe Fabrication (L. B. Lundberg, $H$. E. Martinez, J. Runyan, L. A. Geoffrion, Q-13; W. Doty, S. Armstrong, CMB-6).

a. Molybdenum Screen Tube Wicks. Fabrication of four molybdenum screen tubes was started. The procedures used were those previously developed for the tubes designated MOST-5 and -6 . All heat treating swaging and drawing operations on the mandrels, sheaths, and assemblies are being performed in-house.

b. SPAR-1 Fabrication. SPAR-1, the first 2-m-long straight development molybdenum heat pipe was fabricated this quarter. It was assembled with a recrystallized, low-carbon, arc-cast molybdenum container tube that was $2 \mathrm{~m}$ long by $15.9 \mathrm{~mm}$ o.d. with a 0.94-mm-thick wall. A molybdenum collar was joined to the tube by electron beam welding it at the beginning of the condenser section of the heat pipe, Fig. 15. A calorimeter will be bolted to the welded collar and isolated from the condensor section of the heat pipe during testing. Both end caps and fill tube were joined to the tube by electron beam welding, and a copper brazed stainless steel Swagelok fitting and a stainless steel extension were attached to the recrystallized, low-carbon, arc-cast molybdenum fill tube. The screen tube used was that designated MOST-6, it had a measured bubble point porosity of $34 \mathrm{\mu m}$. The outside diameter of the screen tube was $12.8 \mathrm{~mm}$ and it had a wall thickness of $0.23 \mathrm{~mm}$. The screen tube, which was plugged at one end with a tapered molybdenum plug, was $1.984 \mathrm{~m}$ long and fit into the container tube. A $0.61-\mathrm{mm}$ radial gap existed between the container tube and the screen tube. The screen tube was installed plugged end first into the container tube after the blind end cap had been welded on and after a $8.5 \mathrm{~g}$ stack of hafnium foil had been inserted. The fill end cap with its attached fill tube, brazed Swagelok fitting, and stainless steel extension tube was electron beam welded to the container tube completing the assembly.

$$
\text { c. Material Processing (CMB-6). A 2-m-long }
$$
molybdenum heat pipe scheduled to be SPAR-1 was fabricated, but ran into difficulty. It was made from a molybdenum tube identified as tube number 8 and the molybdenum screen wick was MOST-5. An end cap was welded onto one end of the molybdenum tube; however, during preparation to weld on the other end cap, several longitudinal cracks were discovered near the end of the tube. The tube was cut off and machined several times to get beyond the cracks, and finally a cap was welded on the pipe. A leak was discovered several centimeters up the pipe and this SPAR-1 pipe was scrapped.

We have analyzed the problem and the trouble was with the molybdenum tube number 8 . This tube, which was recrystallized at $1725 \mathrm{~K}$, is a very brittle unacceptable tube. This tube and some others were evaluated using a ring tensile test. Since the samples and tests are both simple, it is an economical way to examine behavior of metal tubes in tension.

The ring tensile test uses a section of tubing about $2.2 \mathrm{~mm}$ high. The inside and outside surfaces of the tubing were not machined and, therefore, represented the actual surfaces of the molybdenum tubing that would be present in the as-received or in the heat-treated condition. A 
5.8-mm-gage length, strain gage was cemented to the outside diameter of the ring specimen. An 0-ring, slightly smaller than the inside diameter and thicker than the ring height, was inserted inside the ring and the unit placed between two flat and parallel platens. As hydraulic fluid was injected into the 0-ring cavity, the pressure (stress) and strain in the ring specimen were monitored. This testing system gives the same data as a uniaxial test; however, the fracture propagates parallel to the tube axis, the weakest orientation, rather than across the tubing. The uniform elongation was obtained rather than the percent elongation normally reported for a standard tensile test. The uniform elongation minimizes the effect of the necked-down portion of the specimen and, therefore, has a lower value than the standard percent elongation. The reduction in area at the fracture is identical in both the ring and uniaxial tests.

Table VI lists the various tubing tested and the results.

It is obvious from this data that annealing the molybdenum tubing resulted in a brittle metal when tested in tension at room temperature. Examination of the structures of selected specimens were significant. Figure 18a shows the structure of the fracture surface of the stress-relieved molybdenum tubing specimen (1). The reduced section is visible. The fracture was fibrous and propagated in the weakest direction of the tubing. Figure 18b shows an optical microscope view of the etched structure through the fracture. The relative reduction or necking of the fracture area can be compared to a non-fractured section, Fig. 18c. The hardness of this as-received material was $240 \mathrm{DPH}$. This was a stress-relieved metal.

Figure 19a shows the SEM fracture structure of the annealed tubing specimen designated with the footnote (3) in Table VI. Its structure was duplex; the outside diameter had a fully recrystallized structure, bottom of Fig. 19a, while the inside diameter had a partially recrystallized structure. The higher strength of this specimen compared to the (4) specimen on Table VI can be explained by the duplex structure. Figure 19b shows the transition zone in the fracture surface with both intergranular and intragranular fracture modes. Figure 19c shows section thraugh the fracture. The hardness of this section was $200 \mathrm{DPH}$. Figure 20 a shows the structure of the annealed tubing (4) fracture. Both this SEM photograph and

TABLE VI

RING TENSILE TESTS ON MOLYBDENUM TUBING

\begin{tabular}{|c|c|c|c|c|c|c|c|c|}
\hline \multirow{2}{*}{$\begin{array}{c}\begin{array}{c}\text { Parent } \\
\text { Tube } \\
\text { Destonation }\end{array} \\
\end{array}$} & \multicolumn{2}{|c|}{$\begin{array}{l}\text { Yield } \\
\text { Strength (8) }\end{array}$} & \multicolumn{2}{|c|}{$\begin{array}{r}\text { Tensile } \\
\text { Strength }\end{array}$} & \multirow{2}{*}{$\begin{array}{l}\text { Uniform } \\
\text { Elongation, } \\
\text { percent (ii) }\end{array}$} & \multirow{2}{*}{$\begin{array}{l}\text { Reduction } \\
\text { In Area. } \\
\text { percent }\end{array}$} & \multicolumn{2}{|c|}{$\begin{array}{l}\text { Apparent } \\
\text { Modulus }\end{array}$} \\
\hline & $\underline{M P d}$ & ksi & & $k s i$ & & & & psi \\
\hline (1) & 620 & 90 & 800 & 116 & 9.1 & 50 & 315 & $45.5 \times 10^{6}$ \\
\hline (1) & 630 & 92 & 790 & 115 & 1.5 & 37 & 325 & $47.0 \times 10^{6}$ \\
\hline (1) & 590 & 85 & 820 & 119 & 5.6 & 46 & 330 & $47.5 \times 10^{6}$ \\
\hline (2) & 630 & 91 & 800 & 116 & 6.6 & 54 & 260 & $38.0 \times 10^{6}$ \\
\hline (3) & & (9) & 405 & 59 & 0 & 0 & 320 & $46.5 \times 10^{6}$ \\
\hline (4) & 295 & $42.5(10)$ & 305 & 44.5 & 0 & 0 & 315 & $46.0 \times 10^{6}$ \\
\hline (5) & 580 & 84 & 730 & 106 & (12) & 33 & 345 & $50.0 \times 10^{6}$ \\
\hline (6) & 300 & 43.5 & 305 & 44.5 & (12) & $3(13)$ & 345 & $50.0 \times 10^{6}$ \\
\hline (7) & & (9) & 420 & 61 & (12) & $3(13)$ & 275 & $40.0 \times 10^{6}$ \\
\hline
\end{tabular}

(1) Old tubing, LNG-1175H, as-received in stress relfeved condition.

(2) Hew tubing, 2KK9-3207J, as-received in stress relieved condition.

3) Tube 11 , same lot as SPAR-3 tube, annealed $2 \mathrm{~h}$ at $1725 \mathrm{~K}$ af ter being stress relieved.

(4) Mo tube 18 (away from end), annealed $2 \mathrm{~h}$ at $1725 \mathrm{~K}$ af ter being stress relieved.

5) Mo tube 18, as -received in stress relfeved condition.

(6) Mo tube 18 , bottom, annealed $2 \mathrm{~h}$ at $1725 \mathrm{~K}$ after being stress relieved

(7) Mo tube 18 , top, annealed $2 \mathrm{~h}$ at $1725 \mathrm{~K}$ after being stress relleved.

(8) Based on $0.2 x$ off set from the apparent modulus.

(9) Specimen failed before $0.2 \%$ off set strain was obtained.

(ii) Est imated by extrapolating strain data.

(ii) Not the same as the standard percent eiongation.

(12) Hot evaluated, see footnote (13)

(13) A more accurate method was devised for obtatning this value over those reported in (3) and (4). We photograph the fracture surfaces and compare those areas with the measured dimension of the starting ring. In brittle specimens such as these, there may be 10 to 12 fracture surfaces. The percent reduction in area is the largest value obtained. The accuracy is est imated to be within $+2 \%$. 


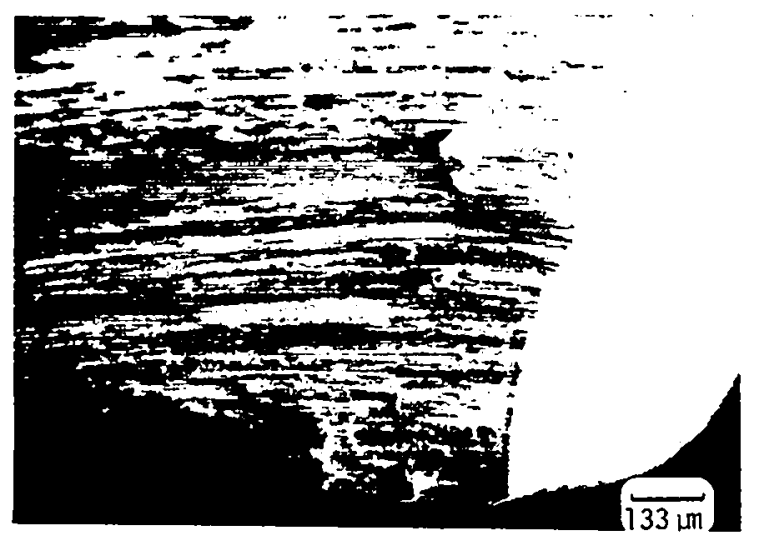

a. SEM photo of fracture.

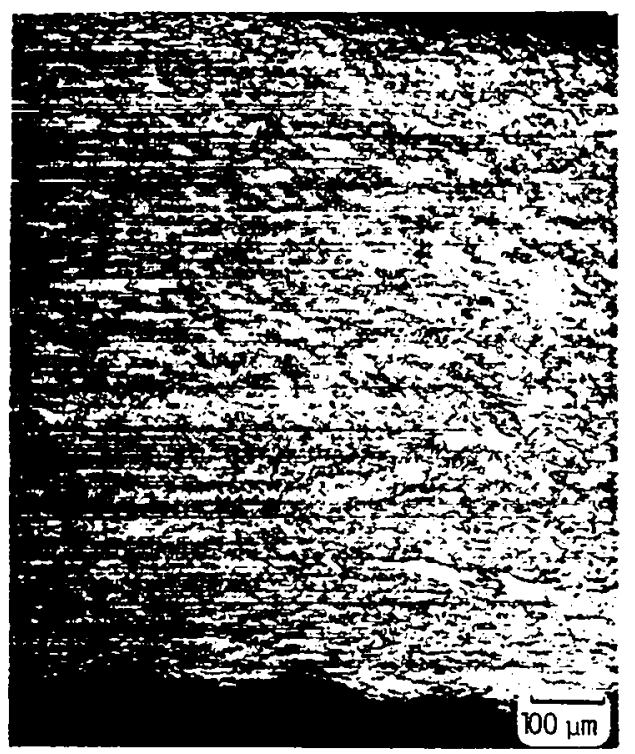

b. Optical photo thru fracture.

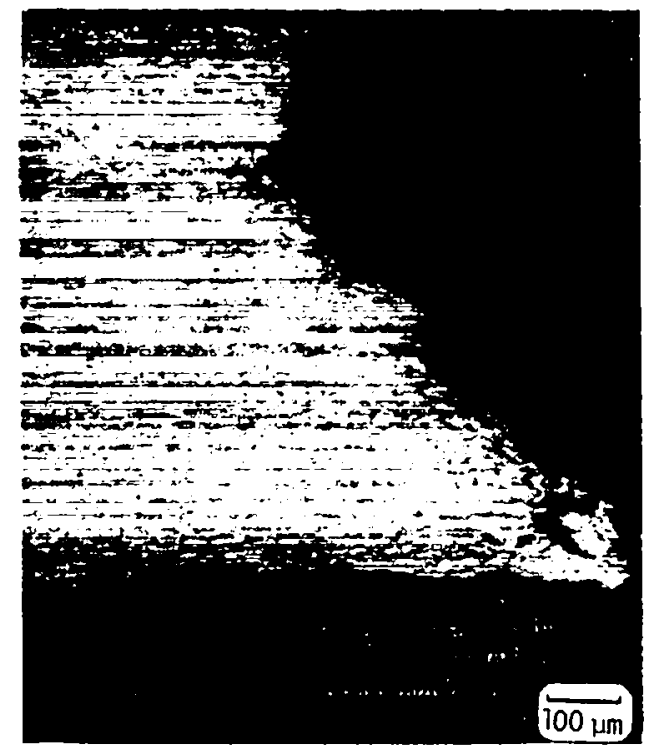

c. Tubing wall thickness.

Fig. 18. As-received, stress relieved Mo tubing.

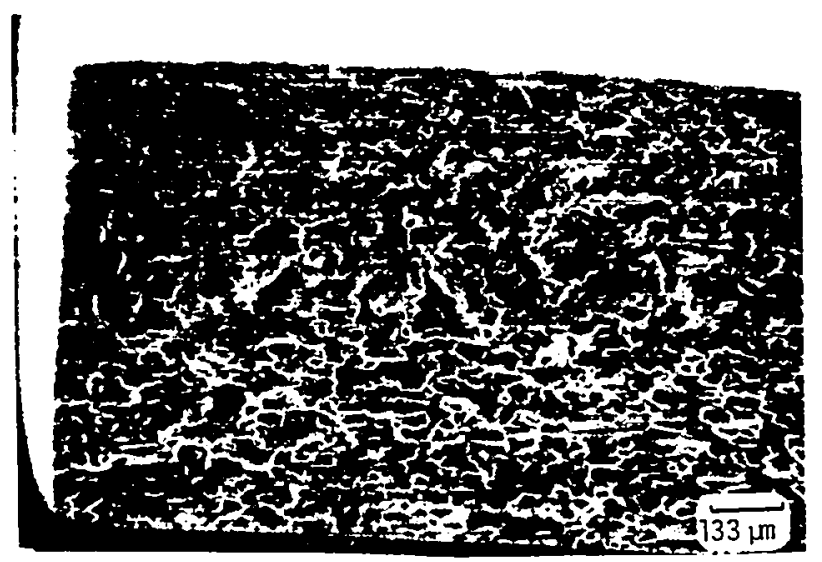

a. SEM photo of fracture.

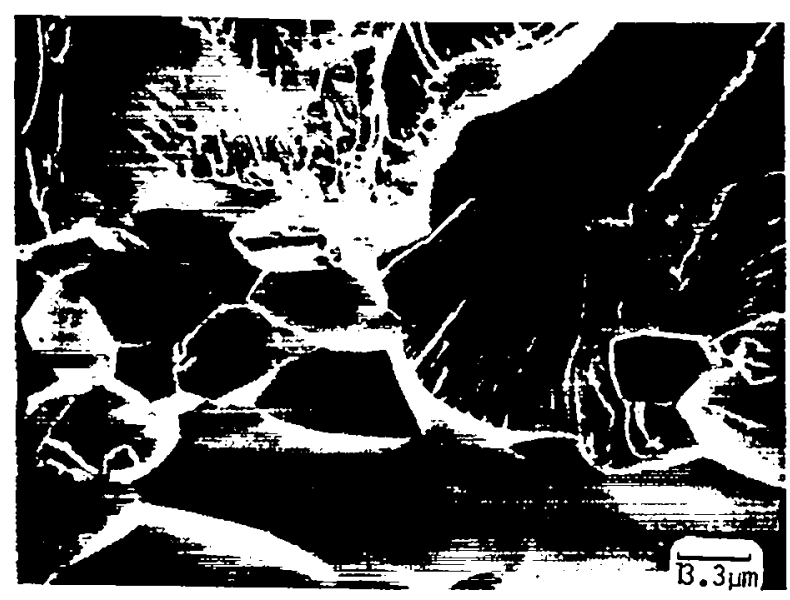

b. Transition zone.

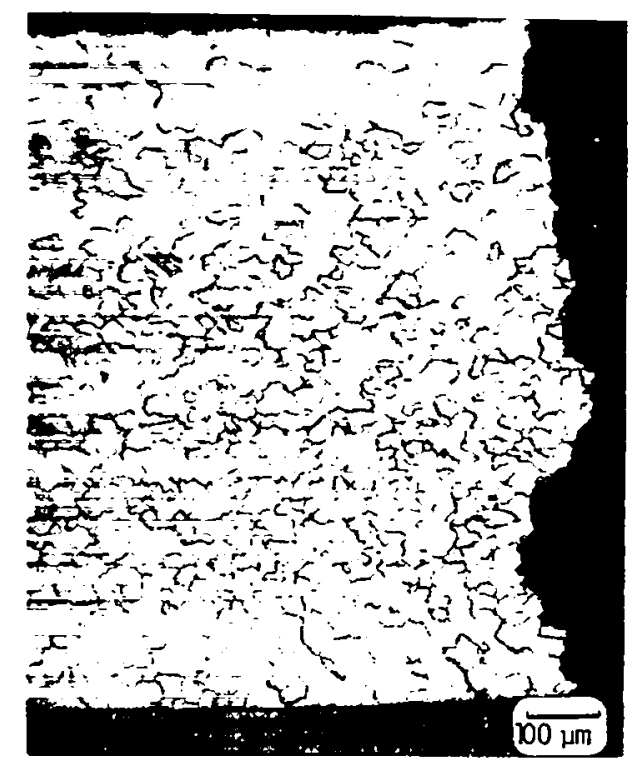

c. Optical photo thru fracture.

Fig. 19. Annealed molybdenum tubing. 


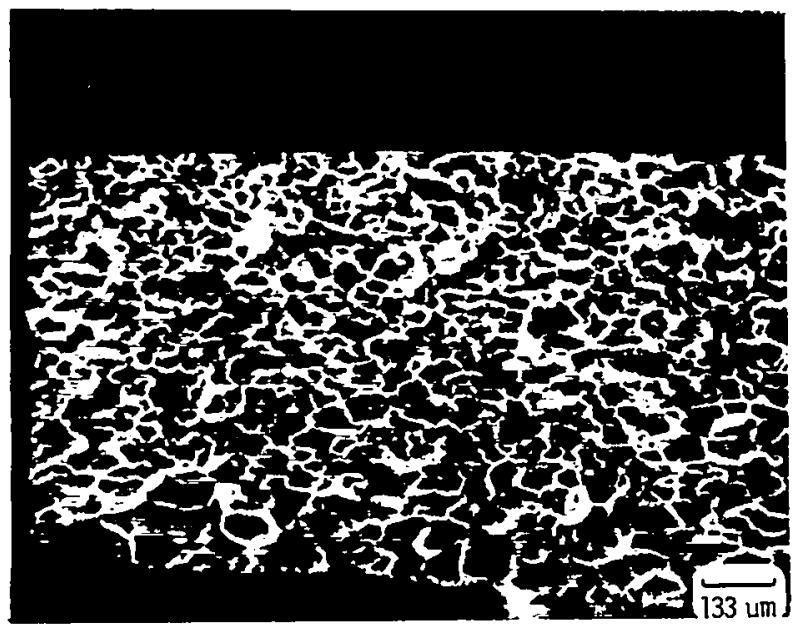

a. SEM photo for fracture.

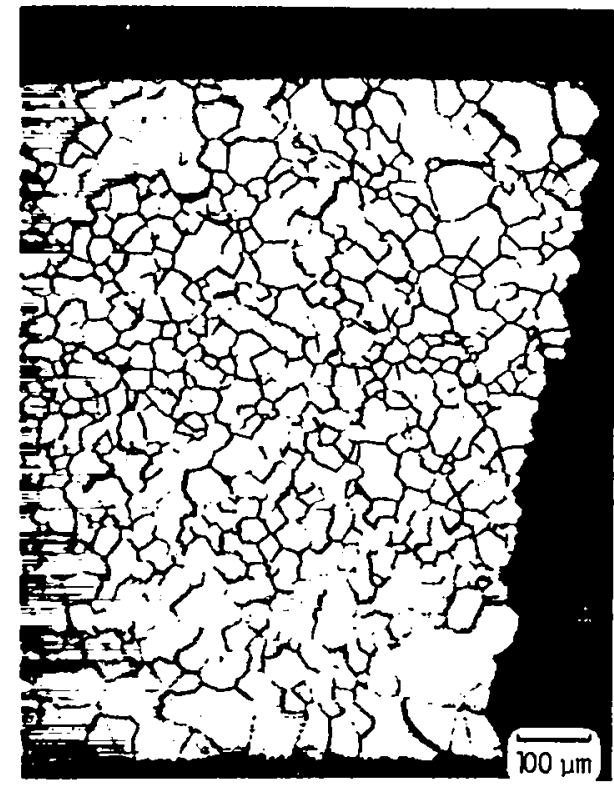

b. Optical photo thru fracture.

Fig. 20. Annealed molybdenum tubing (4).

the optical photograph, Fig. 20b, show a completely recrystallized structure with larger grains on the inside and outside diameters. The reason for this large grain surface structure is probably related to greater work in these areas, which respond to the annealing temperature by early recrystallization and subsequent grain growth. Figure 18 a tends to confirm the greater work at the surface areas. The hardness of this section of annealed tubing (4) was $187 \mathrm{DPH}$.

The microstructure of sample (5) is expected to be similar to Fig. 18, while the structures of samples (6) and (7) should be quite similar to Figs. 19 and 20.

We conclude that the stress-relieved tubing was ductile and that the annealed tubing was brittle when tested in tension at room temperature.

The wick for the inside of the molybdenum tube heat pipe was made from molybdenum screen. A potential candidate wire for fabricating the screen was tested in tension. The stress-relieved wire had the following properties: $0.2 \%$ offset yield strength, $710 \mathrm{MPa}$; tensile strength, $840 \mathrm{MPa}$; $18 \%$ elongation in $64-\mathrm{mm}$; and $77 \%$ reduction in area.

d. SPAR-1 Filling and Sealing. Because of the length of the SPAR-I heat pipe, it was necessary to fill the heat pipe using a $114-\mathrm{mm}-i$.d. by $3-\mathrm{m}-$ long horizontal furnace that was available. The upper portion of Fig. 21 shows the essentials of the apparatus used to fill the SPAR-1 molybdenum heat pipe with sodium. Sodium metal (81 g) was initially placed in a fill pot that was made of austenitic stainless steel and contained a stainless steel screen wall wick. In order to make the fill pot readily reusable, it was attached to a stainless steel fill tube with a stainless steel Swagelok union that can usually be disconnected after filling and sealing of the heat pipe. In Fig. 21, the long tube protruding from the left end of the fill pot serves to allow all the adsorbed gases to be released into the vacuum chamber from the sodium and the heat pipe.

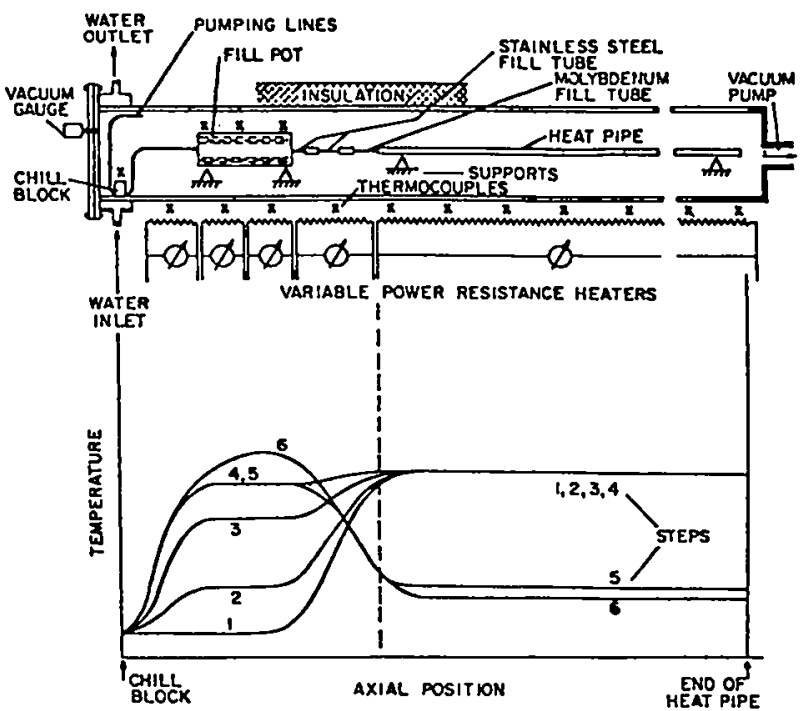

Fig. 21. SPAR-1 sodium filling apparatus. 
After the fill pot was loaded with sodium and sealed to the fill tube of the heat pipe, the assembly was placed in the vacuum chamber and the chamber evacuated to $0.1 \mathrm{MPa}$ or better. The first step in the filling operation involved heating only the heat pipe to $825 \mathrm{~K}$. The temperature profiles down the length of the assembly for all of the six filling steps are shown schematically in the lower portion of Fig. 21. The purpose of this first step was to outgas the heat pipe. In the second step, the fill pot temperature was raised to $425 \mathrm{~K}$ to start outgassing the sodium. Next, the fill pot temperature was raised to $695 \mathrm{~K}$ to further outgas the sodium and decompose the hydrides and nitrides. When the outgassing ceased, the temperature of the fill pot was increased to $765 \mathrm{~K}$ (Step 4) which was the desired sodium distillation temperature. As noted in Fig. 21, the heat pipe temperature was maintained above the rest of the assembly during the first four steps so that all the contaminants would be driven out into the vacuum chamber, and in Step 4 the pumping line was eventually blocked by distilling sodium into it and freezing the sodium at the chill block. The fifth block involves lowering the heat pipe temperature so that the sodium would distill into it. The power input to the fill pot remains constant during the distillation process so, when the fill pot is empty, its temperature starts to rise giving a temperature profile like that shown in Step 6 in Fig. 21. The temperature rise was not significant so that it was difficult to determine whether that distillation was complete.

After the heat pipe was filled and cooled, the assembly was removed from the vacuum chamber, and the fill pot was disconnected from the heat pipe by flattening the stainless steel tube closest to the molybdenum fill tube. The flattened tube was then simultaneously cut and sealed with a TIG welding torch. The cutting and sealing operation was performed in an inclined orientation so that the molten metal pools on top of the cross section of the flattened section and maintains the vacuum inside the heat pipe. At this point, the pumping tube was removed from the fill pot to determine whether or not it was plugged with sodium. The plug was found satisfactory, and it was concluded that the heat pipe was evacuated, and preparations were made for flattening and sealing the molybdenum fill tube.

The 6.35-mm-diam molybdenum fill tube was flattened at $500 \mathrm{~K}$ first using a hand flattening tool with flat jaws $13 \mathrm{~mm}$ wide. Both the tube flattening and the pinching tools are heated with an electric heat gun, and the temperature of the tube was monitored with a thermocouple clamped to the tube. The flattened section of the molybdenum fill tube is first electron beam seal welded, then an overpowering electron-beam weld pass was made across the flattened section on the end away from the heat pipe outside the seal weld to sever the molybdenum fill tube from the heat pipe.

The SPAR-1 heat pipe was then placed in a horizontal quartz vacuum chamber and heated over its entire length with an rf power supply. The heat pipe welds were examined for leaks and the liquid metal was distributed in the heat pipe. The heat pipe was then heated with the rf power supply at one end and the condition of the heat pipe established, i.e., the quantity of excess liquid metal and gas, if present. Once the condition of the heat pipe was established, the cover was welded on the heat pipe over the fill tube to protect it during subsequent testing operations. The fully assembled heat pipe was loaded back into the vacuum furnace and heated to $975 \mathrm{~K}$ for 4 to $8 \mathrm{~h}$ in order promote the wetting of the molybdenum surface with the sodium.

\section{e. SPAR-1A Fabrication. Fabrication of} SPAR-1A heat pipe was begun. The heat pipe will be a $2-m-$ long molybdenum developmental heat pipe and will be characterized by using an as-received (unrecrystallized) container tube and an electron beam welded calorimeter collar.

f. Heat Pipe Bending. Metallographic examinations were performed on the bend samples produced last quarter. The metallographic examinations of the longitudinal sections show no evidence of cracking from the bending operation in any of the stressed surfaces or within the matrix. Examination of the grain size showed little difference between the bent and straight regions for samples of the same heat treatment.

A system for bending the container and screen tube assembly was designated and built. It is a 
standard tube bender fitted with a heating system to heat the tooling and assembly. The system was checked out on stainless steel tube and operated as desired.

\section{g. Material.}

1. Molybdenum Heat Pipe Corrosion Experiments (L. B. Lundberg, Q-13). Studies have continued to determine whether a corrosion problem exists with the SPAR core heat pipes during reactor operation. Addition theoretical studies centered on a determination of possible chemical reactions that could cause corrosion to proceed. Reactions of primary interest are those that involve the reduction of the uranium dioxide fuel by the sodium working fluid or the molybdenum container material.

Thermochemical data were gathered for uranium dioxide, ${ }^{1,2}$ sodium oxide, ${ }^{3}$ molybdenum oxide, ${ }^{4}$ and sodium molybdate, ${ }^{5}$ and they are plotted in Fig. 22. The relative stabilities of the compounds are indicated by their free energies of formation, and the more negative the value the more stable the compound. As can be seen in Fig. 22 , sodium molybdate, molybdenum dioxide and sodium, containing $10 \mathrm{ppm}$ oxygen are all more stable than $\mathrm{UO}_{2.05}$ and hence could take oxygen from it. On the other hand, $\mathrm{UO}_{2.00}$ is not reduced by the heat pipe materials, and hence no problems with unwanted oxygen movement would be expected.

Because predictions based on thermochemistry in systems as complicated as the SPAR core with heat pipes are quite inexact, we are planning experiments to determine mutual compatibility in the $\mathrm{UO}_{2}-\mathrm{MO}-\mathrm{Na}$ system. At present, we are designing a test capsule that will have uranium dioxide inside a molybdenum tube that is, in-turn, sealed inside a sodium-containing molybdenum heat pipe. This capsule will be heated at or above nominal operating temperatures for periods of $1000 \mathrm{~h}$ or more in a vacuum. Detailed chemical and metallurgical examinations after the test should help predict long-term capability in this system. Compatibility tests will also be conducted with uranium dioxide sealed inside TZM-molybdenum alloy tubes.

h. Publications. A paper entitled "Fabrication of High-Temperature (1400-1700 K) Molybdenum Heat Pipes," by L. B. Lundberg and H. E. Martinez

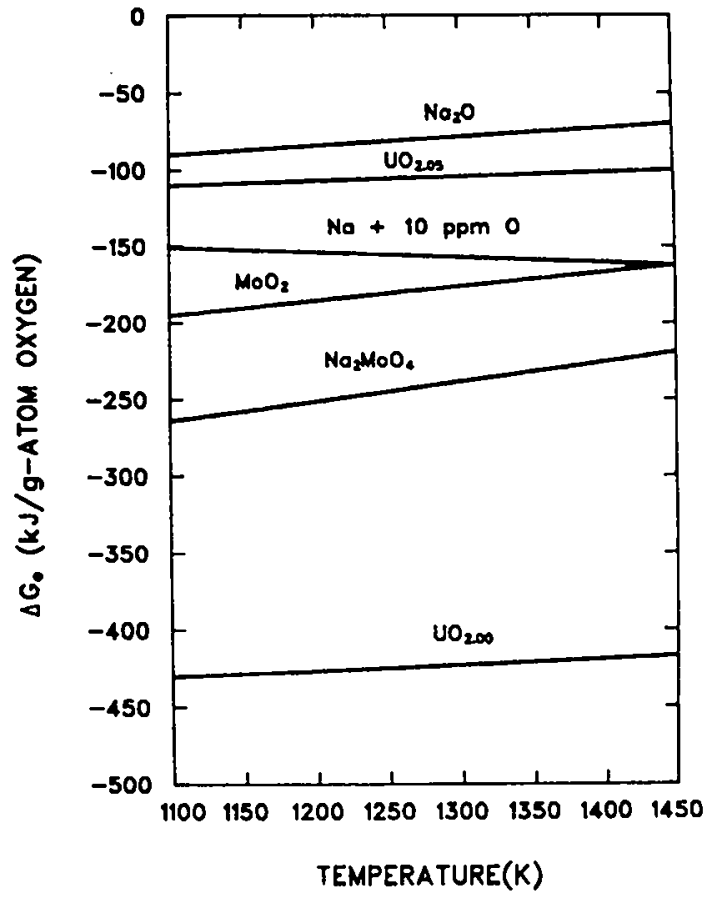

Fig. 22. Free energies of formation for oxides expected in SPAR core heat pipes.

has been accepted for presentation at the 15th Intersociety Energy Conversion Engineering Conference in late August of this year in Seattle. F. Thermoelectric Module Development (W. Ranken, Q-15; G. Fly, Q-13; V. Raag, Syncal Corp.)

1. Materials Research. Syncal has continued work on the p-type material leading to the selection of parameters for its preparation:

- 325 mesh material

- 5-7.5 M/O GaP

- 200-270 MPa pressing pressure

- Press at 1275-1375 K for $4 \mathrm{~h}$

Densities of $98-99 \%$ of theoretical are obtained with these process parameters without the material undergoing the transformation to n-type. A summary of the thermoelectric properties of the p-type material is shown in Fig. 23.

The major limitation for the material in this application is the sublimation of the material at the hot junction. Significant improvements in efficiency could be obtained by increasing the hot junction temperature if the sublimation rates could be limited. Investigations of sublimation rates at temperatures up to $1400 \mathrm{~K}$ are presently 

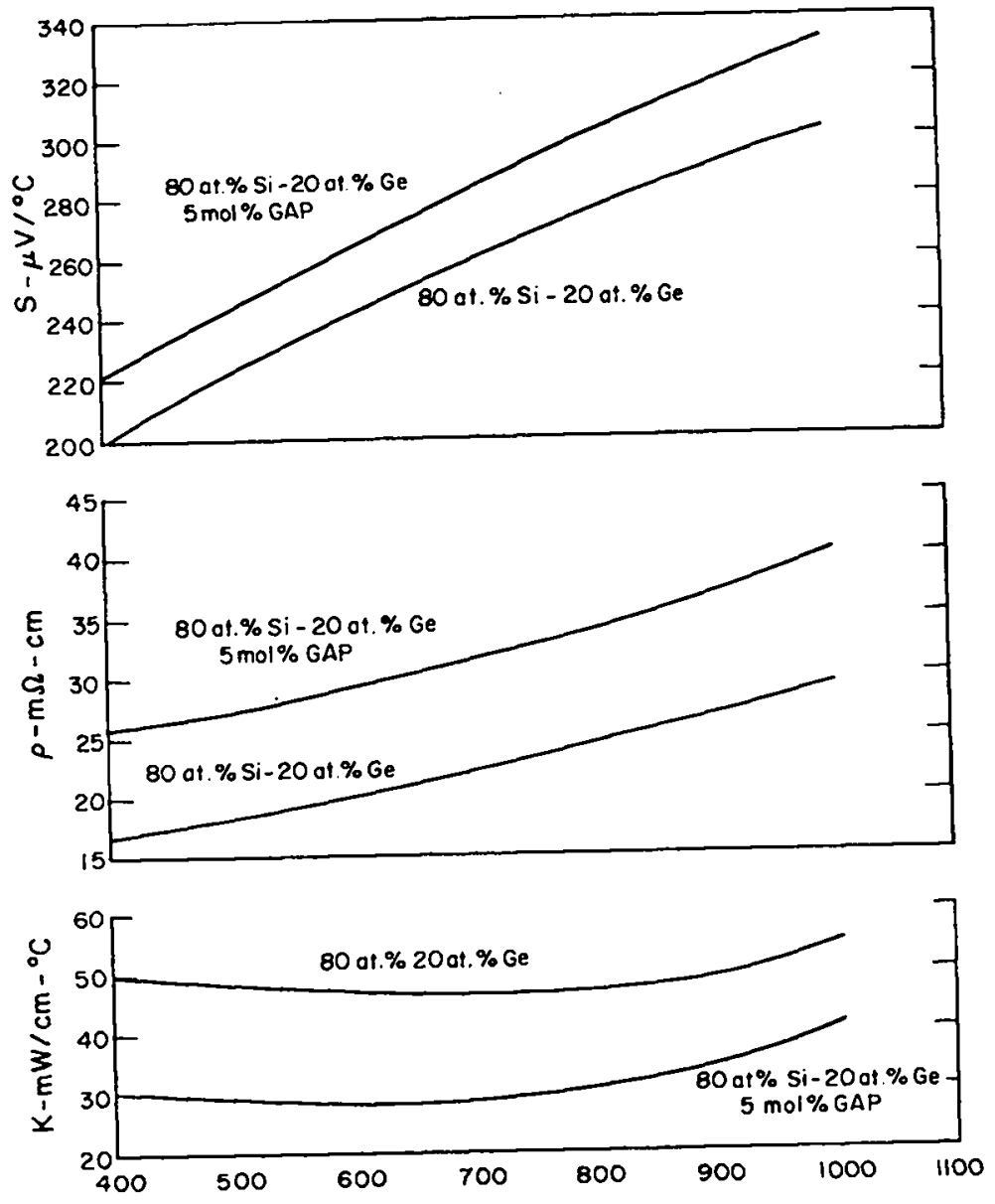

Fig. 23. P-type Sige thermoelectric properties.

being performed on materials coated with high silica glass. If these results are not satisfactory, other coating materials will be investigated.

2. Testing. The SPAR-2A heat pipe was received from Syncal with two compression modules mounted on it. Thermocouple holes had not been drilled in all of the components, so it was necessary to devise alternative methods of mounting thermocouples. The preliminary attempts were to simply spotweld tungsten-tungsten $/ 26 \%$ rhenium thermocouples directly to the molybdenum, but this technique was unsatisfactory. The joints were extremely brittle regardless of the spotwelding procedures used. It was found, however, that a small foil of nickel could be spotwelded to the molybdenum and the thermocouples spotwelded to the nickel. This procedure produced consistent, reliable joints. The modules were instrumented with three thermocouples each; one on the hot side, one on the cold side, and one on the outer niobium ring. This should give a fair idea of what the temperature drops are and where they are occurring. The calorimeters have been attached to the modules and the heat pipe has been installed in a vacuum chamber. Final preparations for performing the two-module test are being completed now.

3. Module Design. A preliminary design for a bonded module has been developed. A layout of this module is shown in Fig. 24. This module uses metaliurgical bonds at every interface to reduce the interface temperature drops. In order to el iminate high stresses due to thermal expansion mismatches, a stress relief member has been incorporated in this design. This member consists of a 2-mil thick corrugated molybdenum foil brazed to a molybdenum ring on the inside and to the niobium insulator backing strips on the outside. This provides radial stress relief. The module is 


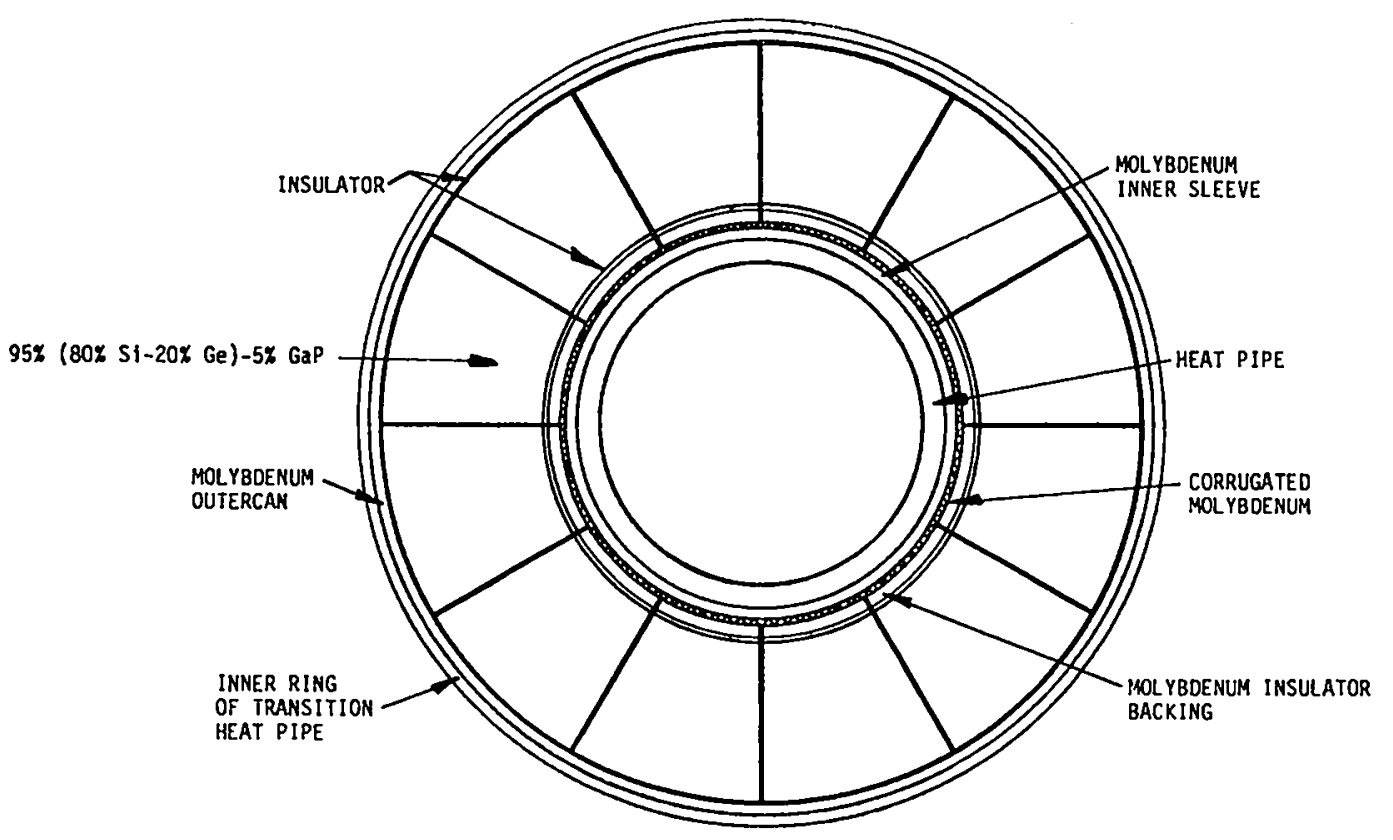

Fig. 24. SPAR thermoelectric module.

circumferentially segmented to provide circumferential stress relief. The temperature drop associated with this design for a stress relief member is approximately $20 \mathrm{~K}$. This stress relief member could be $p$ laced on the cold side where the temperature drop would only be about $10 \mathrm{~K}$. This placement will be determined by which layout gives the maximum temperature drop across the thermoelectric material rather than by the drop across the stress member.

In this design, the thermoelectric material will be GaP-enhanced silicon germanium with 5-7.5 mole percent GaP. Each thermocouple will be coated with 2 mils of $\mathrm{SiO}_{2}-4 \% \mathrm{TiO}_{2}$. The silicon dioxide will be bonded to 10-mil-thick alumina insulators on each end. The alumina will be plasma sprayed onto the niobium backing strips and onto the niobium outer can. Each thermocouple will consist of a $n$ - and a p-leg bonded together with a silicon hot shoe. This thermocouple will be oriented axially. The cold side connections will be with molybdenum foils, which will connect the thermocouples circumferentially. Intermodular connections will also be made on the cold side with molybdenum strips.
4. Insulator Development. Several different insulator materials are being considered for the hot side insulator. In order to limit the conduction losses to $1 \%$ of the total electrical power, the voltage resistivity of the insulator material must be $3 \times 10^{6} \mathrm{ohm}-\mathrm{cm}$ or greater at $1400 \mathrm{~K}$ for an assumed insulator thickness of $0.5 \mathrm{mils}$. The candidate materials that meet this criteria and appear to have sufficient vacuum stability, mechanical strength, and fabricability, are alumina, beryllia, magnesium aluminate (spinel), aluminum nitride, and 15R sialon. Samples of these materials are presently being obtained and a program to investigate their vacuum stability, resistivity, and thermal breakdown resistance is being planned.

5. Stress Analysis. A program utilizing the TSAAS finite element code has been written to analyze the stresses within the module. A representative segment was chosen, as shown in the mesh plot of Fig. 25a. A typical maximum principal stress plot is shown in Fig. 25b. This stress analysis program is presently being modified to include the stress relief member. 


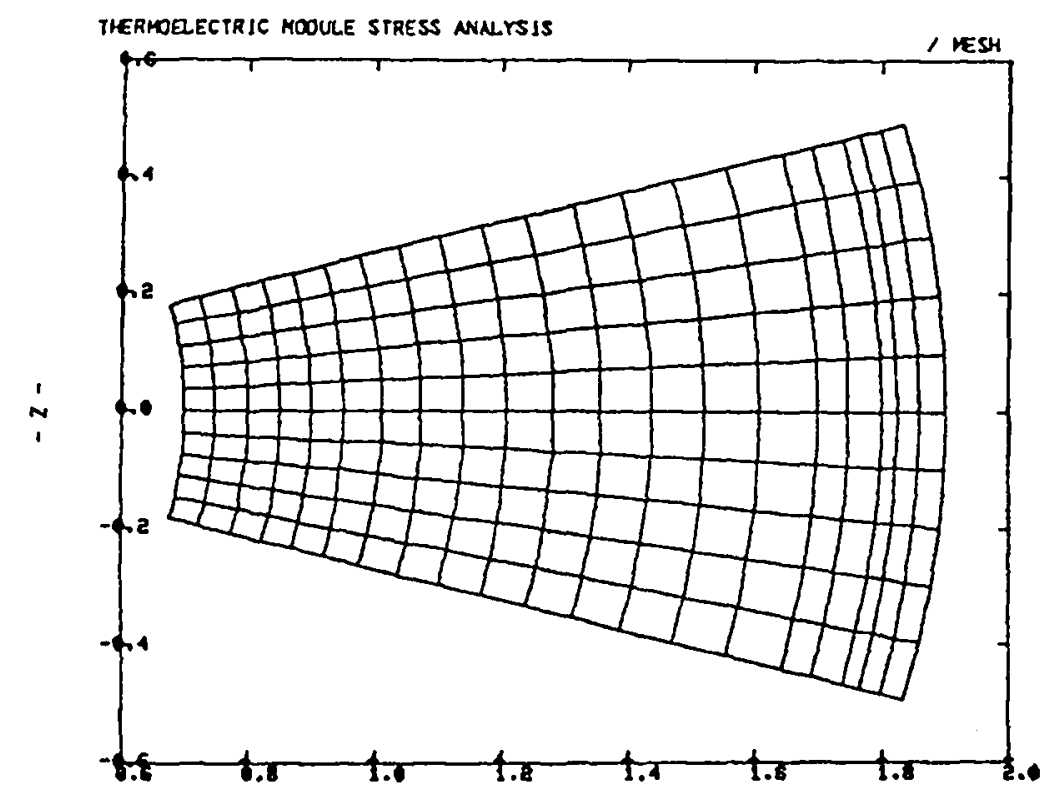

Fig. 25a.

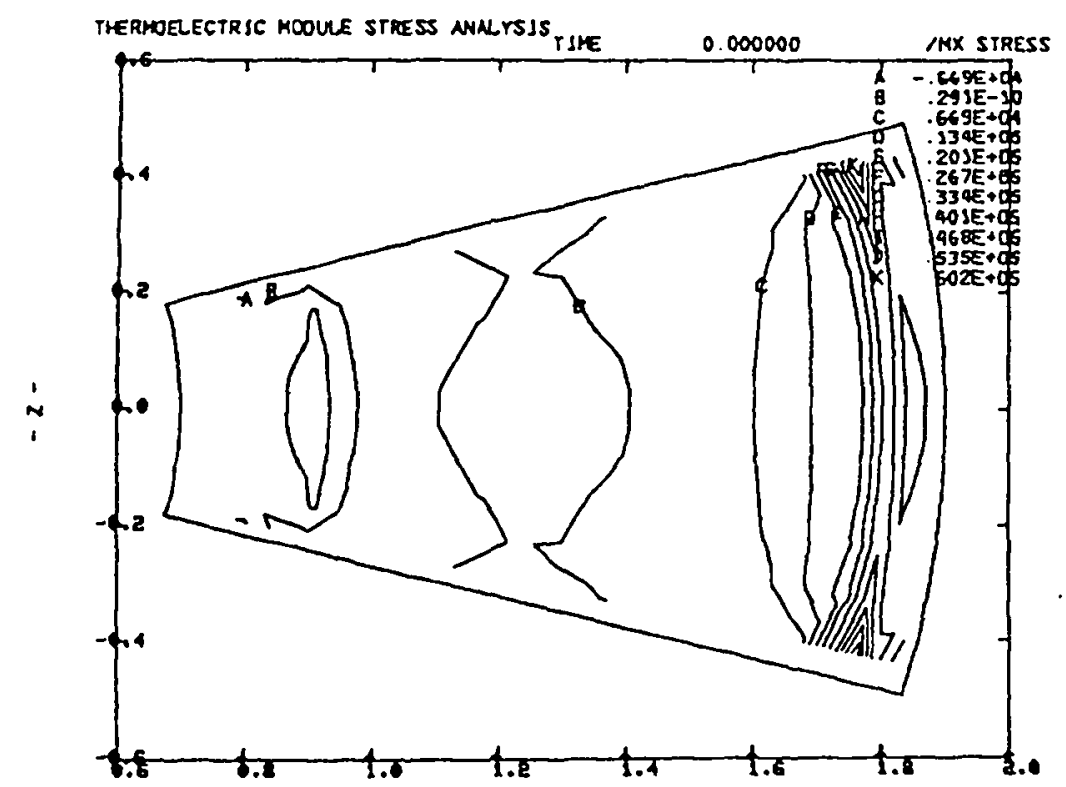

- Fig. 25 b.

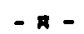

Fig. 25. Finite element model of bonded thermoelectric module.

\section{G. Radiator Development}

1. Analysis (S. P. Girrens, Q-13). Preliminary results from the impact study program at UDRI have favorably affected the radiator design. Data obtained by impacting titanium targets at $775 \mathrm{~K}$ with 1-mm glass bead projectiles traveling near 7 $\mathrm{km} / \mathrm{s}$ indicate the actual armor thickness required is 40 percent less than previously expected.
Since the overall radiator mass is a function of both micrometeoroid mass and the total number of stringer heat pipes, calculations to re-evaluate this dependence were made. The effects of the reduced armor thickness are shown in Fig. 26. It is evident that panel segment designs with three and four stringer heat pipes per TE module result in the minimum mass radiators. The critical 


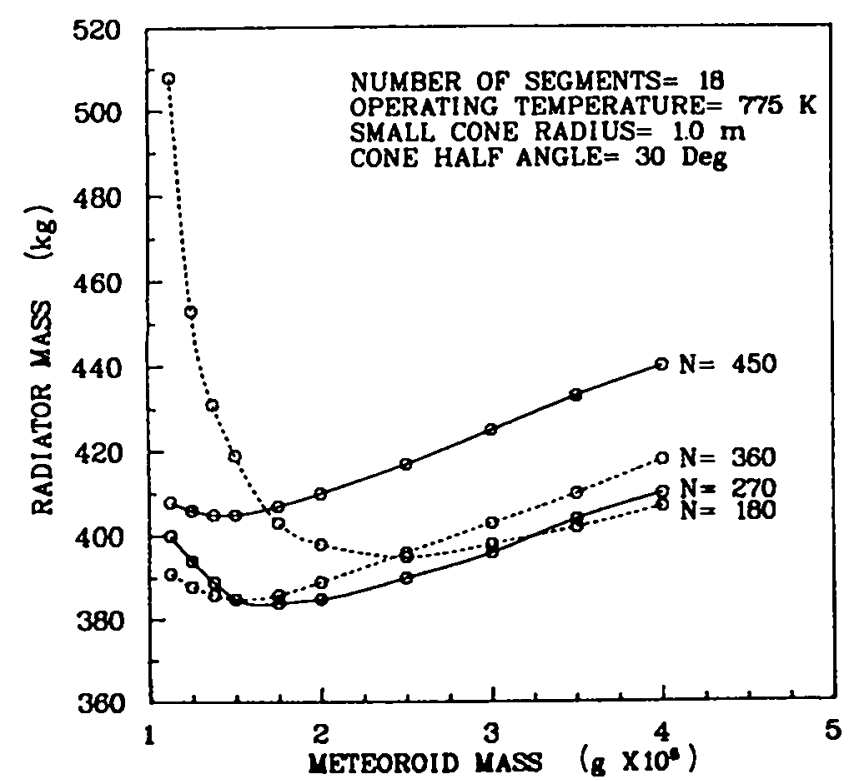

Fig. 26. Radiator mass vs meteoroid mass for various numbers of stringer heat pipes.

micrometeoroid mass, on which the armor thickness is dependent, has increased slightly. By armoring the radiator against a larger micrometeoroid, the number of lost heat pipes will decrease because the number of particles with masses sufficient to penetrate the armor is thereby reduced. Table VII contains a list of radiator characteristics before and after inputing the latest armor data into the design calculations.

A sensitivity study was performed on the reference radiator design to examine the effect of various thermoelectric converter efficiences. Reactor power was increased as converter eff $i$ ciency decreased in order to maintain the desired electrical output of $100 \mathrm{~kW}$. Figures 27 and 28 are plots of radiator mass and stringer length vs cone half angle and thermoelectric converter effeciency, respectively. As shown in Fig. 27, a decrease in efficiency from 0.09 to 0.07 results in a mass penalty of $170 \mathrm{~kg}$ at a cone half angle of $30^{\circ}$. This mass increase is due primarily to the increase in radiator area required to radiate the additional waste heat. As Fig. 28 illustrates, the actual increase in stringer heat pipe length between the same converter efficiencies at a $30^{\circ}$ cone angle is $1.9 \mathrm{~m}$. In summary, a drop in thermoelectric conversion efficiency from $9 \%$ to $7 \%$ results in a radiator mass increase of $44 \%$ and a 36\% increase in radiator heat pipe length.

2. Titanium Heat Pipe Design (S. P. Girrens, Q-13). Design of the distributive wicking system is concentrating on nonscreen wicking surfaces which include steel shot blasting, machined $v$-grooving, and pyramid-shaped embossing. The primary function of the distributive wicking surface is to transport the liquid by capillary force to the arteries in the condenser and away from the arteries in the evaporator. In space, the capillary pumping force, $P_{c}$, need only be sufficient to balance the frictional losses and gravitational effects. The general equation for determining $P_{C}$ is

$$
\Delta p_{c}=\left(\frac{1}{r_{1}}+\frac{1}{r_{2}}\right)=\frac{2 \sigma}{r_{\text {eff }}} \text {, }
$$

where $\sigma$ is the surface tension of the working fluid, $r_{1}$ and $r_{2}$ the two right angle radii of

TABLE VII RADIATOR CHARACTERISTICS AT $100 \mathrm{kH}$ e

Total number of stringers Number of stringers surviving mission Radiator small diameter (m) Cone half angle (deg) $Q_{\text {max }}$ /heat pipe (kW) Critical meteorofd mass $\left(\times 10^{-5} \mathrm{gm}\right)$ Stringer armor thickness (mm) Stringer length (m)

Armor mass (kg)

Stringer wall mass (kg) Artery and fluid mass $(\mathrm{kg})$ Total radiator mass ( $\mathrm{kg}$ ) Dec. 1979

360

312

2.00 30

3.1

1.25

1.05

5.3

307

149
Aprii 1980

360

321

30

3.0

1.50

0.60

5.2

170

143

74

387 


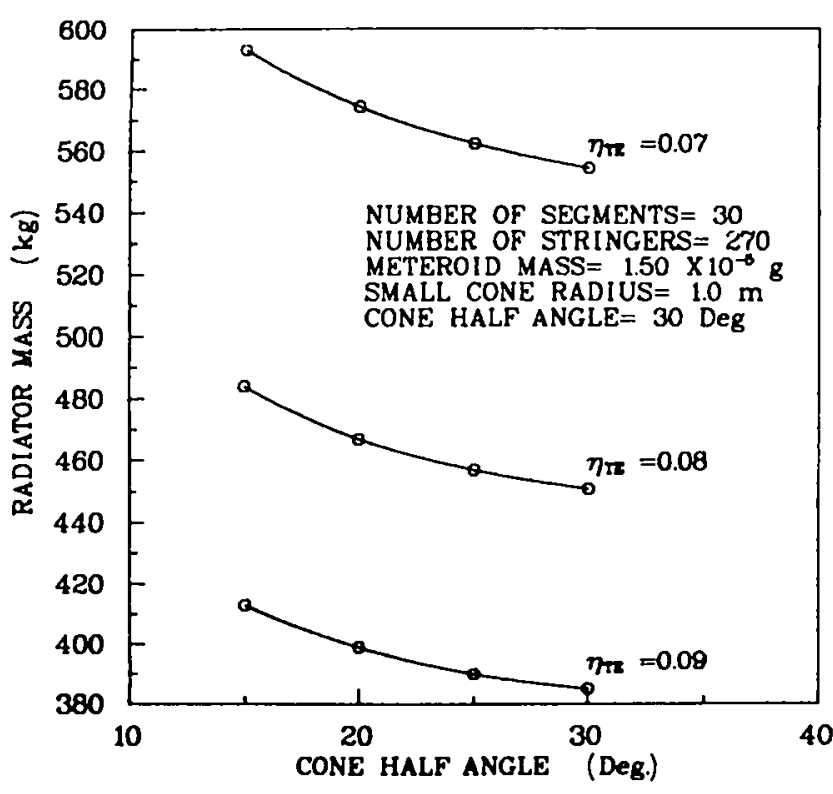

Fig. 27. Radiator mass vs cone half angle for various thermoelectric converter efficiencies.

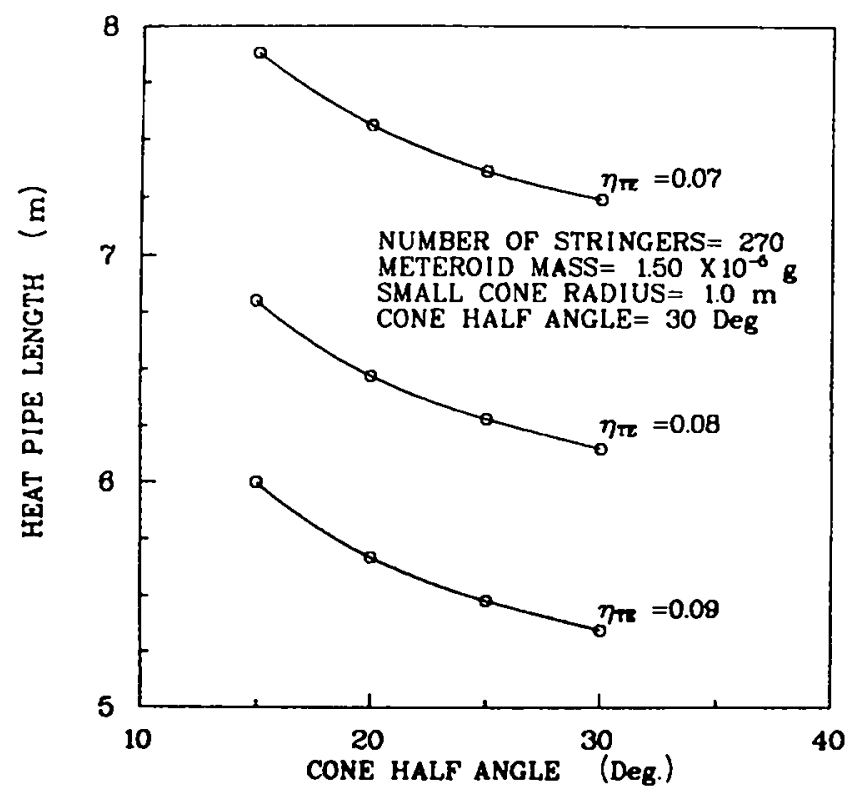

Fig. 28. Stringer heat pipe length vs cone half angle for various thermoelectric efficiencies.

curvature of the meniscus formed, and $r_{\text {eff }}$ the effective pore radius. Wicking height experiments were performed to determine the value of $r_{\text {eff }}$ and compare the wicking capability of the various surfaces. The equation for calculating wicking height is

$$
h=\frac{2 \sigma}{\rho g r_{\text {eff }}},
$$

where $h$ is the wicking height, $\rho$ is the fluid density and $g$ is the acceleration of gravity.

Wicking tests were performed on grooved titanium specimens by suspending the test pieces in a beaker of ethanol at $293 \mathrm{~K}$. The apparatus was covered with a be $11 j$ ar and evacuated, thereby allowing liquid-vapor equilibrium to occur. The expression used to predict the wicking height of grooved surfaces is

$$
h=\frac{2 \cos \beta}{\rho g W},
$$

where $\beta$ and $W$ are defined in Fig. 29. The angle $\beta$ for all of the grooved test pieces was $45^{\circ}$.

Results of measured and calculated values of wicking heights are contained in Table VIII. In all cases the calculated values predict conservative wicking heights for ethanol.

In a similar manner, wicking tests were performed on embossed and steel shot-blasted specimens. The embossed specimens were actualiy pyramid pattern samples on thin PVC sheets. Work is continuing to develop an expression to predict wicking height on embossed surfaces. Results from the tests are contained in Table IX. More tests will be done when actual titanium embossed sheets are obtained.

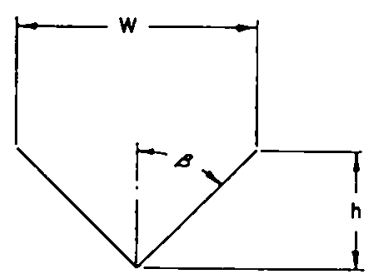

Fig. 29. Wicking height geometry.

TABLE VIII

CALCULATED AND OBSERVED WICKING HEIGHTS FOR RIGHT ANGLE GROOVED TITANIUM SHEETS

$\underset{(\mathrm{mm})}{\operatorname{Groove} \text { Width }} \underset{(\mathrm{mm})}{\text { Calculated Height }} \frac{\text { Measured Heiaht }}{(\mathrm{mm})}$

$\begin{array}{rrr}0.25 & 18.1 & 28.0 \\ 0.51 & 9.0 & 14.0 \\ 0.76 & 6.0 & 9.0\end{array}$


The roughened surface resulting from steel shot-blasting is highiy random as would be expected. The size of the steel particles range from 50 to 500 microns. However, a variety of test specimens was obtained by blasting titanium samples at angles of $90^{\circ}$ (perpendicular to the sheet), $45^{\circ}$ and $30^{\circ}$. As is evident in Table $x$, not only is the wicking height sensitive to blast angle but also to flow orientation. At blast angles of $30^{\circ}$ and $45^{\circ}$, the surface would wick ethanol the furthest when the fluid was allowed to flow parallel to the direction taken by the shot-blasting particles. An explanation for this phenomenon might be that the flow restrictions caused by the "furrowing" effect of the blasting are minimized when the fluid flows in the same direction as the blasting particles.

Table XI contains values of predicted wicking heights for potassium at $775 \mathrm{~K}$ calculated using Eq. (2). Only the best performing samples in each of the surface categories were considered. In current heat pipe designs, the maximum distance the fluid must be transported by the wicking surface is 22 $\mathrm{mm}$. Though the ultimate test of these various distributive wicking systems is successful performance

TABLE IX

O8SERVED WICKING HEIGHTS FOR PYRAMIDAL EMBOSSED SURFACES

\begin{tabular}{lc}
$\begin{array}{l}\text { Pyramid } \\
\text { Width } \\
\text { (mm) }\end{array}$ & $\begin{array}{r}\text { Dimensions } \\
\text { Height } \\
\text { (mm) }\end{array}$ \\
\hline 0.25 & 0.57 \\
0.10 & 0.30 \\
0.11 & 0.51 \\
0.15 & 0.64
\end{tabular}

$\underset{(\mathrm{mm})}{\text { Measured Height }}$

24.0

25.0

18.0

16.0

TABLE $X$

OBSERVED WICKING HEIGHTS FOR STEEL SHOT-BLASTED TITANIUM

\begin{tabular}{|c|c|}
\hline Blast Angle & $\begin{array}{l}\text { Measured Height } \\
\text { Parallel to } \\
\text { Biast Direction } \\
(\mathrm{mm})\end{array}$ \\
\hline $\begin{array}{l}30 \\
45 \\
90\end{array}$ & $\begin{array}{l}24.0 \\
22.0 \\
14.0\end{array}$ \\
\hline
\end{tabular}

Measured Height Perpendicular to Blast Directions (mm)

15.0

9.0

13.0
TABLE XI

PREDICTED POTASSIUM WICKING HEIGHT AT $775 \mathrm{~K}$ FOR VARIOUS SURFACES

Surface Description

Predicted Height $(\mathrm{mm})$

Right angle groove $(W=0.25 \mathrm{~mm})$

103.0

Pyramid emboss $(W=0.10, H=0.30)$

92.0

Steel shot-blast (blast angle $=30^{\circ}$ )

88.0

in an operating heat pipe, the wicking tests indicate that all surfaces should adequately transport liquid in the heat pipe condenser section. However, experiments involving constructed heat pipes are required to determine how surface roughness and evaporation rate will affect the performance of these distributive wicking surfaces.

3. Titanium Radiator Heat Pipe Fabrication ( $J$. Dickinson, J. Muller, D. Sandstrom, W. Zimmer, E. VanDeValde, E. Morris, S. Quintana, H. Casey, C. Javorsky, J. Gray, A. Patterson, F. Flick, V. Vigil, L. Crisler, J. Magnuson, and M. Rickerson, CMB-6). A short, 300-mm-long titanium heat pipe, RAD-1, with an all grit-blasted wicking surface was completed last quarter and work was started on RAD-1A, also a 300-mm-long titanium heat pipe, but with machined grooves in the evaporator section. This pipe was completed this quarter with minimum problems. The fit of the end caps was poor on this heat pipe and one of the laser welds leaked. It was easily repaired using manual GTA welding and gives us assurance that small defects can be repaired. This will be important to the production phase of the SPAR program, since defects are bound to occur.

We have completed construction on RAD-2, a 2-m-long titanium heat pipe, shown in Fig. 30 . This heat pipe was fabricated from the same 0.56-mm-thick titanium sheet used for RAD-1 and $1 A$ and pointed out some of the difficulties associated with scale-up.

The titanium sheet was grit-blasted with iron shot and was warped badly; it also increased in width about $0.5 \mathrm{~mm}$. After cleaning in warm $\mathrm{HCl}$ to remove the residual iron, the sheets were annealed in vacuum at $975 \mathrm{~K}$ for $1 \mathrm{~h}$ between nickel-coated sheet plates. This both flattened and softened the sheet material. 


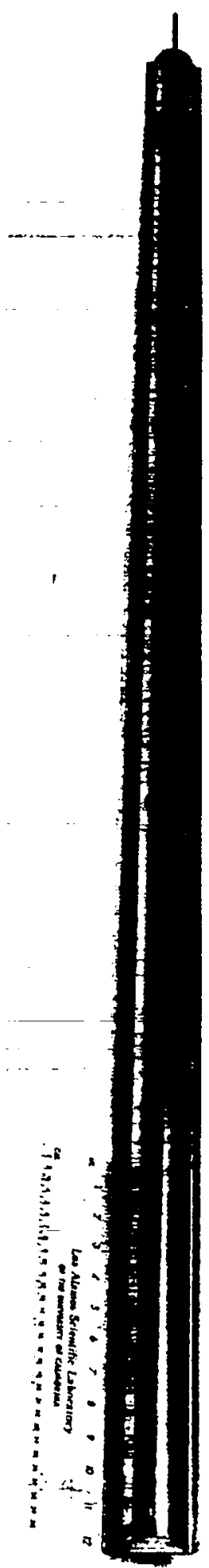

Fig. 30. RAD-2, a completed 2-m-long titanium heat pipe.
The bottom omega-shaped section was formed using a rubber pad fabrication procedure on a press brake. Both this piece and the flat top piece were edge-machined to the desired width. Fifty-mesh titanium screen arteries were hand formed using a 3-mm-diam rod as a mandrel.

These components, the omega-shaped bottom, the flat top plate, and one of the screen arteries are shown in front of the assembly/welding fixture in Fig. 31. After cleaning in hot $\mathrm{HCl}$, the pieces were assembled and welded.

Welding was accomplished using the fixture shown in Fig. 31, and a pulsed current gas tungsten arc (PCGTA) method. A weld was run along the two titanium sheets holding the screen wick in position. The weld then served to form the vacuum seal and secure the screen artery. The torch was precisely positioned and automatically traversed the entire length of the seam. A small shield, also shown in Fig. 31, supplied an argon cover gas to protect the weld area from oxidation.

The mandrel was pulled out of the wick after welding with some difficulty. X-rays taken later showed a variation of wick diameter of from 3 to 6 $\mathrm{mm}$. The wick forming and attachment method will be modified for future RAD heat pipes.

Caps were machined from titanium plate to fit the ends of the welded pipe. One had a tube electron beam welded through it to allow filling the completed heat pipe with sodium. Figure 32 is a photo of this end cap.

The end cap-to-pipe welds shown in Fig. 33, were made using a Nd-YAG computer controlled laser. The laser was programmed to follow the complex seam between the cap and pipe. Joint fitup was excellent and a good weld resulted. Radiographic examination of the welds showed a nice weld penetration of from 0.85 to $1.5 \mathrm{~mm}$ and some small voids--none were problems-- in the size range of 0.3 to $0.5 \mathrm{~mm}$. Porosity in titanium welds is normal, as was expected, and should not be troublesome. It can be reduced by a better preweld cleaning procedure; we recommend an $\mathrm{HF}-\mathrm{HNO}_{3}$ etching treatment, and better protection of the weld area during welding. Because of the variation in diameter of the screen wick, we have developed a better way to fabricate the wick and to join it to the heat pipe tube. 


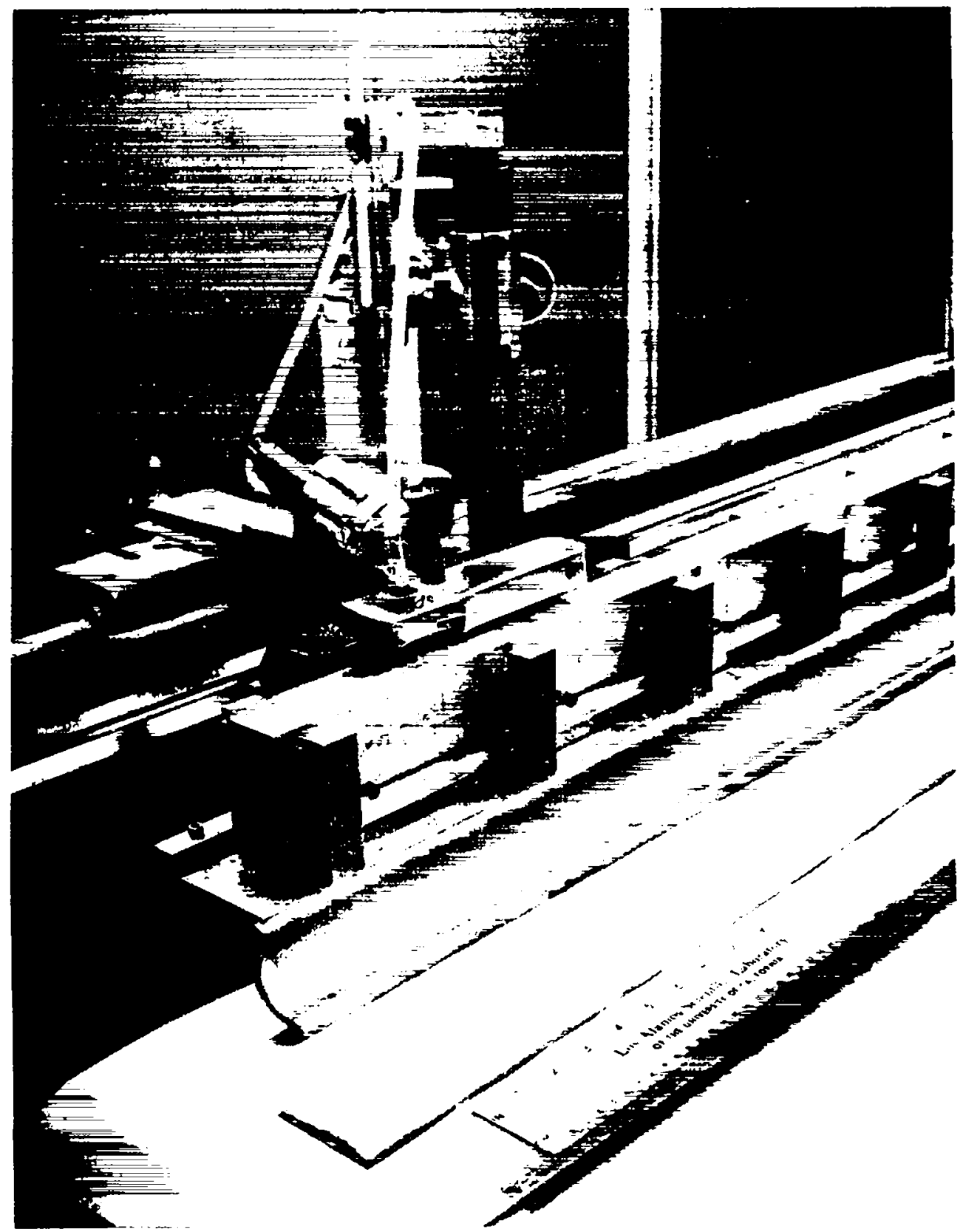

Fig. 31. Assembly and welding fixture for titanium radiator heat pipes showing PCGTA welding head in place.

Screen wicks are now fabricated in a die on the press brake allowing us control of the dimensions. The wicks are then joined to the flat top plate of the heat pipe by spot welding at intervals of a few centimeters. These welds are made very close to the edge so any damage to the screen will be under the contact area of the heat pipe and screen wick. This method allows inspection of the wick diameter before final assembly, and mandrel withdrawal is no problem.
A second 2-m-long heat pipe, RAD-2A, was constructed early in April using the modified procedures.

4. Testing (K. Meier, Q-15). The 300-mm titanium radiator heat pipe with shot blasted inner surface (RAD-1), was tested at $775 \mathrm{~K}$ with $11^{\circ}$ tilt against gravity and performed isothermaity. This showed that the arteries were operating properly. A 2-m long titanium heat pipe with a shot blasted inner surface, RAD-2, was fabricated. 


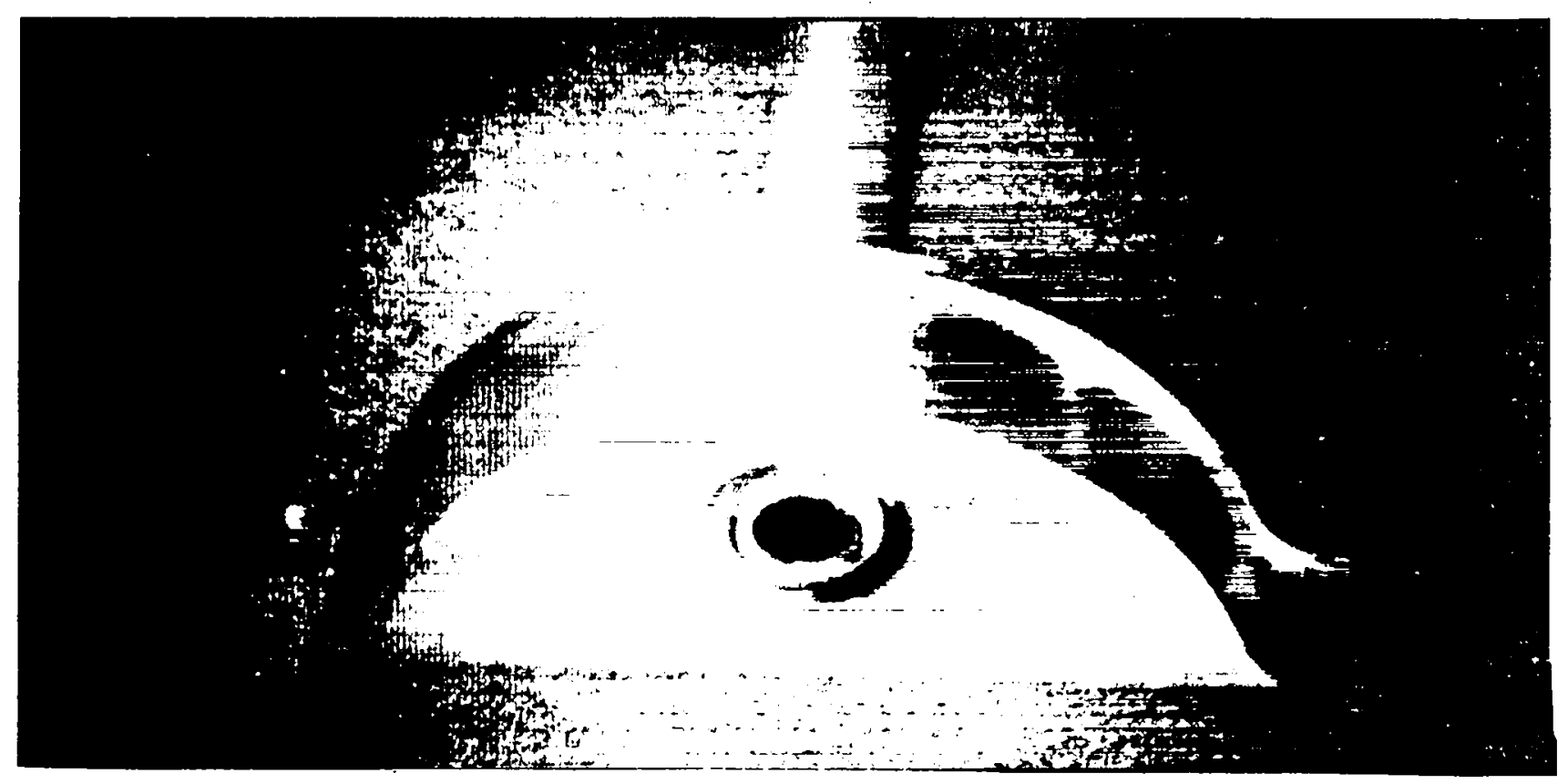

Fig. 32. End cap with EB welded fill tube.

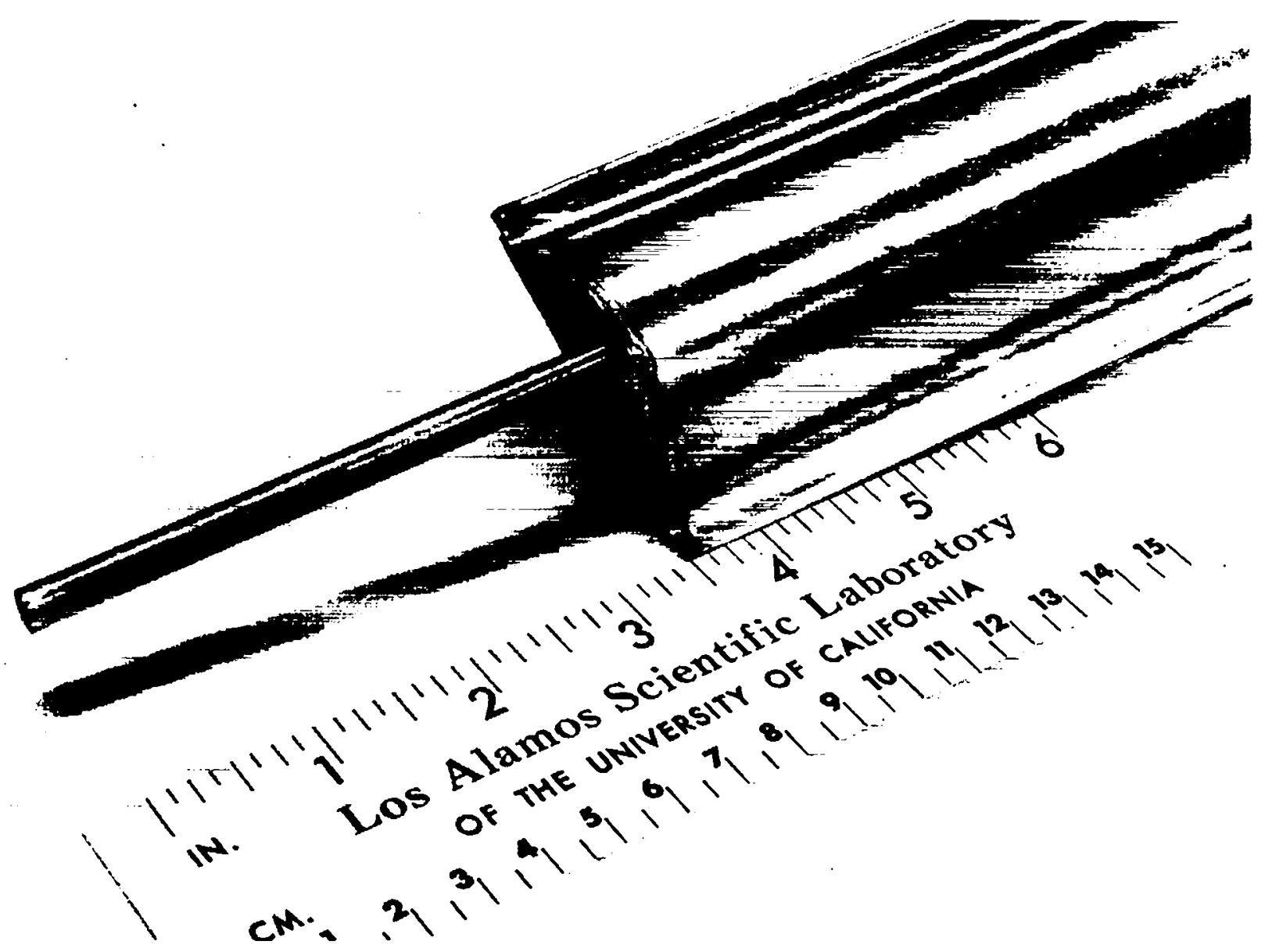

Fig. 33. End view of a titanium heat pipe showing a laser end cap to tube weld. 
This pipe was cleaned in hot $\mathrm{HCl}$, rinsed with water, and then ethanol. The pipe was filled with potassium, with atmospheric pressure on the outside of the pipe. It was wrapped with heat tape to maintain $425 \mathrm{~K}$. During filling, bowing up $4 \mathrm{~mm}$ on the flat side resulted from atmospheric pressure at $425 \mathrm{~K}$. The pipe was wet-in at $775 \mathrm{~K}$ in the 5" diameter vacuum furnace.

The heat pipe was then radiographed. The radiographs showed that one artery was nearly empty of potassium. The other artery was full except for a void about $5 \mathrm{~mm}$ in diameter. The arteries were much larger than the desired 3-mm diameter. They were uneven and, in some places, as 1 arge as $7 \mathrm{~mm}$ diameter. The pipe did not contain enough potassium to fill both oversized arteries.

Because of the inherent difficulties in refilling a heat pipe, it was decided to test RAD-2 for isothermal operation prior to refilling. The tests showed isothermal operation up to $775 \mathrm{~K}$ and $1.4 \mathrm{~kW}$ with a $1^{\circ}$ tilt gravity assist. The heat pipe failed to operate in the horizontal orientation. Another set of radiographs were taken and showed that neither artery was full. RAD-2 is being refilled for further testing.

The RAD-2 heater had a $\triangle T$ of about $50 \mathrm{~K}$ between heat pipe and heater block. This is much less than in RAD-1 tests. Finely powdered copper was placed in between to improve thermal conductivity and make the heat flux more uniform over the evaporator. Figure 34 shows RAD-2 and heater in the vacuum chamber ready for testing.

A 2-m titanium heat pipe with a machine grooved evaporator surface (RAD-2A) is being fabricated. It will be filled in a vacuum furnace so there will be no permanent inward bowing of the flat surface. This will allow lower heater temperatures and more uniform heat flux into the evaporator. This pipe will have properly sized, uniform arteries.

Fabrication of RAD-3, the 5.3-m heat pipe, has begun. Titanium strips have been shot blasted and annealed. Three $1.8-\mathrm{m}$ half shells and flat plates will be welded together to make up the $5.3 \mathrm{~m}$ length.
5. Materials (S. P. Girrens and L. B. Lundberg, Q-13; S. J. Bless, UDRI).

a. Emissivity Coating for Titanium. Emissivity coatings are required for the titanium heat pipes to maximize the heat rejection capability of the radiator. Available coatings capable of withstanding the high operating temperature of $775 \mathrm{~K}$ are limited. Samples of thermal control paints, zinc orthotitanate $\left(\mathrm{Zn}_{2} \mathrm{O}_{4} \mathrm{Ti}\right)$ and carbon black (D-111), have been obtained and tested on titanium substrates. The coatings were found to have total emissivities at room temperature of $0.90 \pm 0.02$. Metallographic samples were prepared to examine the adhesion characteristics of these coatings before and after cycling to $775 \mathrm{~K}$. Figures 35 and 36 contain cross-section views of the zinc orthotitanate and $D-111$ samples, respectively. Both coatings proved porous in each condition. Also, only siight contact between the coatings and titanium substrate is evident.

Another coating under consideration is zinc oxide (z-93). This coating is space qualified and less expensive than its descendent zinc orthotitanate. Since all the above paints use a potassium silicate $\left(\mathrm{K}_{2} \mathrm{SiO}_{3}\right)$ binder, the zinc oxide paint should have adhesion characteristics similar to the coatings described above. The zinc based paints provide better thermal expansion matching and therefore will be used to coat titanium heat pipes being built in the near term. Data obtained during heat pipe testing will further evaluate the thermal and adhesive performance of these coatings. The search for more candidate radiator emissivity coatings will continue.

b. Titanium-Potassium Compatibility. In order to determine the compatibility of Grade 2 pure titanium with potassium in a heat pipe, experiments are underway in which gravity assisted, titanium-potassium heat pipes are being operated for an extended period. The first experiment, which consists of a 5l-mm-diam, smooth-bore (wickless) titanium heat pipe mounted vertically inside a vacuum chamber, has been operating at 775 $K$ for over $100 \mathrm{~h}$. The heat pipe is fitted with a 5l-mm-long calorimeter near the top that is continuously extracting $195 \mathrm{~W}$, which means the radial output heat flux is $61 \mathrm{~W} / \mathrm{m}^{2}$. Resistance heaters imbedded in a copper block that is clamped to the 


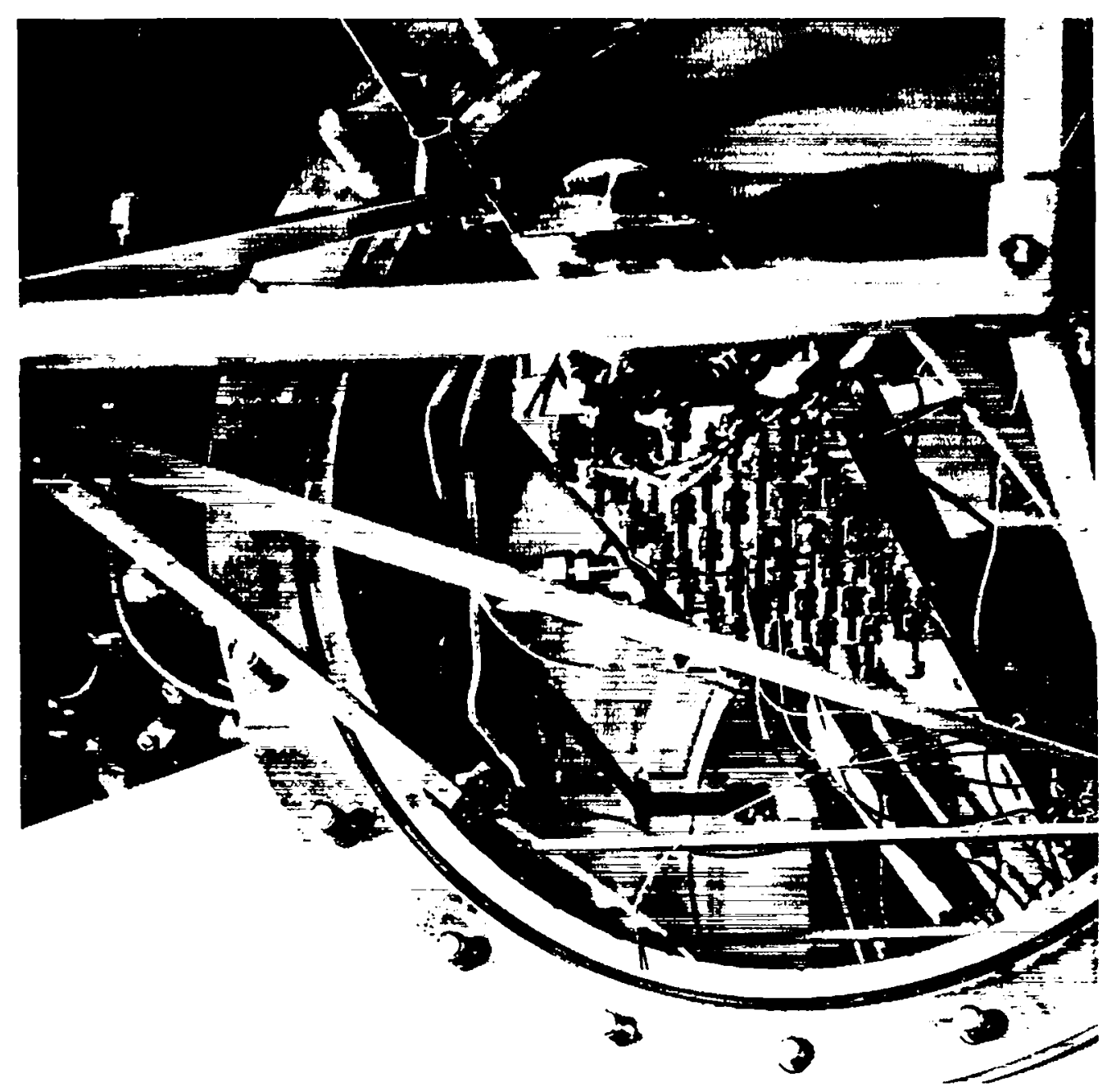

Fig. 34. RAD-2 and heater in the vacuum chamber ready for testing.
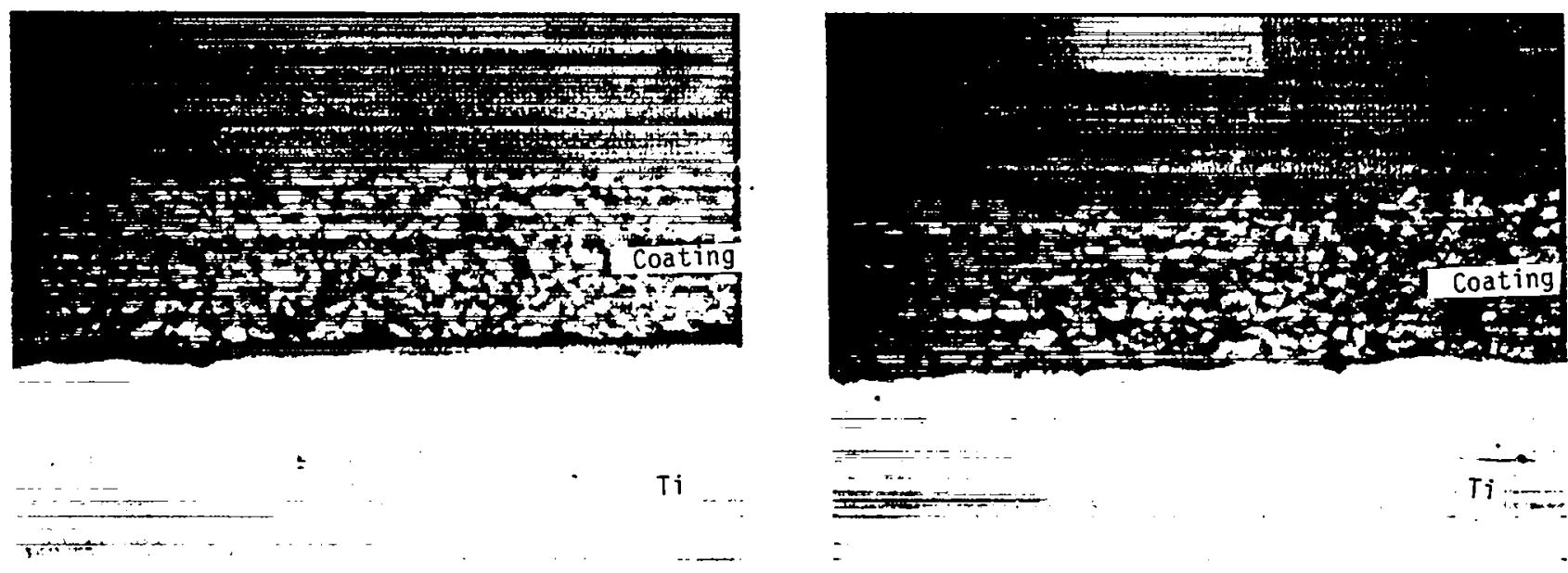


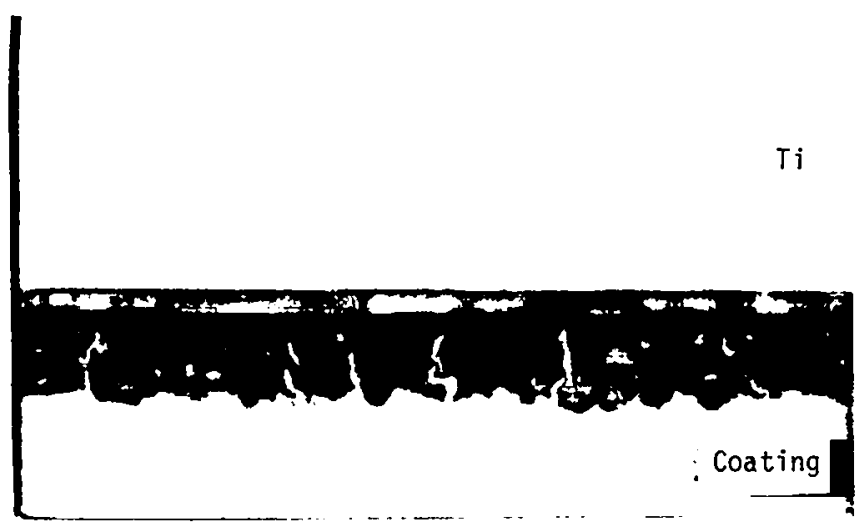

(a)

$40 \mu \mathrm{m}$

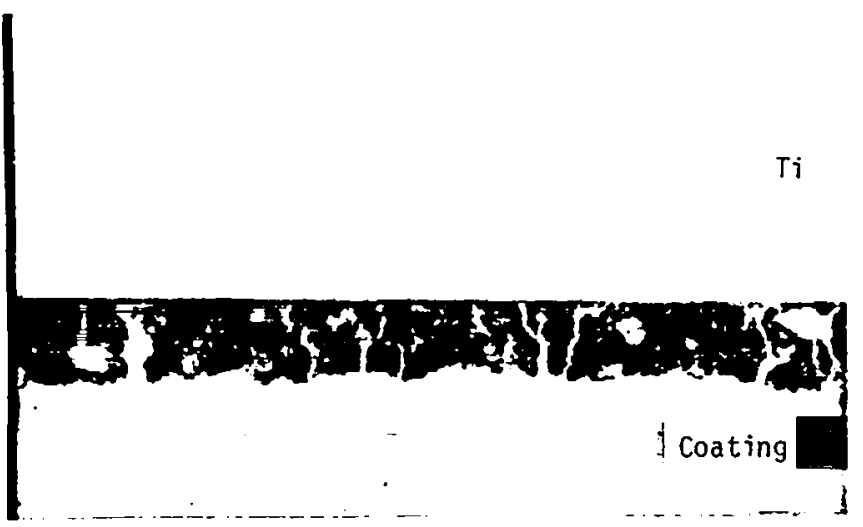

(b)

Fig. 36. D-111 emissivity coating on pure titanium (a) as-received and (b) after one cycle to $775 \mathrm{~K}$.

heat pipe supply heat at about $16 \mathrm{~W} / \mathrm{m}^{2}$ radial flux. The entire assembly is being maintained under a vacuum of $10^{-4} \mathrm{~Pa}$ or better. Both temperature and power output of the heat pipe are being continuously monitored. This experiment is expected to operate for about six weeks before being removed for inspection.

A second experiment is being assembled in which some screen will be placed inside the heat pipe primarily to eliminate $l i q u i d$ super heat and and the resultant liquid slugging problem in the first experiment. Efforts will also be made to achieve both higher operating temperatures and ligher heat fluxes so as to accelerate corrosion.

c. Beryllium-Nickel Interaction. The beryllium-nickel interaction data was reexamined
Ind put into a poster presentation for the 1980 TMS-AIME Annual Meeting in Las Vegas, NV, February 24-28. The presentation was entitled "Berylliumlickel Solid State Reaction" by L. B. Lundberg, W. $\therefore$ Zelezny and N. E. Elliott, and a brief summary :ollows.

The solid-state interdiffusion reaction be:ween beryllium and nickel was studied experiment$111 y$ in order to establish the kinetics and interlediate phases formed. Nickel-clad beryllium rires were heated inside evacuated quartz tubes :rom 7 to $2878 \mathrm{~h}$ at constant temperatures ranging from 675 to $975 \mathrm{~K}$. Reactions were observed and neasured on metallographic cross sections after heating. Distinct layers of both beryllium-nickel intermetallic compounds, $\mathrm{Be}_{2} \mathrm{Ni}_{5}$ and BeNi, were identified with an electron microprobe, and the thicknesses of these layers were established from measurements of both optical and backscattered electron micrographs.

The layer growth data for the total layer and the individual compound layers were fitted to the parabolic rate law for cylindrical geometry, $\mathrm{B}^{2} \rho / 4=k t$. Total layer growth rate constants from this work and others ${ }^{7,8}$ were fitted to the Arrehnius temperature relation, and the best fit was obtained when a change in the slope of the $\log \mathrm{k}$ vs $T / T$ plot at $845 \mathrm{~K}$ was assumed (see Fig. 37). Similar breaks in the Arrehnius plots were observed for both $\mathrm{Be}_{27} \mathrm{Ni}_{5}$ and BeNi layer growth (see Figs. 38 and 39). This indicated "change of mechanism" appears to be related to a broadening of the composition range of $\mathrm{Be}_{21} \mathrm{Ni}_{5}$ observed in the lower temperature regime. The $\mathrm{Be}_{21} \mathrm{Ni}_{5}$ grows much more rapidly than the BeNi layer at all temperatures. Discrepancies between the Handbook values and the electron microprobe measured compositions of the solid solution of $\mathrm{Be}$ in $\mathrm{Ni}, \mathrm{Be}_{21} \mathrm{Ni}_{5}$ and $\mathrm{BeNi}$ phases suggests a need for a reinvestigation of the $\mathrm{Be}-\mathrm{Ni}$ equilibrium diagram.

d. Meteoroid Impact Studies (S. J. Bless, UDRI; L. B. Lundberg. and S. P. Girrens, (Q-13). During the past quarter debugging of the gas gun range was completed at the University of Dayton Research Institute (UDRI) and data for hypervelocity cratering of titanium were obtained. 


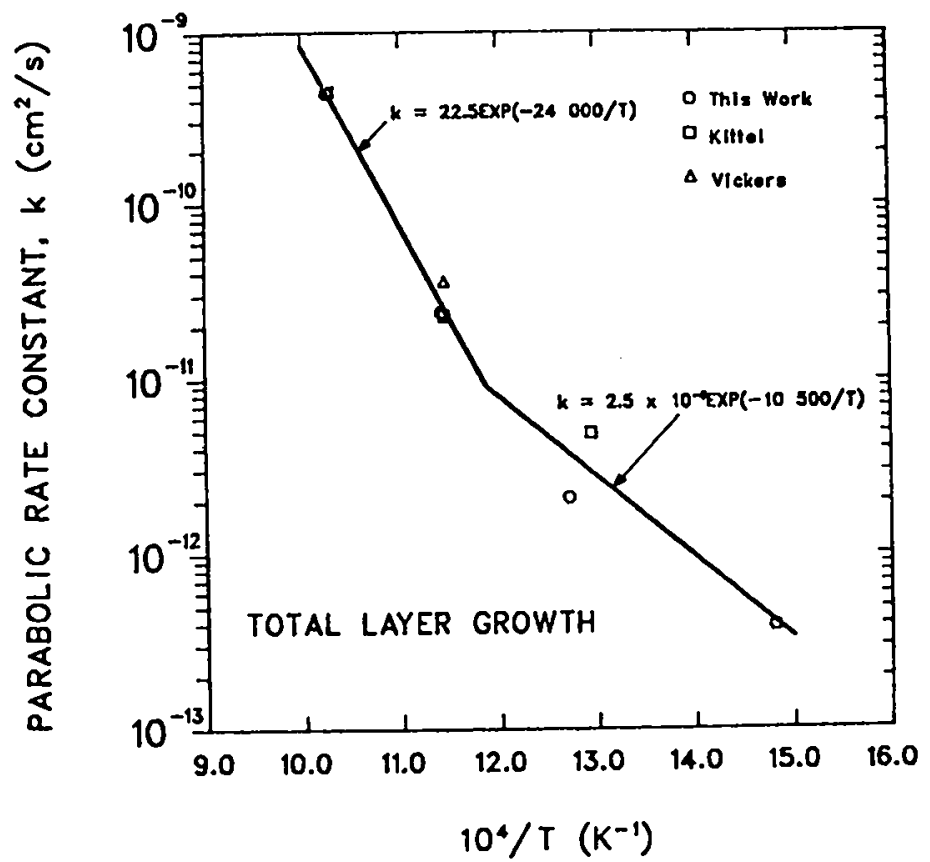

Fig. 37. Arrehnius plot of total layer growth.

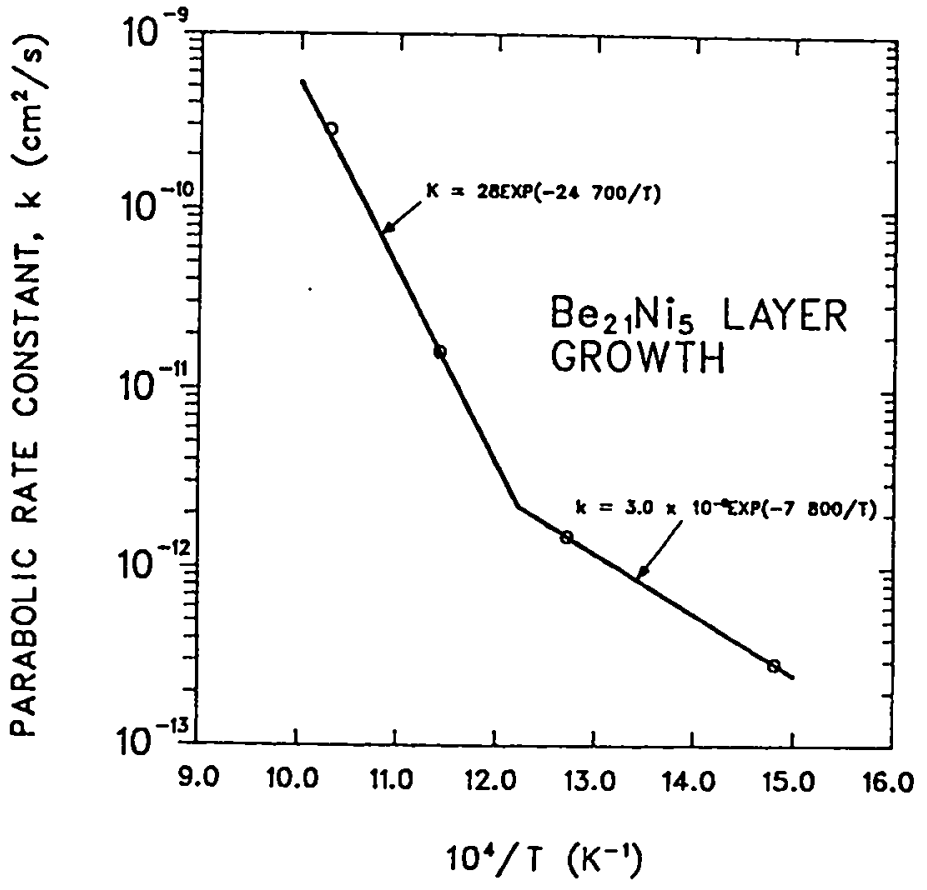

Fig. 38. Arrehnius plot of $\mathrm{Be}_{21} \mathrm{Ni}_{5}$ layer growth. 


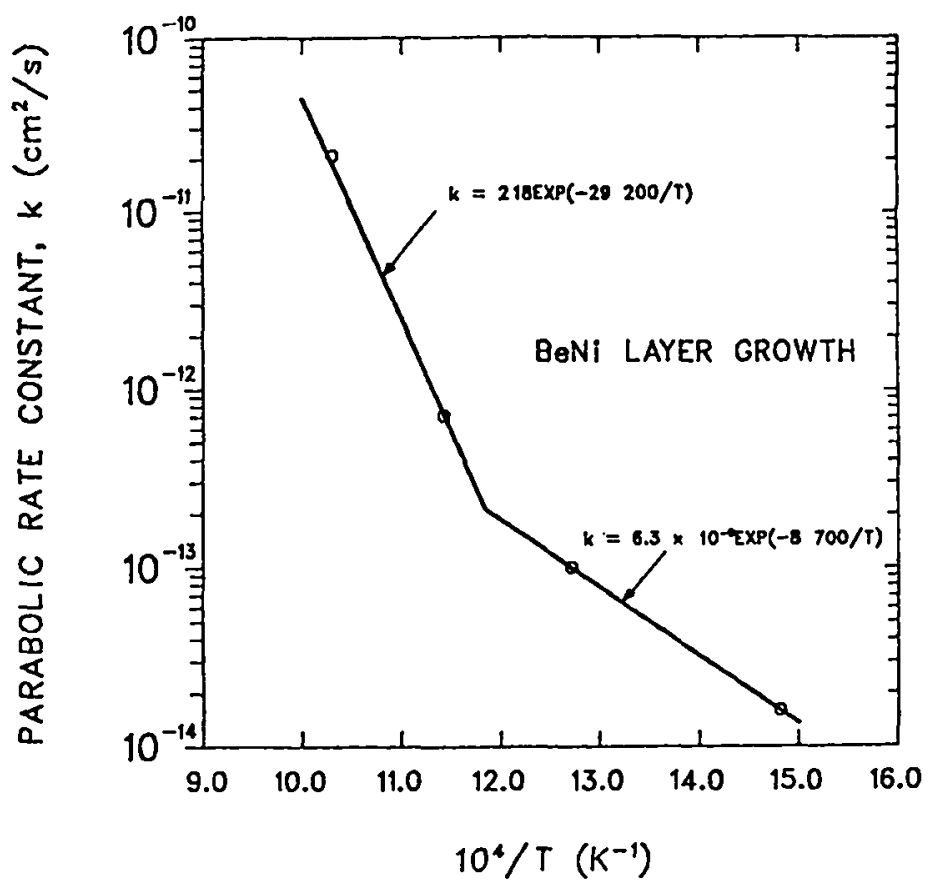

Fig. 39. Arrehnius plot of BeNi layer growth.

1. Technique Development. The shots carried out for this program are listed in Table XII. Several valuable experimental techniques evolved during the test program.

The first few shots were devoted to refining the burst diaphram, so that pieces of it were not launched downrange. A grooved stainless stee? design proved satisfactory.

Measurement of projectile velocity was initially very troublesome. Radiographic confirmation of projectile position at the time the last stations were triggered was very difficult to obtain. Experimentation with different delay times between laser trigger and $x$-ray function did not help. Apparently the laser stations were vulnerable to pretrigger from gas or blow-by debris. No contacting technique could be used to determine projectile position without damaging the sabot. During a sequence of shots several techniques were evolved to more reliably measure projectile velocity. First, the foil switch at the sabot plate was replaced with a contact switch closed by the shock wave induced in the sabot $\dot{p}$ late by sabot impact. The contact switch consisted of a steel pin tightened against a thin sheet of mylar. The switch was connected to a passive pulser unit.
Shock break-out ruptured the mylar and established electrical contact between the pin and sabot plate. Redundant velocity data was obtained with the Beckman and Whitley 300 camera (B \& W 300). This camera takes 48 pictures and rates up to $4.5 \times$ $10^{6}$ fps; it was normally used at 1.2 to $2 x$ $10^{6} \mathrm{fps}$. It was first employed in shot No. 75; we were very anxious to check that the velocity measurements previously obtained were not widely wrong. Since the small beads $(\sim 1 \mathrm{~mm})$ were not visible to the camera due to motion blur, only half a sabot plate (SP) was used. The other half of the sabot traversed the $B \& W 300$ field of view, permitting measurement of velocity by tracking the sabot fragments. Figure 40 illustrates the SP arrangement for one of those shots. It was found that the velocity was a little lower than had been inferred from the previous data.

Beginning with shot No. 76, the signal from the SP was used to stop a digital oscilloscope that recorded the two photo-multiplier (PM) tube signals. In shots No. 76 through 85 , the first PM tube recorded the muzzle flash. In most shots the arrival of the projectile at the laser station could clearly be identified. Figure 41 shows a typical example. The muzzle flash record was 
TABLE XII

RANGE OPERATION DATA

\begin{tabular}{|c|c|c|c|c|c|c|c|c|c|c|c|c|c|c|}
\hline $\begin{array}{c}\text { Shot } \\
\text { Number }\end{array}$ & Date & №. & $\begin{array}{c}\text { roject } \\
d \\
\text { mir } \\
\end{array}$ & Matl. & $\begin{array}{r}\mathrm{u} \\
\mathrm{km} / \mathrm{s} \\
\end{array}$ & $\underline{\text { basis }}$ & $\begin{array}{r}\mathrm{Ti} \\
\mathrm{T} \\
\mathrm{mm} \\
\end{array}$ & $\begin{array}{l}\text { vac } \\
\mathrm{mm}\end{array}$ & $\underline{W}$ & $\begin{array}{c}\text { Gun } \\
\mathrm{P}_{\mathrm{H}} \\
\end{array}$ & $\begin{array}{l}\text { Dia- } \\
\text { phram }\end{array}$ & Pist & Purpose & Results \\
\hline $\begin{array}{l}64 \\
65 \\
66 \\
67\end{array}$ & $\begin{array}{l}8 / 26 \\
9 / 16 \\
9 / 21 \\
9 / 24\end{array}$ & $\begin{array}{r}12 \\
16 \\
6 \\
--\end{array}$ & $\begin{array}{l}\text { Asst } \\
\text { Asst } \\
0.5 \\
---\end{array}$ & $\begin{array}{c}\mathbf{G} \\
\mathbf{G} \\
\mathbf{G} \\
\text { None }\end{array}$ & $\begin{array}{l}--- \\
6.96 \\
6.25 \\
---\end{array}$ & $\begin{array}{c}\text { none } \\
F 1, F 2, C \\
F 1, F 2, C \\
\text { none }\end{array}$ & $\begin{array}{l}--- \\
--- \\
--- \\
---\end{array}$ & $\begin{array}{r}10 \\
0.5 \\
7 \\
15\end{array}$ & $\begin{array}{l}175 \\
175 \\
150 \\
175\end{array}$ & $\begin{array}{l}375 \\
375 \\
280 \\
\text { NR }\end{array}$ & $\begin{array}{r}1 \\
0.5 \\
11.7 \\
1.5 / \\
0.7\end{array}$ & $\begin{array}{l}277 \\
276 \\
276 \\
276\end{array}$ & $\begin{array}{l}\text { Test proj. } \\
\text { Test proj. } \\
\text { Test proj. } \\
\text { Diag.test }\end{array}$ & $\begin{array}{l}\text { Sabot opened } 238 \mathrm{~mm} \\
\text { Diaph. hit target } \\
\text { Diaph. hit target } \\
\text { No diaph. launch }\end{array}$ \\
\hline $\begin{array}{l}68 \\
69 \\
70\end{array}$ & $\begin{array}{l}9 / 24 \\
9 / 26 \\
9 / 27\end{array}$ & $\begin{array}{r}1 \\
16 \\
16\end{array}$ & $\begin{array}{l}3.18 \\
\text { Asst } \\
\text { Asst }\end{array}$ & $\begin{array}{r}\mathrm{Fe} \\
\mathrm{G} \\
\mathrm{G}\end{array}$ & $\overline{---}$ & $\begin{array}{l}m f \\
B W \\
L 2-S P\end{array}$ & $\begin{array}{l}-\cdots- \\
-\cdots \\
1.27\end{array}$ & $\begin{array}{l}15 \\
15 \\
20\end{array}$ & $\begin{array}{l}175 \\
175 \\
175\end{array}$ & $\begin{array}{l}200 \\
200 \\
200\end{array}$ & $\begin{array}{l}1 / 0.7 \\
0.35 \\
1.21 \\
0.4\end{array}$ & $\begin{array}{l}--- \\
276 \\
276\end{array}$ & $\begin{array}{l}\text { Vel. test } \\
\text { Vel. test } \\
\text { Data }\end{array}$ & $\begin{array}{l}\text { No sabot separ. } \\
\text { No sabot separ. } \\
\text { Mult.impact-NG }\end{array}$ \\
\hline 71 & $9 / 28$ & 8 & 0.5 & G & 5.5 & L2-SP & 1.27 & 15 & 175 & 200 & $\begin{array}{l}1.21 \\
0.35\end{array}$ & 276 & Data & $M u 1 t$. impact-NG ${ }^{2}$ \\
\hline 72 & $10 / 3$ & 8 & 0.5 & G & -- & $m f$ & 1.27 & 15 & 175 & 200 & $\begin{array}{l}1.21 \\
0.35\end{array}$ & 276 & Data & Sabot hit target \\
\hline 73 & $10 / 9$ & 8 & 0.5 & G & 6.3 & L2-SP & 1.27 & 15 & 175 & 275 & $\begin{array}{l}1.21 \\
0.35\end{array}$ & 230 & Data & Beads bunched \\
\hline 74 & $10 / 11$ & 17 & Asst & G & 6.0 & L2-SP & 1.27 & 15 & 175 & 275 & $\begin{array}{l}1.21 \\
0.35\end{array}$ & 230 & Data & $\begin{array}{l}\text { No impact on } \\
\text { target }\end{array}$ \\
\hline 75 & $10 / 17$ & 9 & Asst & G & 5.13 & $\begin{array}{l}\text { L2-SP, } \\
\text { BW }\end{array}$ & 1.27 & 15 & 175 & 275 & $\begin{array}{l}1.21 \\
0.19\end{array}$ & 230 & Data & Beads bunched \\
\hline 76 & $10 / 22$ & 1 & 0.5 & G & $\begin{array}{l}5.09 \\
\pm \\
0.07\end{array}$ & $\begin{array}{l}M, L .2 \rightarrow \\
S P\end{array}$ & 1.27 & 15 & 175 & 275 & 1.21 & 276 & Data & Crater w. bulge \\
\hline 77 & $10 / 29$ & 1 & 0.5 & G & $>5.2$ & $M \rightarrow S P$ & 2.59 & 15 & 200 & 275 & $\begin{array}{l}1.21 \\
0.35\end{array}$ & 230 & $45^{\circ}$ obt. & $\begin{array}{l}\text { No impact on } \\
\text { target }\end{array}$ \\
\hline 78 & $10 / 29$ & 1 & 0.5 & G & $>5.7$ & $M \rightarrow S P$ & 25.4 & 15 & 175 & 275 & $\begin{array}{l}1.21 \\
0.35\end{array}$ & 230 & Data & Good crater \\
\hline 79 & $11 / 5$ & 1 & 0.5 & G & 4.50 & $L 2+S P$ & 25.4 & 20 & 180 & 325 & $\begin{array}{l}1.21 \\
0.35\end{array}$ & 270 & Data & Good crater \\
\hline 80 & $11 / 7$ & 1 & 0.5 & G & $>4.91$ & $M \rightarrow S P$ & --- & 20 & 225 & 400 & $\begin{array}{r}1.21 \\
0.5\end{array}$ & 490 & $\begin{array}{l}\text { Test Pb } \\
\text { plate }\end{array}$ & $\begin{array}{l}\text { Piston failed on } \\
\text { launch } 5\end{array}$ \\
\hline 81 & $11 / 12$ & 0 & --- & -- & $-m$ & $m f$ & $\cdots$ & 15 & 175 & 275 & $\begin{array}{r}1.21 \\
0.8\end{array}$ & 276 & $\begin{array}{l}\text { Test new } \\
\text { seal }\end{array}$ & New seal worked \\
\hline 82 & $11 / 13$ & 1 & 0.5 & G & $\begin{array}{l}5.80 \\
\pm \\
0.01\end{array}$ & $\mathrm{BW}$ & 7.44 & 10 & 175 & 275 & $\begin{array}{r}1.21 \\
0.8\end{array}$ & 230 & Data & Good crater \\
\hline 83 & $11 / 15$ & 1 & 1.0 & G & --- & $\mathfrak{m f}$ & 9.34 & 10 & 200 & 325 & $\begin{array}{l}1.21 \\
0.08\end{array}$ & 276 & Data & $\begin{array}{l}\text { Sabot broke on } \\
\text { launch }\end{array}$ \\
\hline 84 & $11 / 27$ & 1 & 1.0 & G & $>4.67$ & $L 2 \rightarrow S P$ & 7.49 & 10 & 175 & 275 & $\begin{array}{l}1.21 \\
0.08\end{array}$ & 276 & Data & Good crater \\
\hline 85 & $11 / 28$ & 1 & 1.0 & G & 6.58 & $L 2 \rightarrow S P$ & 9.30 & 10 & 175 & 275 & $\begin{array}{l}1.21 \\
0.08\end{array}$ & 276 & Data & $\begin{array}{c}\text { No impact on } \\
\text { target }\end{array}$ \\
\hline 86 & $11 / 30$ & 1 & 1.0 & G & 6.59 & $L] \rightarrow S P$ & 9.30 & 10 & 175 & 275 & $\begin{array}{l}1.21 \\
0.08\end{array}$ & 276 & Data & $\begin{array}{l}\text { No impact on } \\
\text { target }\end{array}$ \\
\hline 87 & $12 / 4$ & 1 & 1.0 & G & 6.66 & $\begin{array}{l}\mathrm{LI}+\mathrm{L} 2, \\
\mathrm{BW}\end{array}$ & 9.30 & 10 & 160 & 250 & $\begin{array}{l}1.21 \\
0.08\end{array}$ & 276 & Data & Good crater \\
\hline 88 & $12 / 5$ & 1 & 1.59 & $\mathrm{Cu}$ & 5.62 & $\mathrm{BW}$ & 9.30 & 10 & 140 & 220 & $\begin{array}{l}1.21 \\
0.08\end{array}$ & 276 & Data & $\begin{array}{l}\text { Good crater but } \\
\text { bulge }\end{array}$ \\
\hline 89 & $12 / 7$ & 1 & 1.59 & $\mathrm{Cu}$ & 5.81 & $\begin{array}{l}\mathrm{LT}, \mathrm{L} 2 \rightarrow \\
\mathrm{SP}, \mathrm{BW}\end{array}$ & 13.2 & 10 & 160 & 250 & $\begin{array}{l}1.21 \\
0.08\end{array}$ & 276 & Data & Good crater 8 \\
\hline 90 & $12 / 11$ & 1 & 1.0 & G & 4.43 & $\mathrm{BW}$ & 9.30 & 70 & 165 & 275 & $\begin{array}{l}1.21 \\
0.08\end{array}$ & 276 & Data & Partial crater \\
\hline 91 & $12 / 11$ & 1 & 1.0 & G & $7.40 \pm$ & $\mathrm{BW}$ & 8.13 & 20 & 175 & 275 & $\begin{array}{l}1.21 \\
0.08\end{array}$ & 275 & Data & Good crater 9 \\
\hline 92 & $12 / 14$ & 1 & 1.0 & G & 5.5 & $\mathrm{LI} \rightarrow \mathrm{SP}$ & 6.45 & 20 & 150 & 235 & $\begin{array}{l}1.21 \\
0.08\end{array}$ & 276 & Data & No bead impact ${ }^{10}$ \\
\hline 93 & $12 / 14$ & 1 & 1.0 & G & 6.73 & $L 1 \rightarrow S P$ & 8.45 & 10 & 175 & 235 & $\begin{array}{l}1.21 \\
0.08\end{array}$ & 276 & Data & $\begin{array}{c}\text { Sabot fajled in } \\
\text { barrel }\end{array}$ \\
\hline
\end{tabular}

1 Intr. petal diam and SS diaphram; 2 New barrel; 3 Split SP; 4 25P, 5; 5 Sabot cemented;

6 Intr. laser ladder; 7 X-ray picture; 8 Back plate; 9 New barrel; $10 \mathrm{Ar}$ in tank; $11 \mathrm{Ar}$ in tank.

Note: Basis--mf = malfunction, $L]+S P=$ transit time from first 1 aser to sabot plate, etc. Gun--vac = pressure in blast tank in $\mathrm{mm} \mathrm{Hg}, W=$ powder mass in $\mathrm{g}, \mathrm{P}_{H}=$ hydrogen pressure in psi, pist $=$ piston mass in $g$. 

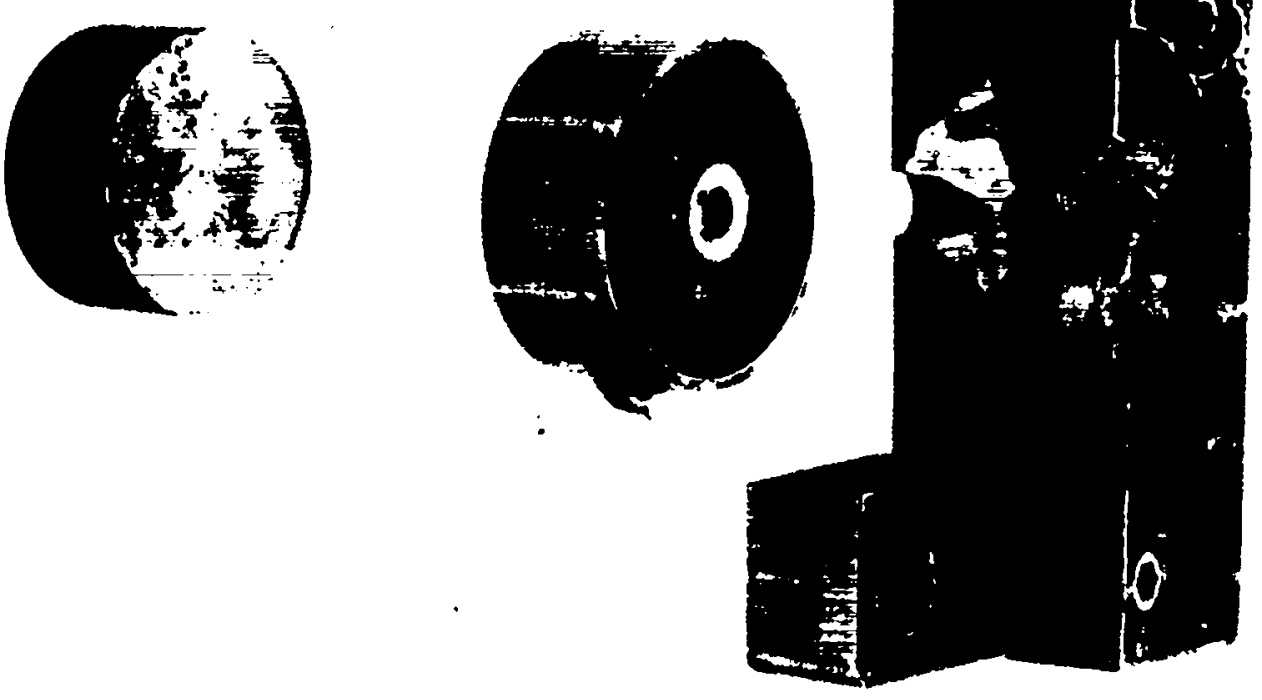

Fig. 40. Sabot plates and target from shot 78 .

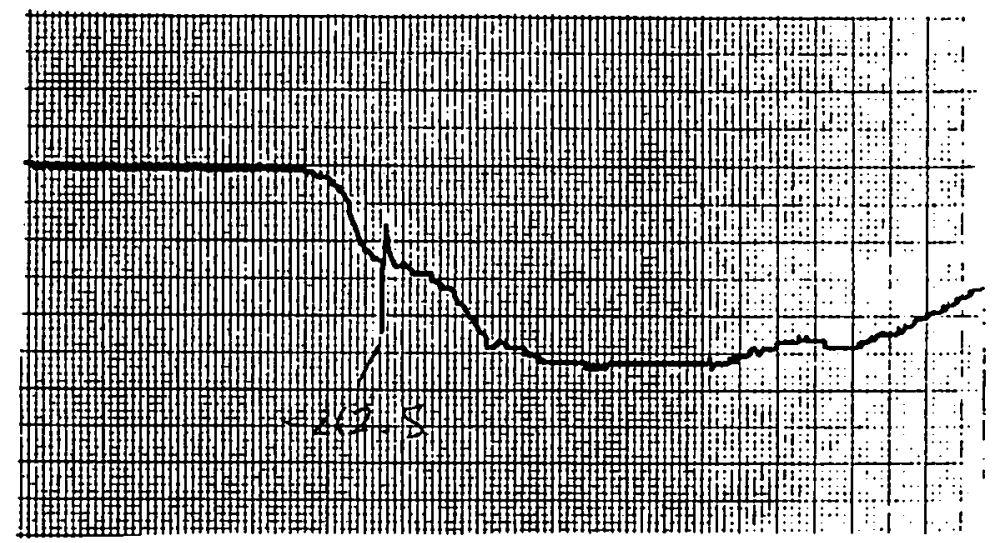

Fig, 41. Portion of oscilloscope record showing typical cut off of second laser beam by projectile and other material launched by gun. The passage of the projectile can be identified as the short downward spike. 
found to exhibit a great deal more structure than anticipated. Figure 42 shows a typical example. Unfortunately, analysis of these results showed that the occurrence of muzzle flash could not be correlated with exit of the projectile. Eventually, the first PM tube was once again used to view a laser. It was found that precaution had to be taken to avoid blinding of this tube by the muzzle flash. The record from the second laser station could not be clearly interpreted in some shots because the sabot had partially opened and did not completly block the beam. This defect was later corrected by using a three-passage laser ladder at the second station.

In later shots, the $B \& W 300$ camera was always used to view the projectile. Beads $1 \mathrm{~mm}$ in diameter and larger were visible. Thus, in most of the later shots two redundant measures of impact velocity were available. Most of the time, the camera data agreed very well with the laser cutoff data obtained with the digital oscilloscope.

By shot No. 79, it was firmly established that the gun could not reliably be fired above $6 \mathrm{~km} / \mathrm{s}$. Past experience indicated that heavier pistons were necessary to achieve velocities in excess of $6 \mathrm{~km} / \mathrm{s}$. Steel had been used, al though stee 1 pistons must be drilled out of the high pressure section after each shot. Only one high pressure section is currently on hand, so wanted to avoid that procedure. A lead-filled polyethylene piston was tried in shot 80 , but the piston failed in the pump tube. The light gas gun had traditionally leaked at the thick copper high pressure seals. In order to improve performance, the seals were redesigned. The new design utilized thin stainiess steel seals that mated to raised lands on the sealing surfaces. The new seals

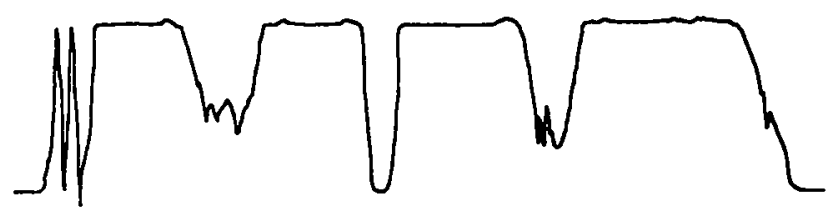

Fig. 42. Typical record of muzzle flash from light gas gun. successful in substantially improving gun performance. Velocities exceeding $7 \mathrm{~km} / \mathrm{s}$ have been achieved with polyethylene pistons; so far as we know, this is the best performance anywhere recorded with such light weight pistons. No significant damage to the high pressure section has resulted. The launch tubes, on the other hand, must be cut off at the breech end after about fifteen shots.

From time to time difficulties were encountered with sabot functioning. Radiographs revealed the surprising fact that the sabots open backward, as seen in Fig. 43. A blast tank pressure of $2.7 \mathrm{kPa}$ seemed to work best, for air, or $1.3 \mathrm{kPa}$ for argon in the tank. Glass beads of $0.5 \mathrm{~mm}$ diameter could only be launched with a success ratio of about one in four. Glass beads of 1.4-mm diameter have been launched with a success rate of one out of two. Copper projectiles could be launched everytime. Copper or $1.4 \mathrm{~mm}$ glass were used in tests that required relatively more sample preparation. Apart from its launchability, copper was aiso selected to check the density dependence of the Charters and Summers (C-S) equation, ${ }^{9}$ and because the Naval Research Laboratory is also conducting some hypervelocity tests on titanium struck by $3.2-\mathrm{mm}$ copper projectiles that may be compared to these results.

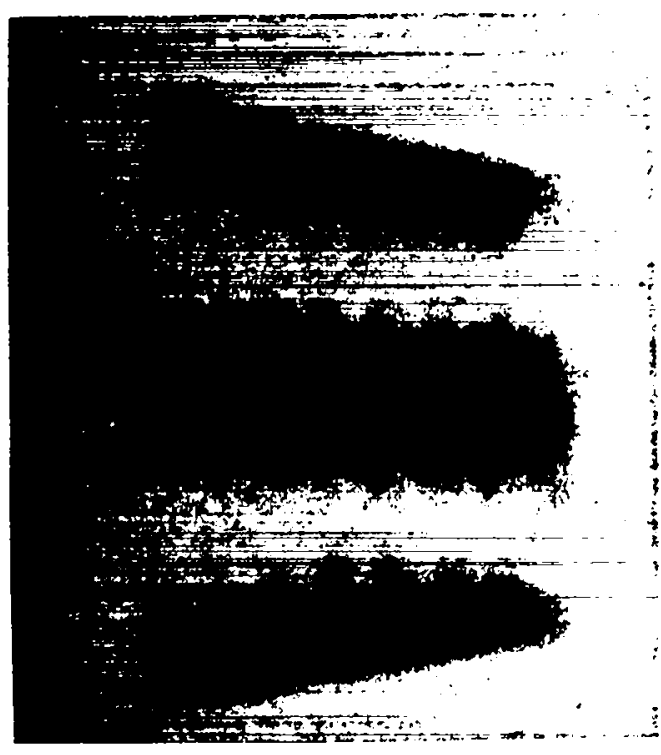

Fig. 43. Radiograph of a sabot carrying a copper projectile, from shot 88 . 
The size of the craters made by the sabot in the SP could be used to estimate impact velocity for shots in which the velocity was not directiy measured. Two different hardness steels were employed for the SP. We have only completed analysis for the softer of these, and the empirical relation between volume of the crater in the SP and launch velocity is shown in Fig. 44.

The glass projectiles used in these tests had a nominal density of $3.99 \mathrm{Mg} / \mathrm{m}^{3}$. Our measurements indicated an average density of 4.19 $\mathrm{Mg} / \mathrm{m}^{3}$ was more appropriate, and this was used in the analysis. The copper projectiles had a cone-cylinder shape, such that the volume was equal to the volume of a sphere that has the same diameter as the projectile.

As described in a previous progress report, problems were encountered in launching multiple glass beads. The beads tended to bunch together. Launch of more than one bead at a time was finally ab andoned.

The shot matrix proposed in a previous progress report is not practical with single bead launch. That matrix called for the determination of ballistic limits, and too many shots would be required. Therefore, an alternate approach was developed. In the new approach, cratering of thick titanium targets will be emphasized. The dependence of crater depth on impact parameters will be determined. Attention will be directed to two potentially useful correlations--(a) the crater volume proportionality to the projectile kinetic energy, and (b) the C-S equation

$$
\frac{p}{d}=\frac{3}{2}\left(\frac{\rho_{p}}{\rho_{t}}\right)^{1 / 3}\left(\frac{\rho_{p} U^{2}}{2 S_{t}}\right)^{1 / 3},
$$

where $p, d, \rho_{p}, \rho_{t}, U$, and $s_{t}$ are crater depth, projectile diameter, projectile density, target density, impact velocity, and strength parameter, respectively. Cratering was first studied for room temperature titanium. Then the effects of target temperature and thickness were investigated.

2. Results of Experiments. The results from the data shots are summarized in Table XIII. Except for shots 76 and 95, these were all with thick targets. Typical craters caused by glass beads and copper balls are shown in Figs. 45 and 46, respectively.

Some of the data in Table XIII are believed to be spurious. Specifically, in shot 96 the rear surface bulged out considerably, affecting crater formation. In shot 78 the crater is anomolously tiny; it was probably caused by a piece of the

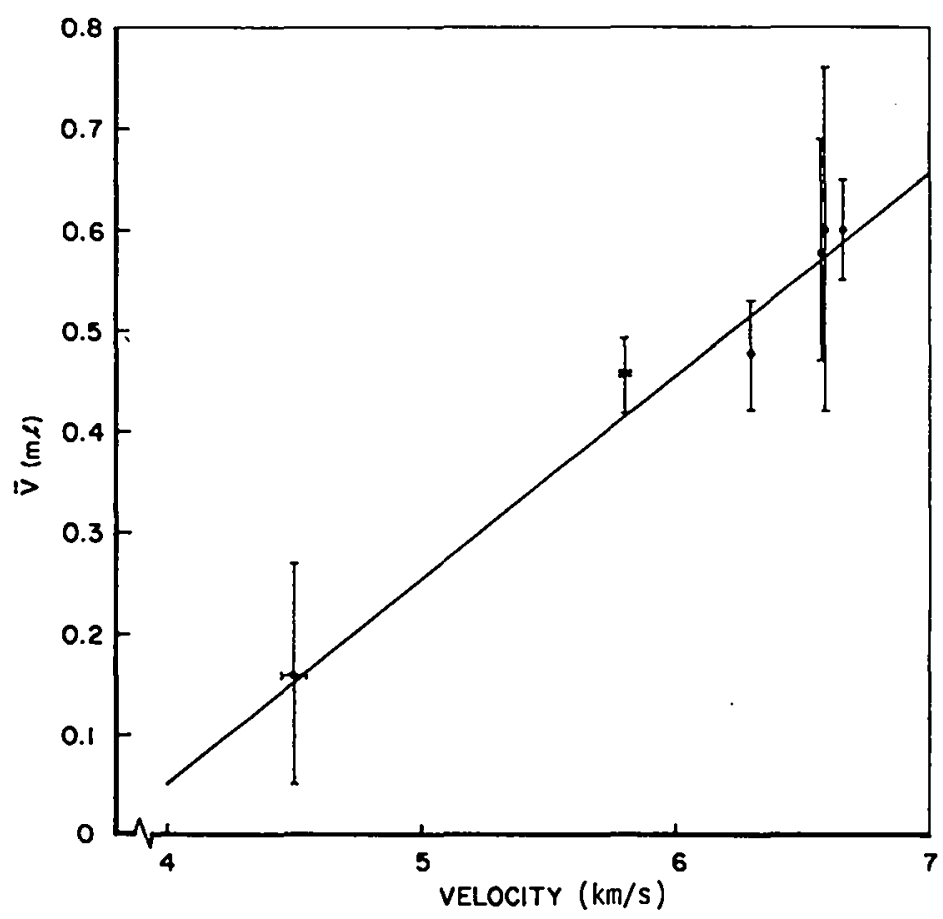

Fig. 44. Relationship between volume of the crater in the mold steel SP and the launch velocity. 


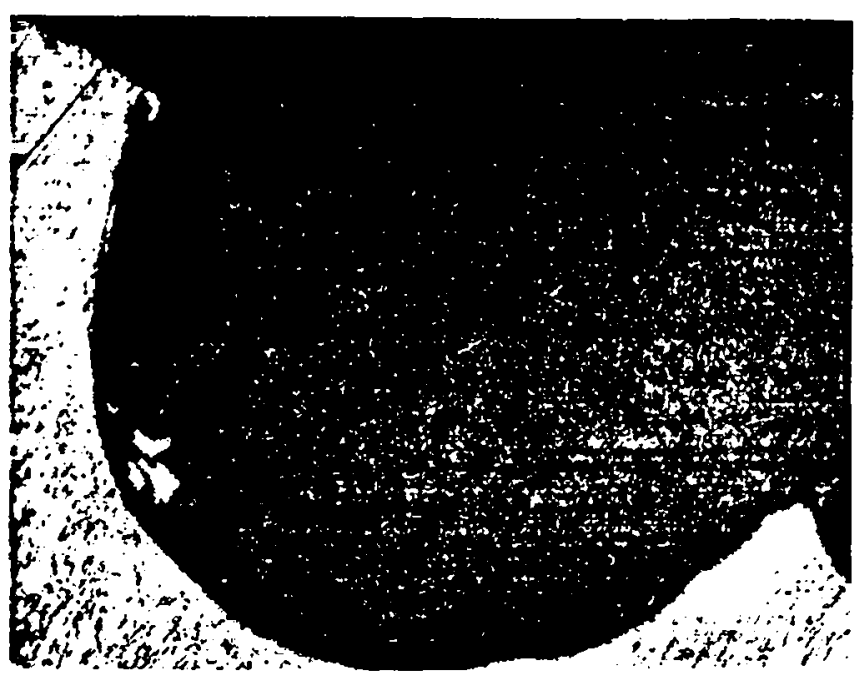

Fig. 45. Crater made by $0.5-\mathrm{mm}$ glass bead in shot 82 .

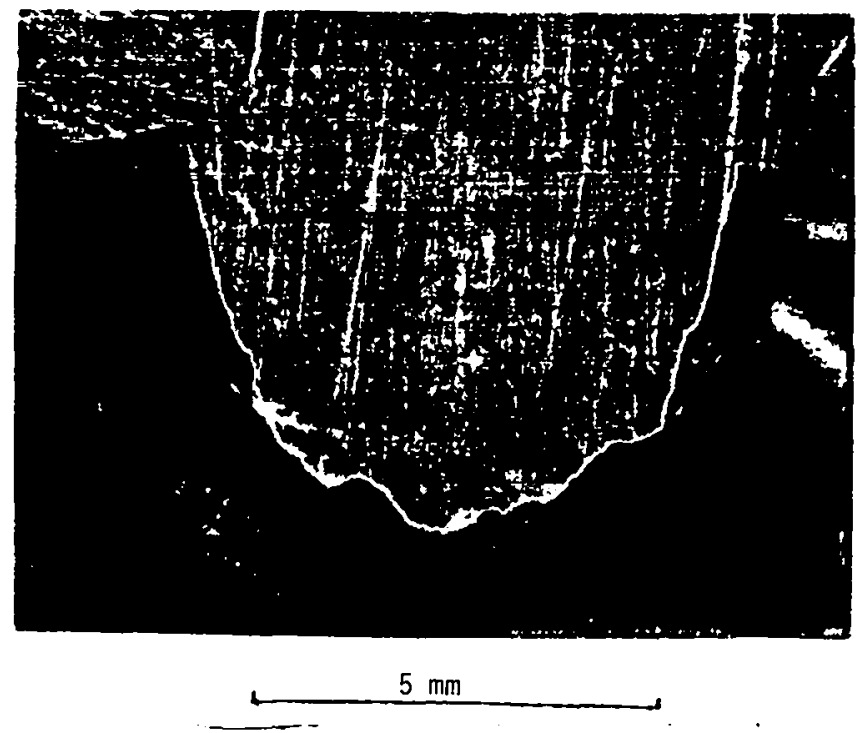

Fig. 46. Crater made by copper projectile in shot 89 .

sabot. In shot 79 , the crater was not round, and was probably caused by an angular fragment from the sabot plate. In shots 87 and 91 , the craters were shallow, as indicated by the parameter $d / 2 p$ in Table XIII. In shot 88 , a slight bulge formed in the target; although the data have been retained, the crater volume seems to have been slightly reduced by this effect. (Bulges were eliminated in later shots by the use of backing plates.) An EDAX microprobe was used to search many of these craters for stee 1 sabot plate fragments. However, no indication of any residual projectile material could be found in any of the craters examined.

The data for crater volume that we feel to be useful for analysis are listed in Table XIV. The numerical data given for shots 94-96 are preliminary. The limited analysis carried out to date has shown the following.

- The criteria that crater volume is simply proportional to projectile kinetic energy is rather good. The constant of proportionality (excluding shot 96 ) is $4.16 \pm$ $0.85 \mathrm{GJ} / \mathrm{m}^{3}$.

- The C-S equation also fits quite well. The value of $S_{t}$ (excluding shot 96 , the most recent shot) is $4.79 \pm 0.74 \times 10^{12}$ $\mathrm{g} / \mathrm{m}-\mathrm{s}^{2}$. $\mathrm{s}_{\mathrm{t}}$ for copper and glass differ by $22 \%$, which indicates that the density dependence in the formula is not quite correct.

If we include shot 96 , we get an average and standard deviation for $S_{t}$ of $6.19 \pm$ $3.76 \times 10^{12} \mathrm{~g} / \mathrm{m}-\mathrm{s}^{2}$. Before we accept this, we want to more carefully analyze the record from shot 96 for possible errors. If the data survive reanalysis, then suspicion would be cast as the velocity dependence of the $C-S$ equation.

- A volume version of the $C-S$ equation, in which $12 \mathrm{~V} / \pi$ is substituted for $\mathrm{p}^{3}$, does not fit as well. The value of the material constant of this form S' $t$ ', (excluding shot 96) is $9.07 \pm 2.4 \times$ io ${ }^{12} \mathrm{~g} / \mathrm{m}-\mathrm{s}^{2}$, and the values of $\mathrm{s}^{1} t$ for glass and copper projectiles differ by $42 \%$.

Shot 95 was conducted to test the hypothesis that the protection thickness was 1.5 times the crater depth in a thick target. This was found to be very nearly correct--the target was not perforated, but a spall plate was ejected at 0.21 $\mathrm{km} / \mathrm{s}$. Figure 47 shows part of the camera sequence from this shot.

3. Planned Work. Only a small number of shots are planned for the next quarter because the range must be used for a different program. We intend to carry out two crater volume shots at 775 $K$ with 1.4-mm-diam glass beads. We may also 
TABLE XIII

CRATER VOLUME DATA

\begin{tabular}{|c|c|c|c|c|c|c|c|c|c|c|}
\hline $\begin{array}{l}\text { Shot } \\
\text { No. }\end{array}$ & $\begin{array}{l}\text { Diam } \\
\text { (mm) }\end{array}$ & $\begin{array}{c}\text { Projectile } \\
U \\
(\mathrm{~km} / \mathrm{s}) \\
\end{array}$ & $\begin{array}{c}\text { Projectile } \\
\text { Energy } \\
\text { (joules) } \\
\end{array}$ & $\underset{(\mathrm{mm})}{\mathrm{T}}$ & $\begin{array}{l}\text { Target } \\
\text { Temp } \\
\text { (K) } \\
\end{array}$ & $\stackrel{d}{(m m)}$ & $\stackrel{p}{\stackrel{p}{(m m)})}$ & $\left(\mathrm{mm}^{3}\right)$ & $d / 2 p$ & Remarks \\
\hline 76 & 0.5 & $5.04 \pm 0.7$ & 3.48 & 1.27 & $a m b$ & 3.07 & 1.09 & 3.85 & .81 & $\begin{array}{l}\text { Target } \\
\text { bulged }\end{array}$ \\
\hline 78 & 0.5 & $>5.4$ & & 25.4 & $a m b$ & $1.05 \pm .05$ & $M$ & NM & & \\
\hline 79 & 0.5 & $4.50 \pm .05$ & 2.22 & 25.4 & $a m b$ & $3.00 \pm .16$ & & 2.57 .12 & & $\begin{array}{l}\text { Crater not } \\
\text { round }\end{array}$ \\
\hline 82 & 0.5 & $5.80 \pm .01$ & 4.60 & 7.44 & $a m b$ & $1.75 \div .02$ & $0.80 \pm .04$ & $1.13 \pm .05$ & 1.09 & \\
\hline 84 & 1.0 & 6.43 & 45.3 & 7.49 & $a m b$ & $3.70 \pm .08$ & $1.70 \pm .03$ & $11.92 \pm .09$ & 1.09 & \\
\hline 87 & 1.0 & 6.66 & 48.6 & 9.30 & $a m b$ & $2.50 \pm .15$ & $0.69 \pm .03$ & $1.97 \pm .06$ & 1.81 & \\
\hline 88 & 1.59 & 5.62 & 334.2 & 9.30 & $a m b$ & $6.56 \pm .26$ & $4.72 \pm .18$ & $85.1 \pm 3$ & .69 & $\begin{array}{l}\text { Crater damaged } \\
\text { target bulged }\end{array}$ \\
\hline 89 & 1.59 & 5.81 & 351.7 & 13.2 & $a m b$ & $7.19 \pm .25$ & $4.54 \pm .18$ & $95.3 \pm 1.2$ & .79 & \\
\hline 90 & 1.0 & 4.43 & 21.5 & 9.30 & $a m b$ & $2.36 \pm .13$ & $1.36 \pm .04$ & $3.66 \pm .08$ & .87 & Crater damaged \\
\hline 91 & 1.0 & $7.40 \pm .20$ & 60.0 & 8.13 & amb & $3.58 \pm .13$ & $.91 \pm .03$ & $5.49 \pm .10$ & 1.97 & \\
\hline 94 & 1.59 & 5.64 & 336.5 & 13.5 & 475 & $7.02 \div .15$ & $4.66 \pm .17$ & $93.7 \pm .7$ & & \\
\hline 95 & 1.0 & 6.13 & 41.1 & 2.78 & $a m b$ & & & & & Spall \\
\hline 96 & 1.40 & 7.30 & 160 & 14.5 & amb & $4.92 \pm .09$ & $1.87 \pm .08$ & $22.3 \div .8$ & 1.32 & \\
\hline
\end{tabular}

TABLE XIV

CALCULATIONS OF CRATER PARAMETERS

\begin{tabular}{lccccc} 
& $\begin{array}{c}\text { Shot } \\
\text { No. }\end{array}$ & $\begin{array}{c}E \\
\mathrm{GJ} / \mathrm{m}^{3}\end{array}$ & $\begin{array}{c}\mathrm{S}_{\mathrm{t}} \\
g / \mathrm{m}^{2} \mathrm{~S}^{2}\end{array}$ & $\begin{array}{c}\mathrm{S}_{\mathrm{t}^{\prime}} \\
\mathrm{g} / \mathrm{m}-\mathrm{s}^{2}\end{array}$ \\
\cline { 2 - 4 } & & & & \\
$0.5 \mathrm{~mm}$ glass bead projectile & 82 & 4.07 & $5.36 \times 10^{12}$ & $6.36 \times 10^{12}$ \\
$1.0-\mathrm{mm}$ glass bead projectile & 84 & 3.80 & $5.49 \times 10^{12}$ & $5.93 \times 10^{12}$ \\
& 90 & 5.87 & $5.09 \times 10^{12}$ & $9.16 \times 10^{12}$ \\
$1.4-\mathrm{mm}$ glass bead projectile & 96 & 7.18 & $14.60 \times 10^{12}$ & $11.20 \times 10^{12}$ \\
$1.59-\mathrm{mm}$ copper projectiles & 88 & 3.93 & $3.55 \times 10^{12}$ & $11.50 \times 10^{12}$ \\
& 89 & 3.69 & $4.27 \times 10^{12}$ & $10.97 \times 10^{12}$ \\
& 99 & 3.59 & $5.00 \times 10^{12}$ & $10.52 \times 10^{12}$
\end{tabular}

repeat shot 96 . We will also continue analysis of the data on hand, taking into account: (a) the exact values of $d$ and $\rho$ for each shot, instead of average values; (b) the effect of measurement uncertainties on $S_{t}$; and (c) the velocity, mass, and density scaling actually implied by the data. H. U0 Fuel Fabrication (K. Davidson, R. Riley, H. Sheinberg, CMB-6)

A cost estimate for the fabrication of uranium dioxide fuel and assembly with molybdenum cooling fins has been prepared. This estimate assumes that the core vessel, with heat pipes, is assembled prior to core assembly and is not included in this cost. Actual core design is still being studied; however, a reference design has been used for discussion. The reference design used for this estimate assumes a core inventory of $100 \mathrm{kgs}$ of uranium dioxide in the form of a 2-mm-thick tile to fill the space around a heat pipe as shown in Fig. 48. This concept would require varying numbers of 16 different segment shapes to make up the 126 pieces required for one layer in the core cross section and 115 layers for a full core. A total of 14,490 tiles would be required for the core plus $5 \%$ spares and $25 \%$ rejects. The reject rate may seem high; however, when one considers the number of shapes, the number of processing steps, the required quality of the final part and the steps in assembly, a $25 \%$ reject rate may be optimistic.

Approximately two years will be required to complete the process development and manufacture 


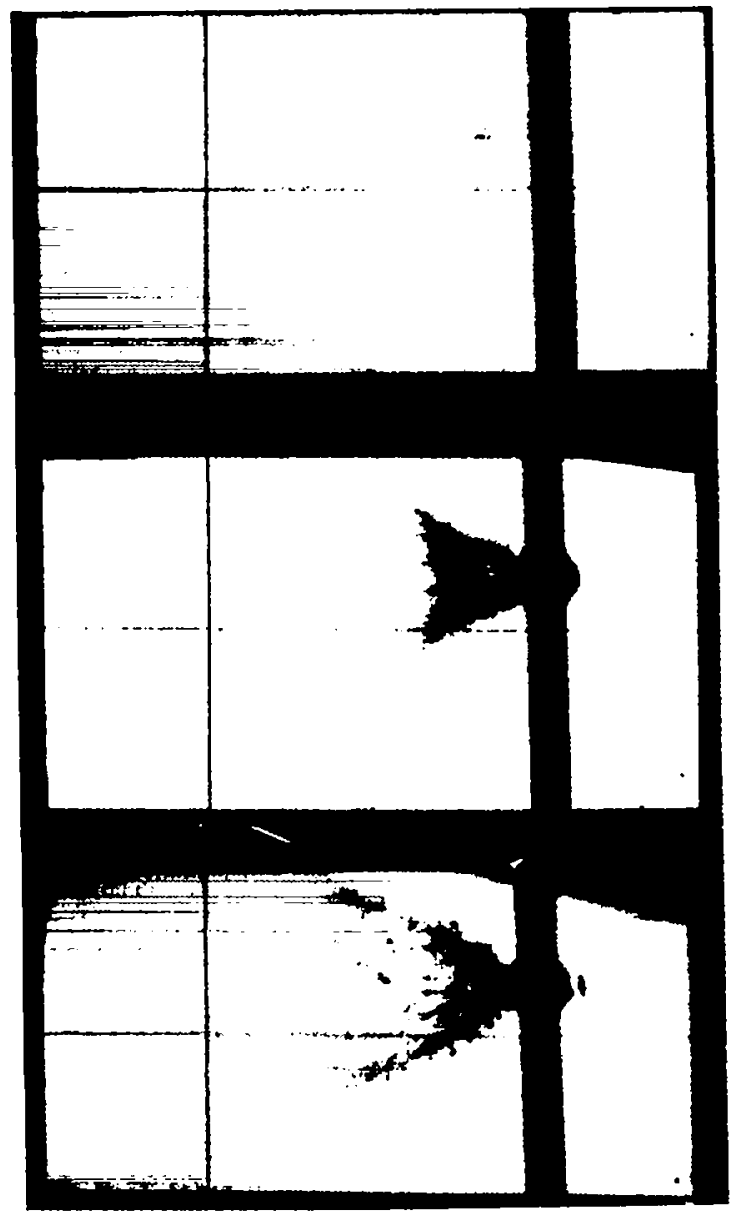

Fig. 47. Three frames selected from B\&W 300 record from shot 95, showing projectile prior to impact, bulge in rear target surface, and ejection of spall plate.

of the uranium dioxide tiles for this core. Process development includes uranium dioxide powder characterization, blending procedure and preparation of a powder suitable for automatic pressing, and determination shrinkage of the pressed part after firing to optimize die design and minimize final machining of the part.

Careful control of uranium dioxide powder characterization to provide uniform shrinkage on the finished part should hold the external geometry to $\pm 0.08 \mathrm{~mm}$; therefore, on ly the thickness of the tile would need to be ground. A thickness tolerance of $\pm 0.05 \mathrm{~mm}$ would be required to ensure a fit during assembly of the fuel tiles with the molybdenum foils. Inspection of the external tile geometry would be performed with a shadowgraph and

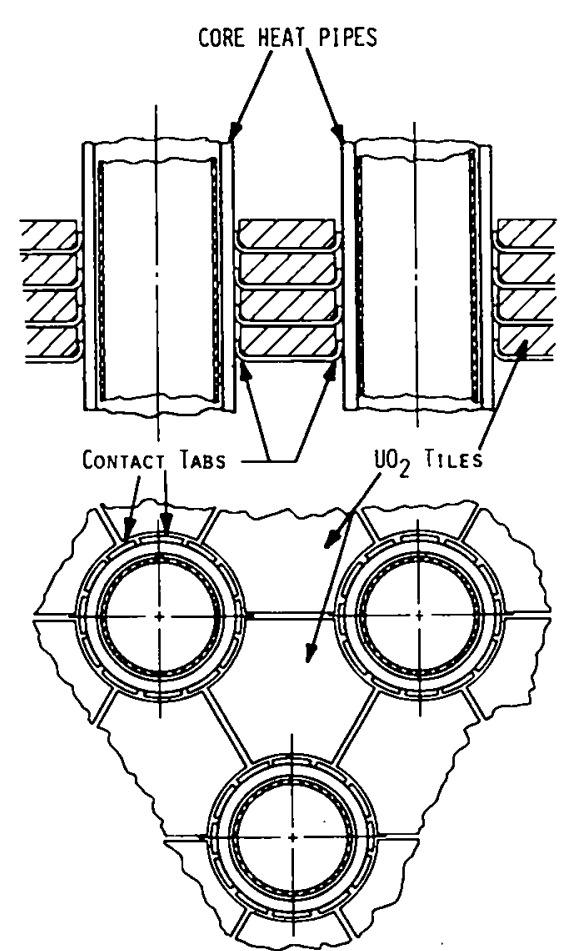

Fig. 48. Sketch of reactor core with $\mathrm{UO}_{2}$ tiles.

template, and thickness would be determined with a sweep gauge and spot checks of the tiles would be done with a micrometer. The density for a part of a nominal geometry would be determined and a minimum weight would be established and this would establish a "go no go" for a part of acceptable dimensions.

Chemical analysis would include spectrographic analysis and isotopic analysis of a random selection of parts to assure quality of the uranium dioxide tile material. The starting uranium dioxide powder lot would include the same analyses as well as powder particle distribution characterization.

The core assembly effort would require a mockup of a portion of the reactor to establish assembly procedures. Practice with a mockup assembly will help to design fixturing and tooling for the actual core assembiy. Working with mockups will establish safety procedures and should speed up the actual core assembly.

DOE requirements for accountability and the security and safeguards for SNM will require a full-time person to document all of the operations 
and handling of material during the manufacturing of fuel and the assembly of the reactor core.

Verification that the fuel is manufactured according to specification and that it meets all product specifications will require a full-time QA Specialist and a Project Manager will be required to coordinate all of the operations involved.

I. Facilities (K. Meier, E. Brown, Q-15)

The third core heat pipe vacuum chamber has been assembled, mounted on a stand, instrumented, and checked out. Two additional core heat pipe chambers have been fabricated and shipped by the vendor. A TE element test chamber has also been fabricated and assembiy begun.

The disposition and status of each of the five core heat pipe vacuum chambers is as follows. Three chambers are complete. One is being used for SPAR $-1 \mathrm{MO} / \mathrm{Na} 2-\mathrm{m}$ heat pipe testing. A second is currently being used for TE module tests. These two chambers $c$ an be used with heater coils or molybdenum conduction heaters. The third completed chamber is being used for 2 m-titanium radiator heat pipe tests with copper block conduction heater. Two chambers have been fabricated, but not assembled. They will be used for Mo/Na corrosion tests. These two chambers use molybdenum conduction heaters. The TE module vacuum chamber is currently being assembled. It can use a molybdenum conduction heater or an rf coil.

The radiator heat pipe vacuum chamber design has been changed so that the total chamber length is about $6 \mathrm{~m}$ and will be used to test the 5.3-m titanium heat pipe. The main section is about $1 \mathrm{~m}$ long and $36 \mathrm{~cm}$ in diameter. It is identical to the center portion of the core heat pipe vacuum chamber. The main section contains feed-thrus for electrical power, data, water, gas, vacuum pumping, and rough pumping. The copper block conduction heater is housed in the main section. The condenser of the $5.3-\mathrm{m}$ pipe is housed in a $15-\mathrm{cm}-$ diam, 5-m-long pyrex glass section. The glass allows the use of low-light TV to examine the radiator surface for small differences in temperature over the entire heat pipe surface. A portable calorimeter is placed around the glass tube to measure the power, radiated from the pipe.

The SPAR radiator heat pipes will only radiate heat from their flat sides when used in space. A system of rotatable mirrors as shown in Fig. 49 is used to simulate conditions. inside the SPAR radiator and prevent heat radiation from the curved side of the pipe. The mirrors may be rotated varying amounts so that when limit measurements are to be made the total heat pipe power can be increased by a factor of 2.5 over that at normal operating conditions. This heat pipe is designed to operate far below its limit. Changes in the heat pipe performance will not be noticeable over the duration of a one year test. It is expected that any degradation of the heat pipe can be detected by periodically testing the pipe at its limit and noting the change in limit performance.

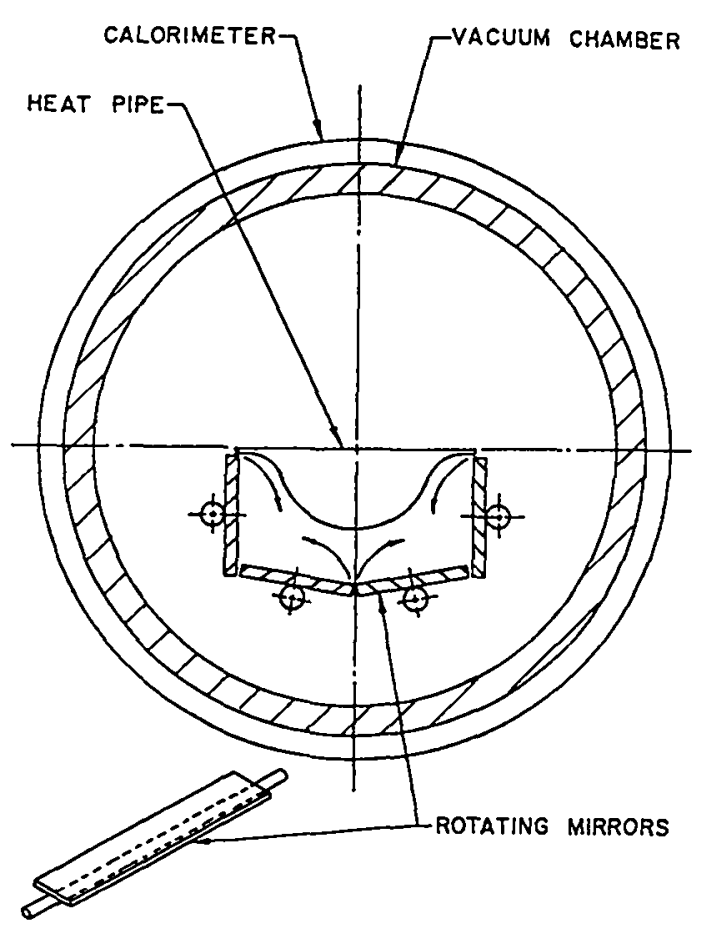

Fig. 49. Rotatable mirror calorimeter design. 


\section{REFERENCES}

1. K. Hazemark and M. Broli, "Equilibrium Oxygen Pressures over the Nonstoichiometric Uranium Oxides $\mathrm{UO}_{2+\mathrm{x}}$ and $\mathrm{U}_{3} \mathrm{O}_{8-\mathrm{x}}$ at Higher Temperatures," J. Inorg. Nucl. Chem., 28 (1966) $2837-2850$.

2. M. Tetenbaum and P. D. Hunt, "High-Temperature Thermodynamics of Oxygen Deficient Urania," J. of Chem. Phys., 4911 (1968) 4739-4744.

3. A. J. Leffler and N. M. Wiederhorn, "Thermodynamics of the Liquid Potassium-0xygen and Sodium-Oxygen Systems," J. of Phys. Chem., 6810 (1964) 2882-2889.

4. D. L. Smith and K. Nateson, "Influence of Nonmetallic Impurity Elements on the Compatibility of Liquid Lithium with Potential CTR Containment Materials," Nucl. Tech., 22 (1974) 392-404.

5. P.A.G. O'Hare, K. J. Jensen, and H. R. Hoekstra, "Thermochemistry of Molybdates IV. Standard Enthalpy of Formation of Lithium Molybdate, Thermodynamic Properties of the Api eous Molybdate Ion, and Thermodynamic Stabilities of the Alkali-Metal Molybdates," J. Chem. Thermodynamics, 6 (1974) 681-691.

6. H. S. Van Klooster, Z. Anorg. Chem., Vol. 85 (1914), p. 55.

7. J. H. Kittel, "Layer Formation by Interdiffusion Between Some Reactor Construction Metals," Argonne National Laboratory report ANL-4937 (June 1949).

8. W. Vickers, "The Compatability of Beryllium with Various Reactor Materials," in The Metallurgy of Beryllium pp 335-349, Chapman and Hall Ltd. (196I).

9. A. C. Charters and J. L. Summers, "High Speed Impact of Metal Projectiles in Targets of Various Materials," Proc. Symp. Hypervelocity Impact, 3rd Armor Res. Foundation, Chicago, Illino is (1958). 
II. REACTOR SAFETY: GAS-COOLED FAST REACTOR SAFETY EXPERIMENTS

A. Executive Sumary (D. L. Hanson, Q-13)

The basic assembly module of the gas-cooled fast reactor (GCFR) is a subassembly comprising 264 fuel rods, 6 corner support rods, 1 central rod (instrumented), and their surrounding duct. The duct is a right hexagonal cylinder. The purpose of this out-of-pile experimental program is to demonstrate the behavior of the GCFR core module in the event of loss of core coolant flow (LOFA) and subsequent shutdown of reactor power to the level resulting from decay heat alone. The LOFA will be simulated in the steel melting and relocation test (SMART) and the loss-of-pressure accident will be simulated in the depressurized accident condition (DAC) test. These experiments require the development of an electrically-heated fuel rod simulator capable of delivering $2 \mathrm{~kW}$ of power while operating at surface temperatures exceeding $1650 \mathrm{~K}$ and the development of a fixture that will permit operation of an ensemble of 438 such rods ( 1 core module thermally guarded by segments of the six surrounding modules) at helium pressures up to $9.1 \mathrm{MPa}$. This guarded core module (GCM) fixture will be the largest in a sequence of four test fixtures developed in the course of this program. The others are:

- Ten-inch, single-rod fixture,

- One-meter, seven rod fixture, and

- Full-length subgroup (FLS) 37-rod fixture.

The GCM fixture will be used first for the SMART and subsequently for the DAC test.

Because of funding I imitations, SMART I will not be assembled this year. Design work will be completed, however, and the FLS-3 test will be performed.

The diameter of the central hole in the upper GCM pressure vessel cover must be enlarged. The effects of this enlargement were found by analys is to be acceptable. Cooling of the GCM pressure vessel was analyzed and found to be a non-problem.

In the FLS-3 current design, the diameter of the lower pipe and the valve have been reduced and the horizontal pipes have been lengthened to increase flexural compliance to thermal distortion. Only a moderate amount of effort remains to complete the SMART I design.

All of the piping, flanges, and fittings required for $\mathrm{FLS}-3$, including the ball valve, have been received. A differential pressure measurement system and a temperature-compensated hot $\mathrm{film}$ anemometer are on order. A significant number of SMART I parts is on hand and many are on order, but no new orders are being placed because of funding limitations.

Instrumentation wiring between the test cell and the data acquisition system is now installed, bringing the system capacity up to 210 channels. Testing is underway to determine the cause of variations in the measurements of graphite heater rod resistance. Experimental work is continuing to determine feasibility of $x$-ray diagnostics, and arrangements have been made to try this technique on the FLS-3 test.

B. Program Planning (D. L. Hanson, Q-13)

Design of the SMART I test assembly progressed during this quarter to a point from which a reasonably accurate estimate of the cost of completion could be made. The estimate was made and found to exceed the amount allowed by our arbitrarily assigned funding level for this year. Since an increase in funding allocation proved to be impossible given the current political and economic climate, no further procurement will be initiated and the test will be postponed until next year, at least. We now plan to allocate the time remaining in this fiscal year to completion of the FLS-3 test and the SMART I design.

c. Analysis

1. SMART I (A. J. Giger, Q-13). Because of changes in design concept that routed main electric power through single conductor pass-throughs at each end of the pressure vessel (PV), it became desirable to enlarge the central hole of the PV closure. To examine the increase in size from $57.2 \mathrm{~mm}$ to $66.7 \mathrm{~mm}$, a SAPV model was made of the closure and end of the PV. Stresses found in the material adjacent to the central hole are shown in Fig. 50. When these values were ratioed down to the GCM test pressure of $9.1 \mathrm{MPa}$, maximum tensile values of $1.207 \times 10^{8}$ and $1.296 \times 10^{8} \mathrm{MPa}$ were 


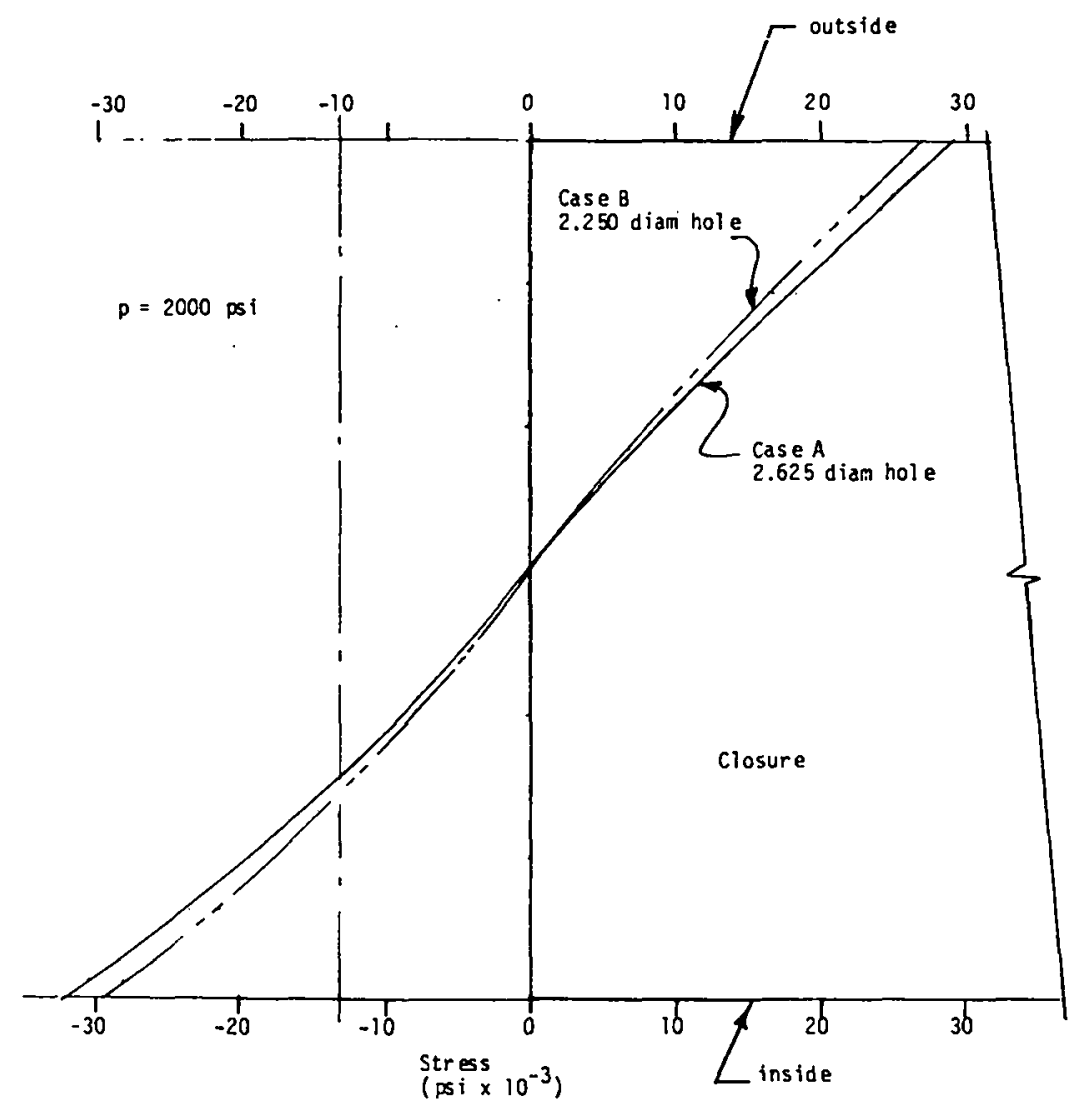

Fig. 50. Center hole circumferential stress.

found at the outer surface for the 57.2 and 66.7 $\mathrm{mm}$ holes, respectively. These values were then compared with the vessel material (A-515) yield of $2.62 \times 10^{8} \mathrm{MPa}$ and margins to yield of $54 \%$ and $51 \%$, respectively, were noted and considered reasonable and safe.

An examination was made of the need for cooling the GCM pressure vessel by using the AYER code to provide a transient analysis. The model, shown as Fig. 51, was composed of four materials: C-1020 stee 1 for stanchions and PV, 316 stainless steel for the ducts, low-density $\mathrm{Al}_{2} \mathrm{O}_{3}$ permeated with 85 atmosphere He for the void between guard heaters and the support frame, and "smeared" graphite, $\mathrm{Al}_{2} \mathrm{O}_{3}, 316$ stainless steel and 85 atmosphere $\mathrm{He}$ for the space interior to the ducts.

The analysis was accomplished by initialyzing the entire model to $20^{\circ} \mathrm{C}$ and allowing the conduction process to begin. The temperatures within the stanchions were held to $25^{\circ} \mathrm{C}$ and a heat transfer coefficient of $5.7 \times 10^{-4} \mathrm{~W} / \mathrm{cm}^{20} \mathrm{C}$

(Case 1) or twice this value (Case 2) was specified for the PV outer wall.

Results for Case 1 at $2 \mathrm{~h}$ and $64 \mathrm{~h}$ are shown as Figs. 52 and 53 , temperatures are ${ }^{\circ} \mathrm{C}$. Figure 54 shows the heat losses in Cases 1 and 2 . It is seen that the stanchions intercept and dispose of most of the heat from the experiment. In Case 1, 93\% of the heat flow is into this sink at $4 \mathrm{~h}$.

- For base Case 1 the maximum PV temperature noted was $37.3^{\circ} \mathrm{C}$ at $8 \mathrm{~h}$. Results indicated that given a reasonable approximation of the insulation assumed in the model an expensive or elaborate cooling system is not required for the PV--a standby spray cooling for emergencies would probably suffice.

2. Rod/Spacer-Grid Intersection (F. Ju, Q-13). The efficient beam column finite element has the advantage of reducing the total number of elements necessary to model the fuel rods in the 


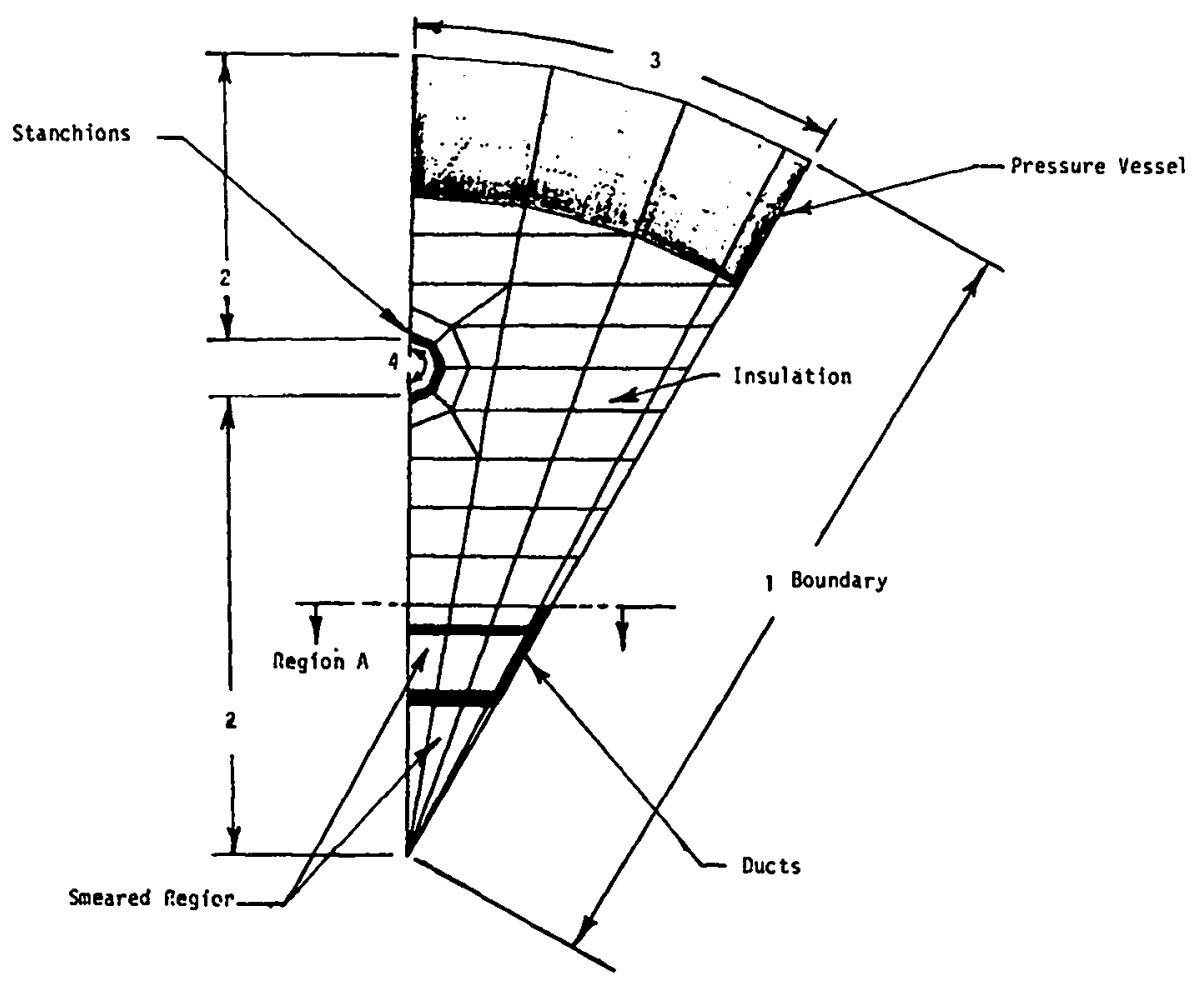

Fig. 51. GCM model.
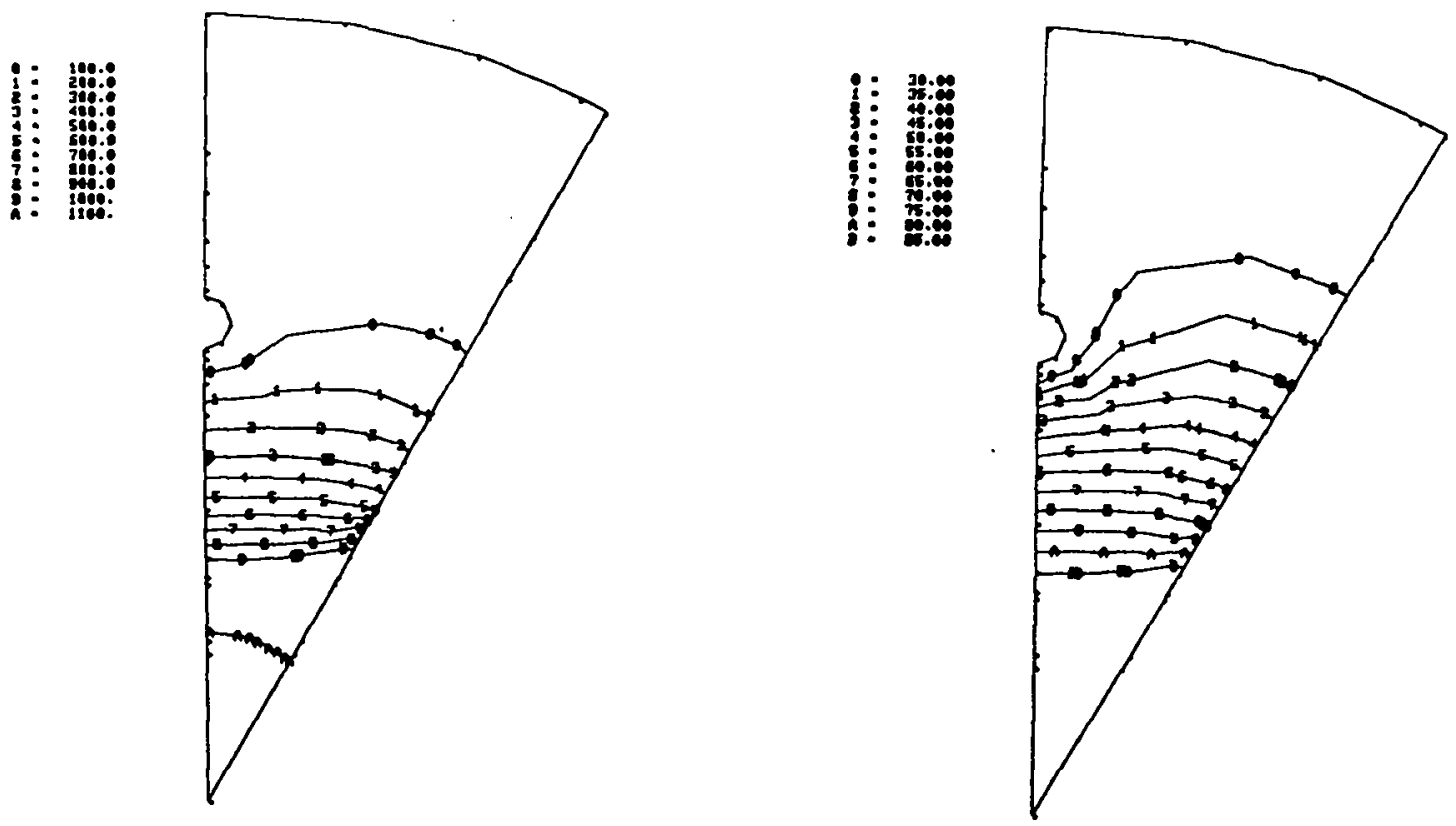

Fig. 52. Results for Case 1 at $2 h$.

Fig. 53. Results for Case 1 at $64 \mathrm{~h}$. 


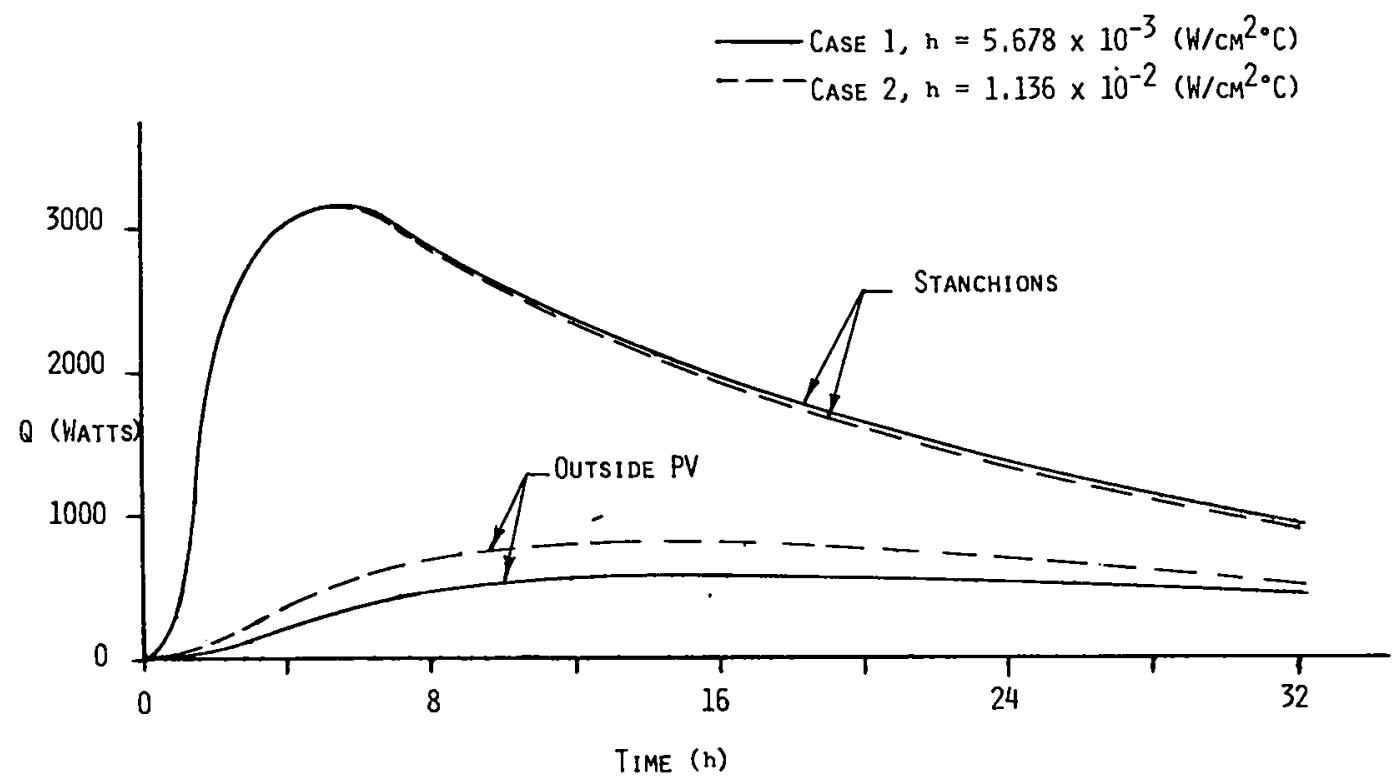

Fig. 54. Heat losses in GCM experiment.

GCFR by an order of magnitude as compared to the standard finite element methods such as in ADENA. A report on the new efficient beam column finite element is now available in LASL publication LA-8229-MS. Currently, work is in progress to adapt the new finite element to the GCFR production code. The column stability effect in the code appears only when the deformation of the column at the spacer support would produce an axial friction force larger than the axial force in the beam column (the fuel rod). The program in the code should reproduce the progressive thermal deformation of the fuel rod and the successive locking of the multiple spacer support along the fue] rod.

D. Design

1. FLS-3 (E. Ferdinand, J. Anderson, D. L. Hanson, Q-13). Because of a concern over piping stresses caused by differential thermal expansion of the two long vertical legs of the FLS-3 convection loop, the lengths of the short horizontal legs were doubled, and the lower leg was changed from 6 in. to 3 in. nominal schedule 80 pipe. The reduction in pipe size was then carried over to the ball-type shutoff valve below the heat exchanger, and its cost was thereby reduced by a factor of three. These changes violate the original design ground rules in that the major portion of the external flow loop impedance will no longer be concentrated in the heat exchanger. They are considered prudent, however, because the 2.5 in. nominal schedule 5 pipe in the center of the heat exchanger was a fragile link in an otherwise stiff, redundant loop structure. The new configuration is shown in Fig. 55 .

2. First 271 Rod GCM Experiment (SMART-1) (A. J. Giger, Q-13; J. Churchman, SD-2). Minor redesign of the bottom electrical pass-through was completed. Ali detail drawings for upstream and downstream electrical connections were completed and released. Design of the experiment main seal was reviewed and found acceptable; $40 \%$ of the detail drawings for the seal were completed and released. Remaining areas requiring moderate design effort are the bottom frame guide, void insulation between experiment and frame, guard heater internal and assembly details, top gas baf$f l e$, and the $x$-ray window. The PV port insulation requires a minor effort.

E. Procurement and Fabrication

1. FLS-3 (J. Anderson, D. Bennett, Q-13). A11' of the piping, $f l$ anges, and fittings have been received and will be sent to the Zia welding shop for assembly per Fig, 55 with an expected completion date of 5-1-80. The insulation will be inserted as soon as the piping returns from welding. 


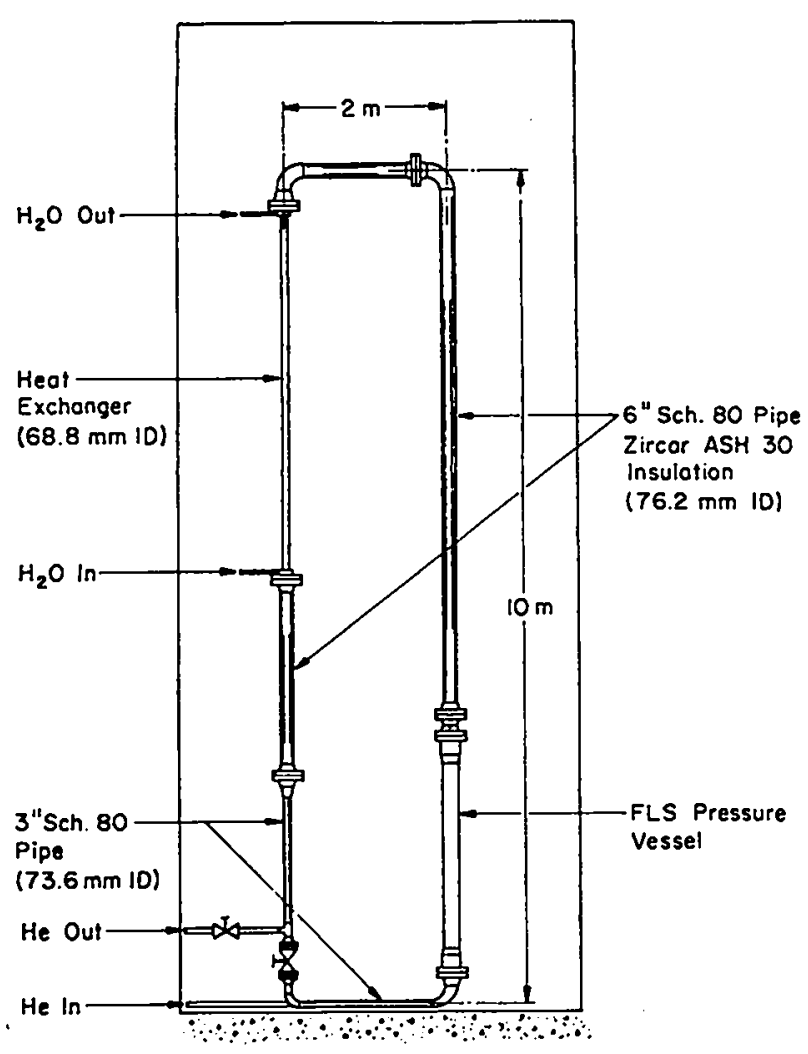

Fig. 55. The FLS3 circuit.

The nominal 3-in. ball shutoff valve has been received. It is remotely actuated, but the actuation was found to be slower than desired. It has been subsequently modified to fully open or close in approximately $\mathrm{I} \mathrm{s}$.

A temperature-compensated hot film anemometer system has been ordered from Thermo-Systems Inc. to measure helium mass flow in the FLS-3 convective loop. This system can measure velocities down to $0.06 \mathrm{~m} / \mathrm{s}$ in operating temperatures up to $325^{\circ} \mathrm{C}$. Delivery of the system is expected by mid April.

2. SMART-1 Test Assembly (A. J. Giger, Q-13; J. Churchman, SD-2). The experiment support frame was completed and delivered. The stanchions were sent out for protective nickel plating. of a total order of $1279 \mathrm{~m}$ of alumina insulation, $669 \mathrm{~m}$ have been received. The received sleeves were reworked to improve end squareness.

other parts that were completed and received were: two duct weldments, core support plate, insulation spring holdown plate, downstream molybdenum contact plate, load support plate, shunt contact plate, and 284 macor sleeves.

Orders were placed for current shunts and the upstream electrical connections.

Bids were received for $610 \mathrm{~m}$ of chromel alumel thermocouple wire, main duct molybdenum blanket rods, downstream support rods, and the downstream electrical components.

Items in the previous paragraph are on indef $i-$ nite hold (i.e., no order placement) due to funding constraints.

Specifications for purchase of high temperature springs and sheathed nickel lead wire were prepared and are on hold.

F. Assembly, Installation, and Checkout

1. SMART I Instrumentation (D. Bennett, $R$. Ortega, Q-13; J. Simmons, J. Miller, E-2). The HP3052 A data acquisition systems have now been wired into Test Cell $\# 1$ and into the High Bay addition. The instrumentation wiring completed the 210 channel capacity dual system, where up to 160 channels can be used for thermocouple data.

Checkout of the newly wired system is not complete. G. Testing

1. FLS-3 Rod Resistance Tests (R. Ortega, J. Anderson, A. J. Giger, D. Bennett, Q-13; J. Miller, E-2). Testing of the FLS-3 graphite heater rods for rod resistance indicated a resistance distribution similar to the FLS-2 distribution, but was biased in the direction of greater rod resistance. An investigation into the cause of this bias has also revealed that individual rod resistance can vary from day to day in a random manner. To date, graphite temperature and humidity dependence, measuring-contact resistance, power supply fluctuations, voltmeter sensitivity and resolution, and the test fixture have been checked as to their contribution to the resistance variations. Statistical evaluation of the resistance data has led to the use of a 1-ohm resistance shunt to measure circuit current, rather than the 0.01-ohm shunt used previousiy. Test device electrical contacts are also being investigated. 
2. X-ray Techniques (D. Bennett, Q-13; Art Hasenkamp, SLA; Larry Bryant, M- I; Jim Hyder,

$\mathrm{H}-1)$. Arrangements have been made for the use of the Sandia Laboratories owned 250 -curie ${ }^{60}$ Co

$x$-ray source and the Delcalix image intensifying

system during FLS-3 testing. This system can

furnish a real time $x$-ray image of the FLS- 3 test

insert during pressurized testing conditions.

Confirmation of this capability came by placing a

37-pin array model into the FLS pressure vessel

and using the $x$-ray system to determine rod chan-

nel resolution. The system will, in all prob-

ability, be able to indicate an interstitial

blockage caused by melted duct wall and rod

cladding. 
III. REACTOR SAFETY: STRUCTURAL ANALYSIS

A. Executive Summary (C. A. Anderson, Q-13)

In the HTGR Structural Program, work has continued on the NONSAP-C code development task with the major progress being the addition of a tendon element to the element library of the code. A study of the vulnerability of the Zion and Indian Point containments to steam explosion and hydrogen explosions was completed. In the former, the possibility of generating large missiles was found to be remote, and in the latter case, a containment static failure pressure of 154 psig was determined, whereas dynamic loading with a peak pressure of 200 psig was found to cause structural collapse.

B. HTGR Structural Evaluation (C. A. Anderson, L. M. Carruthers, C. Wijg, Q-13)

The major efforts in the HTGR structural safety program during the past quarter have been continuation of the work on NONSAP-C code development and the structural evaluation effort for the Zion containment building, which is reported separately. In the NONSAP-C code task, there were four efforts: CRAY conversion, development of a tendon element, development of a creep-crack model, and, finally, an evaluation of code performance on a large concrete creep problem.

Conversion of the NONSAP-C code to the CRAY computer was relatively straightforward, and is an indication that the code is easily adapted to other computing systems. A repeat of the test problems (see Ref. I) indicated a factor of 3 to 5 decrease in running times with the higher reductions being observed in the larger problems. The code remains 10 bound, and we will see more improvement in performance as we optimize the code for CRAY usage.

A tendon element has been added to the element library of NONSAP-C, which will enhance the capability of the code to handle post-tensioned containment buildings as well as prestressed concrete reactor vessels. The tendon finite element is a multi-node line element that can adapt itself to an arbitrary array of nodes in three dimensional space. A version of the tendon element has been checked out on simple concrete structures where the tendon is free to slip. Figure 56 illustrates a simple test problem in which a concrete cube is loaded axially by four tendons along the edges and then allowed to deform as a function of time through concrete creep. Results of the calculations by NONSAP-C, which are in excellent agreement with analytical predictions, are shown in Fig. 57. Another version of the tendon uses a parameter to indicate the degree of bondedness to the concrete, which can vary from 0 to 1 for unbonded to fully bonded tendons, respectively. This version of the tendon has not been checked out on test problems although the code developmental work has been completed.

One of the milestones for this year's program is to add a cracking capability to the concrete creep module in NONSAP-C. The mechanics for implementing the cracking capability is relatively straightforward, since a crack algorithm is already present in the time-independent concrete constitutive model. A program has been laid out to combine the crack and creep capabjlities with the major efforts being in changing to a strain rather than stress crack criterion and to allow for iteration in the creep module to redistribute stresses across a crack. Interest has been expressed by Rockwell International at Hanford, Washington, in using such a capability to analyze long-term behavior of waste storage tanks, and they may fund a portion of this work.

Evaluation of the performance of NONSAP-C on large creep problems has been started. A finite element mesh of a $60^{\circ}$ sector of the Zion containment building has been put together. A $60^{\circ}$ sector is necessary for modeling since the dome tendon array introduces a $60^{\circ}$ symmetry as do the buttressess for the hoop tendons in the containment building cylinder. The mesh for the model is shown in Fig. 58. The entire model consists of 117 concrete elements, 117 steel liner elements on the inside surface of the concrete elements, and 41 tendons on the dome and cylinder of the model. Linear isoparametric elements are being used. The resulting stiffness matrix contains 746 equations with a bandwidth of 716 . An elastic solution takes about 5 minutes of combined IO and CPU time.

Creep of the containment will be studied with a one or two term viscoelastic constitutive model to minimize computing costs. Particular attention will be paid to the following issues: 

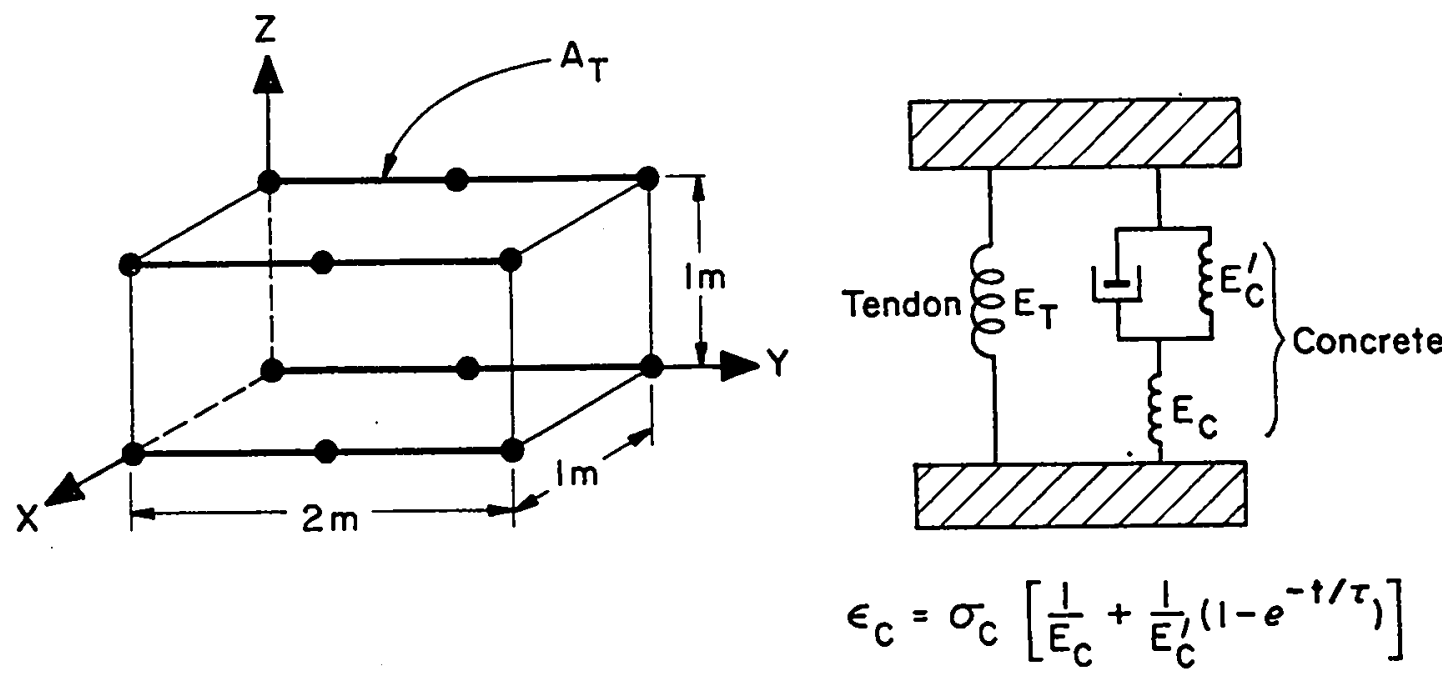

Fig. 56. Concrete cube with four tendons and one-dimensional viscoelastic analogy.

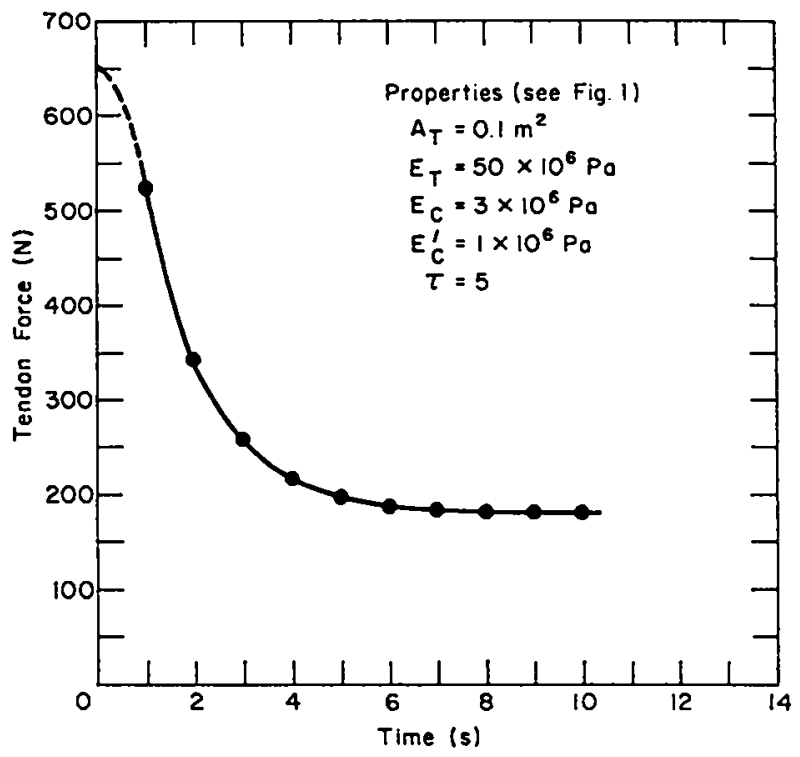

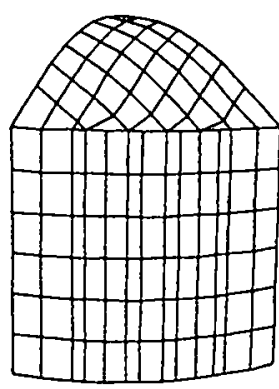

a. Back view

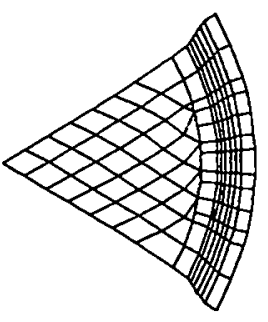

c. Bottom view

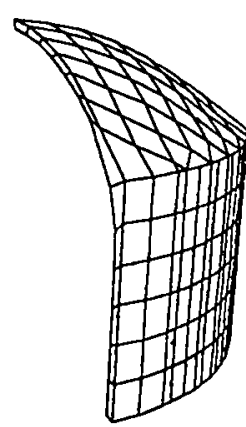

b. Side view

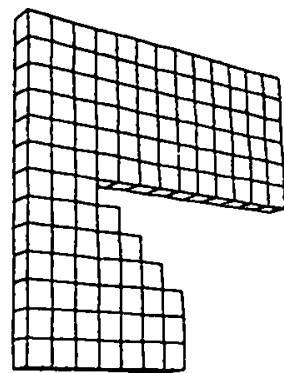

d. Loaical mesh stress redistribution and creep for the Zion containment building. ${ }^{2}$

C. Structural Margins to Failure

This program started on April 1, 1980; therefore, this report will mention activities planned for the second quarter.

Fig. 58. Views of the finite element mesh for the Zion containment building. 
1. Category I Structure Safety Margins (E. G. Endebrock, R. C. Dove, Q-13). Sources of information on Category $I$, non-containment structures will be located and obtained. In addition, information on the modeling of concrete structural elements and systems will be collected and reviewed. A test plan will be prepared based on the collected information.

2. Containment Buck ling Safety Margins (J. G. Bennett, T. Butler, Q-13). A meeting was held with the NRC Technical Monitor and the overall plan for this program was discussed. A work statement is being prepared in accordance with NRC's needs. The thrust of the program will be directed at research in the dynamic buckling of containments. In addition, current NRC needs in the area of static buckling safety margins will be accomodated wherever possible.

D. Zion and Indian Point Study (C. A. Anderson,

J. G. Bennett, F. Beihl, T. Butler, L. M.

Carruthers, K. C. Cooper, Q-13)

We studied the structural response of the $\mathrm{Zion}$ Nuclear Plant Unit No. I to several possible aspects of a Class IX accident. Included were analyses of the pressure vessel structural re. sponse to steam explosions, of containment structural and thermal response to hydrogen explosions, and of missile penetration into thick concrete structures. Reference 3 gives a detailed descrip$t i$ on of the work summarized here.

A noninear, structural dynamic model of the pressure vessel was developed using the ADINA finite element computer code ${ }^{4}$ for use in determining the response of the upper head to static and dynamic pressure loads generated by postulated steam explosions. The model was loaded statically with both a uniform pressure load and a stepped pressure distribution to determine its ultimate quasistatic capability. The pressure loads were predicted by LASL Group Q-7 with the SIMMER computer code. For the uniform pressure load an ultimate capability of 9500 psi (70 MPa) was calculated with the failure mechanism taking the form of a plastic hinge at the location on the vessel head where a thickness change occurs. For the stepped pressure distribution, the maximum pressure achieved at the shell apex was 11600 psi ( 80 $M P a)$. In this case, failure is characterized by excessive membrane stretching at the shell apex. Figure 59 depicts deformed shapes and illustrates the failure mechanisms for these cases.

Dynamic response of the upper head to both spatially uniform and spatially stepped pressure time histories generated by postulated steam explosions was calculated. For both cases, the pressure history was described by a triangular impulse with a peak at $15 \mathrm{~ms}$ and a duration of 60 ms followed by a constant overpressure of 3625 psi (25 MPa). The peak pressure for the spatially uniform distribution was 11025 psi (75 MPa) at the vessel apex. Response to the dynamic loadings was similar to the companion static load cases. Again, for a spatially uniform pressure distribution, a plastic hinge develops. For the stepped pressure distribution, the largest displacement and strains occur at the head apex. The vesse? can withstand both imposed dynamic pressure loadings without sustaining a failure.

Several simple hand calculations were performed to check other aspects of vessel failure. Some conclusions of these are that head bolts will not fail before a hydrostatic pressure of 14300 psi ( $100 \mathrm{MPa})$ and that for hydrostatic loads, the failure will most likely occur in the lower portion of the reactor vessel with rupture of the cylinder at $1400 \mathrm{psi}(44 \mathrm{MPa})$. Also, a plug could be sheared out of the head by a highly focused pressure on the axis of symmetry of 82000 psi (565 MPa).

The primary conclusion of this study is that for the postulated dynamic loading provided by the SIMMER code, the possibility of generating missiles is remote. The containment structure is a lightly reinforced, post-tensioned concrete structure composed of a right circular cylinder and a spherical dome. Because of the structure's complexity, we did the analysis in steps by first performing some simple hand calculations and then developing a small and simplified Tinear model with the SPAR finite element computer code. ${ }^{5}$ Calculated static responses from the linear model were then used to guide the development of a nonlinear model using the ADINA finite element computer code.

Even though the containment building is not truly axisymetric, we made this simplifying 

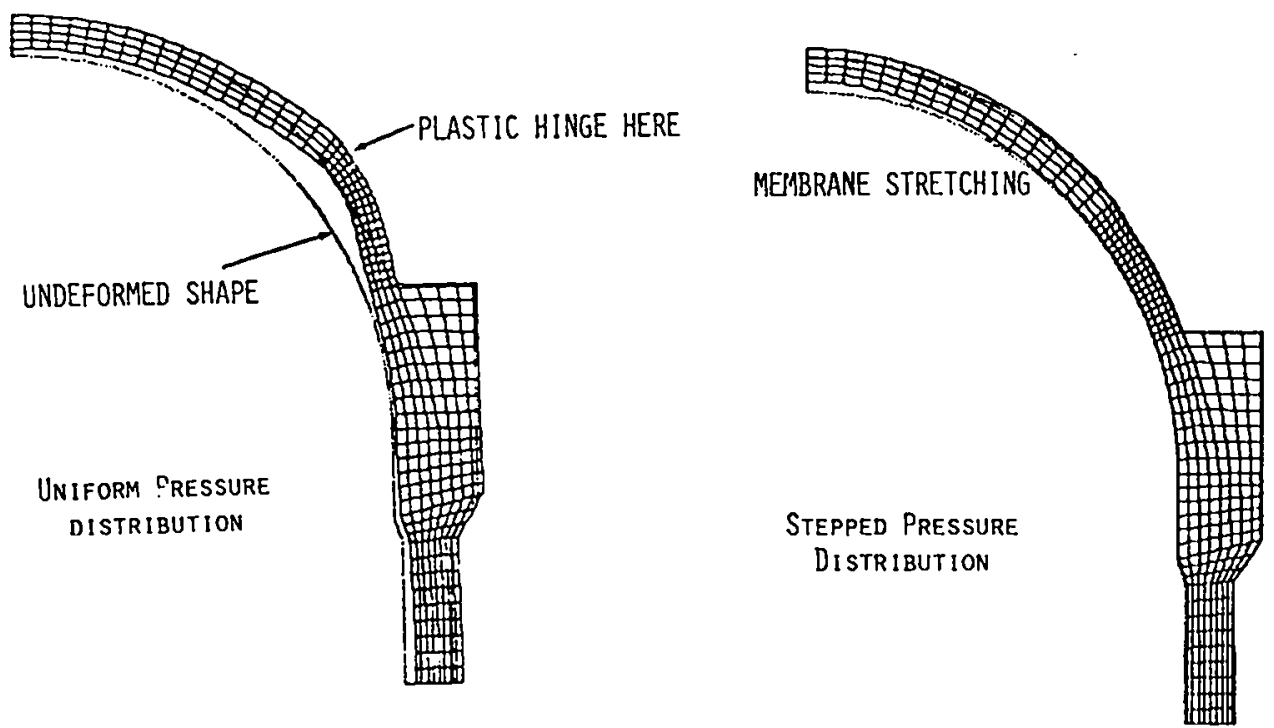

Fig. 59. Results from static pressure loads.

assumption so that our analytical model could be kept to a reasonable size. A nonlinear material model resident in the ADINA code was used to represent the concrete. It allows for tension cracking, nonlinear compressive behavior, and crushing. The reinforcing bars and tendons were modeled with separate elements and were represented with a bilinear material model. The liner was modeled with an axisymetric shell element previously developed at LASL. 6 It was also represented with a bilinear material model.

The resulting model was loaded quasistatically first with post-tensioning and gravity loads. Post-tensioning was introduced with an initial strain in the truss elements representing the tendons. A uniform internal pressure was then added to these loads. The response is presented in Table XV. To determine the failure pressure of 154 psig (1.06 MPa), we used a pressure-moment interaction diagram for a section of the cylindrical wail immediately below the dome transition ring (Fig. 60).

TABLE XV

SUMMARY OF STATIC RESPONSE

Pressure

(psig)
The diagram is based on yielding of the reinforcement on the inner wall of the building, because once it yields the ductile liner can experience enough stra in to separate and allow radioactive materials to escape to the atmosphere Three points are shown on the diagram that were established using the ADINA finite element model. The first point has a moment of zero and indicates the pressure (67 psig) at which the moment induced from post-tensioning is overcome. A line was drawn through these three points to establish a failure pressure of 154 psig.

Based on the results of the static analysis, we have recommended a conservative pressure set point for a filtered vented containment system relief valve of 67 psig $(0.46 \mathrm{MPa})$. A less conservative, but realistic, set point is 92 psig (0.64 MPa) where concrete cracking begins.

The model was also subjected to dynamic impulses with 100 and 200 psig peaks. The impulses were triangular with a width of $15 \mathrm{~ms}$. For the 100 psig (0.7 MPa) peak impulse, the concrete was severely cracked throughout the walls of the vessel. Crushing of the concrete occurred at the dome apex. However, no reinforcement yielded so the pressure holding capability of the liner is retained. For the $200 \mathrm{psi}(1.4 \mathrm{MPa})$ peak impulse, some of the tendons yield and the failure is probably catastrophic. 


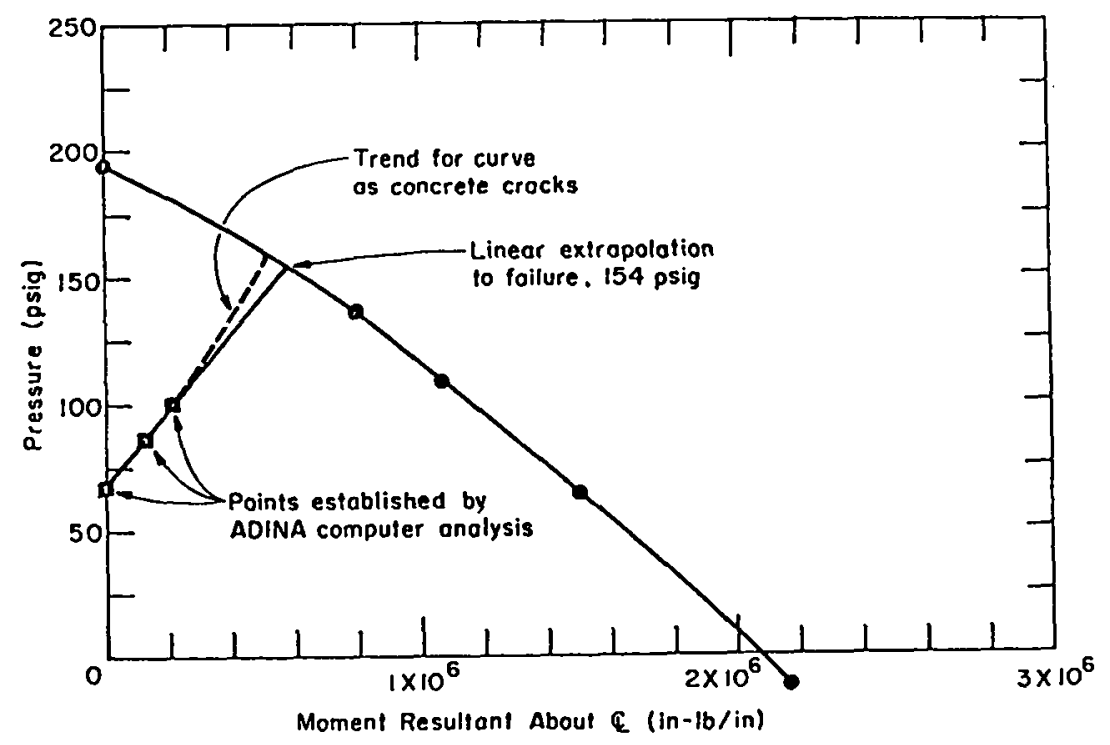

Fig. 60. Pressure-moment interaction curve at cylinder-ring intersection.

The containment structure was also analyzed to determine whether the concrete would overheat after a hydrogen burn. Results indicate no temperature problem.

\section{REFERENCES}

1. P. D. Smith, and C. A. Anderson, "NONSAP-C: A Nonlinear Stress Analysis Program for Concrete Containments Under Static, Dynamic, and Long-Term Loadings," Los Alamos Scient if ic Laboratory report LA-7496-MS, October 1978.

2. A. Walser, Sargent and Lundy, personal cormunications.
3. M. G. Stevenson, "Report of the Zion/Indian Point Study, "Volume II, Los Alamos Scientific Laboratory report LA-8306-MS, NUREG CR/1411, April 1980.

4. K. J. Bathe, "ADINA: A Finite Element Program for Automatic Dynamic Incremental Nonl inear Analysis" MIT report 82448-7, Sept. 1975 (Revised Dec. 1978).

5. W. D. Whetstone, "SPAR Structural Analys is System Reference Manual," Vol I NASA report NASA-CR-145098-1, Feb. 1977.

6. W. A. Cook, "Linear and Nonlinear Symmetrically Loaded Shells of Revolution Approximated with the Finite Element Method," Los Alamos Scientific Laboratory report LA-7538-MS, Oct. 1978. 
IV. HEAT PIPE TECHNOLOGY DEVELOPMENT

A. Executive Summary (M. Merrigan, Q-13)

This quarter's efforts in heat pipe technology development have involved the continuing evaluation of envelope, closure, and working fluid materials for the ceranic heat pipe program, and analysis of the economics of ceramic recuperator application in the steel, glass, and aluminum industries. The investigation of limiting conditions in gravity assisted heat pipes has continued with fluid inventory and operating angle as basic parameters.

A semi-annual ceramic heat pipe program review was presented to Pittsburgh Energy Technology Center (PETC) personnel on 20 March 1980. The Field Task Proposal Agreement for the program for fiscal year 1981 was prepared and submitted to PETC through the LASL program office and DOE, Albuquerque.

An alumina heat pipe using an organic working fluid selected for operation between $323 \mathrm{~K}$ to 473 $K$ has been assembled for evaluation of potential applications in wet $\mathrm{SO}_{2}$ scrubbers.

Thermal shock screening of CVD silicon carbide coatings on molybdenum substrates has been conducted and a coating method chosen for evaluation on molybdenum heat pipe. This fabrication technique offers the potential for higher temperature operation than that currently used. A prototype design and cost analysis of ceramic heat pipe recuperators in selected industrial applications has been completed by Garrett-AiResearch under contract from LASL. Overall conclusions of the report indicate fuel cost savings of $40 \%$ to $50 \%$ and payback periods of less than six months.

Development work associated with the use of Carborundum-KT material for ceramic heat pipes has continued with the investigation of tungsten deposition techniques and braze materials compatible with the high percentage of free silicon present in the material. LASL materials personnel are assisting in the evaluation of weld and weld-braze techniques for closure of these pipes.

Heat pipe engineering efforts have been concentrated on the conduct of performance tests of gravity assist heat pipes. Performance tests have been completed on a $0.8-\mathrm{m}$ heat pipe. The test parameters investigated were volume of the working fluid and tilt angle. Two limits have been identified, an entrainment limit which results in overheating of the evaporator wall near its midpoint and a pressure drop limit resulting in overheating at the base of the evaporator. The former is a function of the vapor flow characteristics and was observed to be independent of the liquid volume and tilt angle; whereas the latter is related to the liquid behavior and is strongly related to both the tilt angle and the liquid inventory in the heat pipe.

B. Ceramic Heat Pipe Technology Development Program (M. A. Merrigan, E. S. Keddy, W. E. Dunwoody, and L. Lundberg, Q-13).

1. Introduction. The goal of the LASL Ceramic Heat Pipe Program is the development of the technology required for the construction of long life, high-temperature heat pipes from ceramic materials. These heat pipes need to be suitable for operating in harsh environments such as high-temperature air, flue gases of various chemical compositions, and fluidized coal beds. Successful development will lead to the incorporation of these units in high-temperature heat exchangers for heat recovery from industrial processing furnaces.

Recuperation of heat from the exhaust gases of high-temperature furnaces is not being accomplished with high effectiveness at the present because of materials limitations. Typically, loss of strength restricts the air preheat temperature capability of metallic recuperators to about 1000 K. Ceramic materials have been used in conventional brickwork heat exchanger configurations to increase allowable temperatures, however these designs have inherent leakage problems from the opening of the multitude of ceramic joints under the action of thermal gradients, differential thermal expansion, and flow-induced vibration. The design of ceramic heat pipe recuperators eliminates the sealing problems that have limited the use of ceramic material in heat recovery installations in the past. Ceramic heat-pipe-based recuperators offer the opportunity for high corrosion and abrasion resistance, high temperature capability, reduced leakage, element redundancy, and simplified replacement and cleaning. 
The development of ceramic heat pipe recuperator elements to the point of industrial acceptance involves the screening and selection of materials and fabrication techniques that have the potential for economical production, demonstration of technology in sub-scale tests, design and test of components for full-scale recuperator applications, and demonstration of heat pipes in subscale and full-scale recuperator installations.

Work on the program began with material compatibility studies leading to the selection of candidate pipe envelope materials, working fluids, and protective envelope liner materials. Aluminaniobium-lithium and silicon carbide-tungstensodium combinations were selected for tests. Alumina materials were eliminated in early testing because of thermal shock failures. Tungsten-lined CVD silicon carbide heat pipes using sodium as a working fluid were fabricated and operated in vacuum, air, and combustion gases at temperatures to $1200 \mathrm{~K}$. These pipes showed some liner-shell bond deterioration after operation for periods of approximately $100 \mathrm{~h}$. Current investigations are directed toward the elimination of these bonding problems and associated pipe sealing problems through the development of new fabrication methods and the use of new material combinations.

2. Program Planning. A Field Task Proposal Agreement covering ceramic heat pipe work $p$ lanned for 1981 has been prepared and submitted to the Pittsburg Energy Technology Center (PETC) at their request. This document, covering funding and activities for the 1981 fiscal year, was submitted by $F A X$ in draft form with the final version following through the DOE Albuquerque office from the LASL ADEP office.

A program review meeting was held by Pittsburgh Energy Technology Center on 20 March 1980 at Pittsburgh. A summary of efforts on the program during the last six months was presented.

On March 21 the Morgantown Energy Technology Center (METC) was visited for discussion of potential applications of heat pipes in coal gas cleanup. Low temperature ceramic heat pipes for use in acid environments were discussed with Robert Stewart, who is responsible for sulfur cleanup of combusion gases, and with Gary Friggens, who is concerned with wet scrubber 7 imestone systems.
Both expressed interest in possible ceramic heat pipe applications in $\mathrm{SO}_{2}$ scrubbers.

Some discussion of future applications was held with Ken Markel, who is in charge of gas cleanup for fluidized bed combustor--open cycle gas turbine systems. If it should prove necessary to cooldown and reheat gases during cleanup he feeis ceramic heat pipe recuperator technology would be applicable to his programs.

These potential applications in $\mathrm{SO}_{2}$ cleanup were suggested by Foster-Wheeler visitors as reported last quarter. In the interval since then additional requests have been received for information on applications of ceramic and other hightemperature heat pipe configurations in industrial installations. An inquiry was received from $R$. Thomas of Corning Glass, Corning, New York, regarding high-temperature heat pipe development for heat recovery from molten glass baths. The temperature range and local environment in this case would permit the use of molybdenum as a heat pipe envelope material with sodium the most likely choice for a working fluid. Information as to the present status of molybdenum heat pipe development at LASL is being forwarded to Corning. A second inquiry was received from $D$. Poole of the Bureau of Mines, Reno, Nevada, concerning the use of ceramic heat pipes in temperature control of zinc reduction electrolytic cells. The combination of molten zinc and the salts used in the cell ( $\mathrm{ZnCl}$, $\mathrm{NaCl}, \mathrm{KCl}$ ) limits the heat transfer material to nonmetallics. The operating temperature of the cell is between $723 \mathrm{~K}$ and $823 \mathrm{~K}$, within the range of potassium as a heat pipe operating fluid. Required pipe dimensions would be approximately the same as the sub-scale pipes used on the present program. Details of the applications are being forwarded by the Bureau of Mines, Reno Research Center, for review and suggestions.

\section{Prototype Ceramic Heat Pipe Development.}

Alumina heat pipes using an organic working fluid selected for operation in the range of $323 \mathrm{~K}$ to $473 \mathrm{~K}$ have been assembled as a demonstration of the applicability of ceramic heat pipe technology to wet sulfur dioxide scrubber gas reheat. These heat pipes use an alumina envelope, 200 mesh stainless steel screen wick, and recrystallizing 
glass closure seals. Two models have been assembled, the first for incorporation in the LASL display at the 7 th Energy Technology Conference and Exposition, Washington, D.C., March 24 through 26, 1980, and the second for developmental test. Performance characteristics of this second pipe will be investigated on a time available basis. Testing to date has been limited to verification of operation and a brief demonstration of compatibility of the envelope material with dilute sulfuric acid solutions.

Investigation of KT-silicon carbide heat pipe closure brazes has continued in an attempt to determine the causes of joint leakage. Sample braze joints have been prepared and analyzed by the metallurgical laboratory. Their investigation indicates that palladium-cobalt braze material is penetrating the tungsten layer, resulting in a reaction between the palladium and the free silicon in the tube wall. The resulting palladiumsilicon eutectic has a melting temperature of about $1100 \mathrm{~K}$. The result is a leaching of ceramic material from the area immdediately behind the tungsten, leaving void spaces and leakage paths as shown in Fig. 61 .

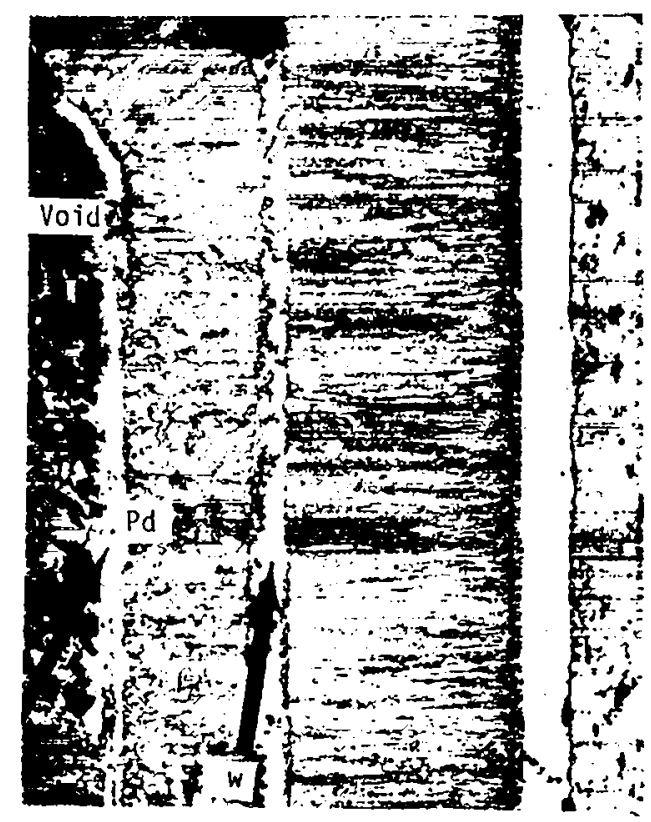

$50 x$

Fig. 61. Longitudinal section through tungsten coated silicon carbide heat pipe and end-plug which was brazed at 1300$1400^{\circ} \mathrm{C}$ with Palco and Paloro.
Microcracking of the tungsten, which is a cause of this problem, was not observed in prior metallic film deposition on solid CVD silicon carbide substrates. The problem has been discussed with the tungsten coating vendor (Chemetal) and an investigation of methods of reducing or eliminating the problem is underway. Additional KT tube samples have been furnished to Chemetal for coating. An attempt will be made to eliminate the cracking by reducing the deposition temperature and consequently the deposition rate. However, attack of the free silicon in the tube wall by deposition reaction products may limit improvement. As a secondary method of problem solution an evaluation of alternative braze materials has been reopened.

Six molybdenum tube samples, coated with various thicknesses of fine grain CVD silicon carbide have been received from Chemetal and subjected to a series of thermal shock tests both in a vacuum furnace and in a natural gas flame. The objective was the evaluation of the coating adhesion. Temperature cycling in the vacuum furnace covered the range from approximately $400 \mathrm{~K}$ to $1500 \mathrm{~K}$. The samples were inspected after one, three, and six temperature cycles. Following these tests, the surviving samples were subjected to natural gas flame heating and ambient air cooling for a total of approximately 40 cycles. The conclusion reached in these preliminary tests is that when a thin intermediate layer of tungsten is used the molybdenum substrate-CVD silicon carbide coating will withstand the thermal stresses over the temperature range of interest. No evidence of layer separation was disclosed in metallographic examination of tube samples. A photomicrograph of the tube wall section after test is shown in Fig. 62.

Continued investigation of solid molybdenum tube as a basis for ceramic heat pipes appears warranted, based on these tests. The next action planned is the fabrication of a molybdenum heat pipe to be coated with CVD silicon carbide after assembly. This pipe will be approximately 12 in. long and $0.625 \mathrm{in}$. in diam. The heat pipe will be assembled and tested prior to silicon carbide deposition. This will allow the use of welded closures and complete ceramic encapsulation, two advantages that together will permit an increase 


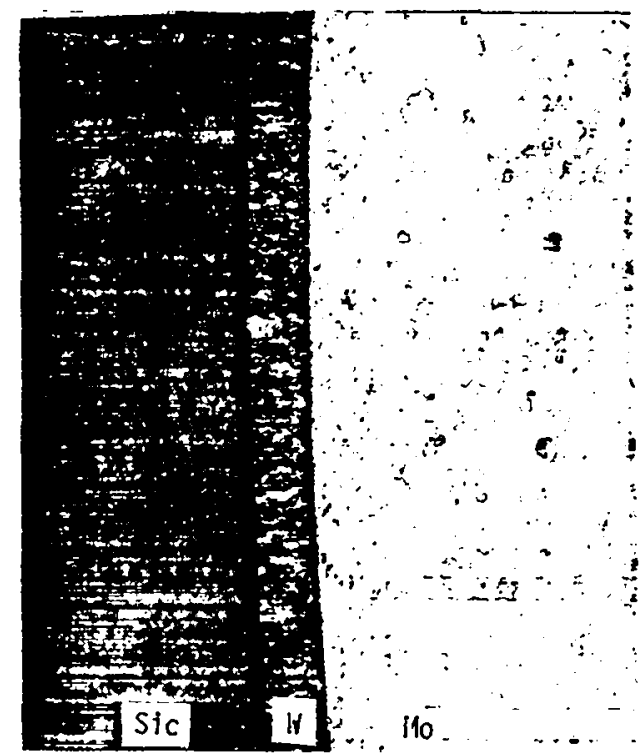

Fig. 62. Cross section of thermally cycled $\left(1500^{\circ} \mathrm{C}\right)$ molybdenum tube plated with tungsten and silicon carbide.

in operating temperature over the present configuration, which is limited both by the braze material reflow temperature and by oxidation of exposed tungsten and braze materials.

4. Design and Thermal Analys is Activities. In parallel with the hardware development, program effort has been directed to evaluation of the economic feasibility of ceramic heat pipe recuperators in industrial applications. To this end a Work Statement was prepared and released for vendor bid during FY-80 soliticing the conduct of a design study of three specific ceramic recuperator applications. The three application conditions selected were based on prior studies conducted for DOE by Battelle-Columbus and represent typical industrial applications in a steel reheat furnace, an alumina melting furnace, and a glass melting furnace. A summary of the design conditions is given in Table XVI. Fuel costs used in the study were also taken from the Battelle study and were based on actual costs from the year 1978, escalated at $7 \% / y$ in addition to the effects of general inflation, and presented in constant 1979 dollars. The study involved the conduct of an initial tradeoff exercise for each of the applications to optimize both the heat pipe external parameters and the cut-off point at which transition from the counter flow heat pipe recuperator configuration shown in Fig. 63 to a metallic heat exchange surface would be made. In addition, the design of the metallic portion of the recuperator was optimized for each application, based on a stainless steel plate-fin configuration as shown in Fig. 64 and the metaliic exchanger costs, together with ducting and structure costs, included in the total. Based on the initial trade-off studies, the three cases in Table XVII were selected for more detailed design and analysis in order to determine the total recuperator installation cost for each application and the simple payback period in terms of fuel cost. The economic analysis included accounting of fabrication and assembly material and labor for the basic metallic and ceramic heat pipe sections of the recuperator as well as ducting, insulation, support structure, $f$ ans, controls and instrumentation, and architect and engineering fees. Tabulated costs for these items are given in Table XVIII for the three cases. General conclusions resulting from the study were as follows;

1. The use of ceramic waste heat recovery heat exchangers can increase the fuel savings as compared with metallic heat exchangers by extending the air preheat temperature range. In addition, with the larger possible air-to-gas temperature differences, heat exchanger effectiveness and, hence, size can be greatly reduced.

2. Ceramic heat pipe waste heat recovery units offer a substantial size and weight advantage over conventional heat exchanger designs made from ceramic tubes. This is because the tube inside surface, which has a much smaller thermal conductance than the outside finned surface, is removed from the air and gas streams, with both fluids flowing outside the tubes.

3. Metallic heat exchangers should be used in conjunction with the ceramics to preheat the cold incoming air. It is economical to use the metallic units to as high a temperature as possible, roughly corresponding to a gas temperature of $1500^{\circ} \mathrm{F}$. 
TABLE XVI

CERAMIC HEAT PIPE RECUPERATOR DESIGN CONDITIONS

\begin{tabular}{|c|c|c|c|}
\hline Application & $\begin{array}{c}\text { Steel Soakjing } \\
\text { Pit }\end{array}$ & $\begin{array}{l}\text { Aluminum Remelt } \\
\text { Furnace } \\
\end{array}$ & $\begin{array}{l}\text { Glass Melting } \\
\text { Furnace } \\
\end{array}$ \\
\hline \multicolumn{4}{|l|}{ Air Side } \\
\hline $\begin{array}{l}\text { Flow rate, } \mathrm{Kg} / \mathrm{s} \\
\text { Inlet temperature, } \mathrm{K} \\
\text { Out let temperature, }{ }^{\mathrm{K}} \\
\text { Inlet pressure, } \mathrm{N} / \mathrm{m}^{2}\end{array}$ & $\begin{array}{l}2.47 \\
311 \\
1144 / 1255 \\
1.03 \times 10^{5}\end{array}$ & $\begin{array}{l}2.97 \\
311 \\
1144 / 1255 \\
1.05 \times 10_{5}\end{array}$ & $\begin{array}{l}2.04 \\
311 \\
1144 / 1366\end{array}$ \\
\hline $\begin{array}{l}\text { Pressure drop, } \mathrm{mm} / \mathrm{H}_{2} \mathrm{O} \\
\text { Flue Gas Side }\end{array}$ & 155 & 324 & 324 \\
\hline $\begin{array}{l}\text { Flow rate, } \mathrm{Kg} / \mathrm{s} \\
\text { Inlet temperature, } \\
\text { Inlet pressure, } \mathrm{N} / \mathrm{m}^{2} \\
\text { Pressure drop, } \mathrm{m} / \mathrm{H}_{2} \mathrm{O}\end{array}$ & $\begin{array}{l}2.61 \\
1436 \\
1.01 \times 10^{6} \\
222\end{array}$ & $\begin{array}{l}3.13 \\
1422 \\
1.01 \\
1029\end{array} \times 10^{5}$ & $\begin{array}{l}2.15 \\
1644 \\
1.01 \times 10^{5} \\
470\end{array}$ \\
\hline
\end{tabular}

TABLE XVII

HEAT PIPE RECUPERATOR PRELIMIMARY DESIGNS

\begin{tabular}{|c|c|c|c|}
\hline Parameter & $\begin{array}{c}\text { Steel } \\
\text { Soaking Pit }\end{array}$ & $\begin{array}{l}\text { Aluminum Remelt } \\
\text { Furnace } \\
\end{array}$ & $\begin{array}{l}\text { Glass Melting } \\
\text { Furnace } \\
\end{array}$ \\
\hline $\begin{array}{l}\text { Number of tubes } \\
\text { Weight, Kg } \\
\text { Fraction air length } \\
\text { Flow length, m } \\
\text { No-flow length, m } \\
\text { Number of flow rows } \\
\text { Number of no-flow rows } \\
\text { Cost, s } \\
\text { Maximum Mach number } \\
\text { Gas side pressure drop, }\end{array}$ & $\begin{array}{l}180 \\
626 \\
0.50 \\
0.21 \\
1.22 \\
6 \\
30 \\
52,970 \\
0.24\end{array}$ & $\begin{array}{l}176 \\
613 \\
0.60 \\
0.28 \\
0.90 \\
8 \\
22 \\
51,790 \\
0.36\end{array}$ & $\begin{array}{l}220 \\
766 \\
0.50 \\
0.35 \\
0.90 \\
10 \\
22 \\
64,740 \\
0.32\end{array}$ \\
\hline $\begin{array}{l}\mathrm{mm} / \mathrm{H}_{2} \mathrm{O} \\
\text { Air side pressure drop, }\end{array}$ & 130 & 583 & 173 \\
\hline $\begin{array}{l}\mathrm{mm} / \mathrm{H}_{2} \mathrm{O}^{\circ} \\
\text { Gas inlet temperature, } \mathrm{K} \\
\text { Gas out let temperature, } \mathrm{K} \\
\text { Air in let temperature, } \mathrm{K} \\
\text { Air out let temperature, } \mathrm{K}\end{array}$ & $\begin{array}{l}90 \\
1436 \\
1085 \\
719 \\
1144\end{array}$ & $\begin{array}{l}180 \\
1422 \\
1085 \\
738 \\
1144\end{array}$ & $\begin{array}{l}121 \\
1644 \\
1087 \\
687 \\
1366\end{array}$ \\
\hline
\end{tabular}

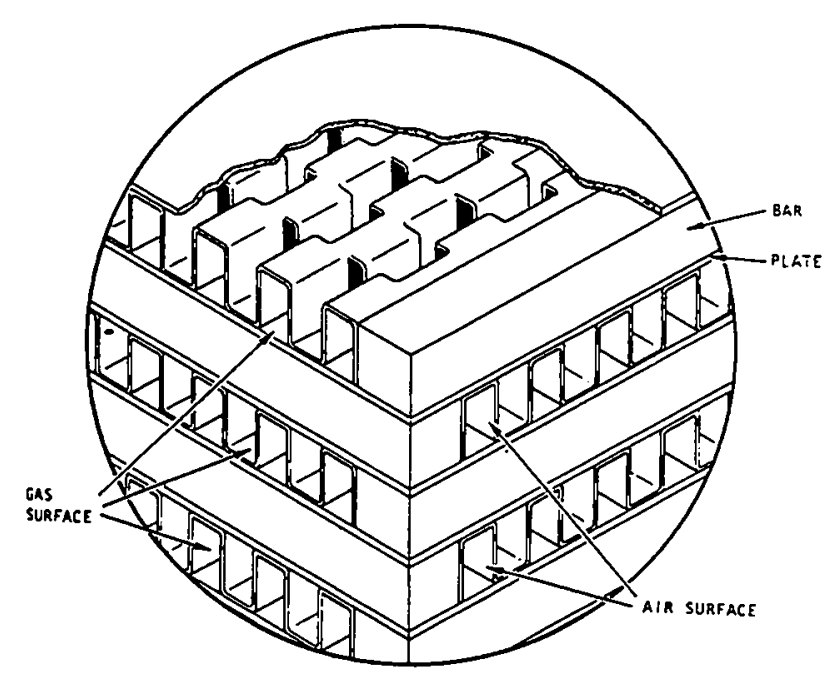

Fig. 63. Heat pipe recuperator arrangement.

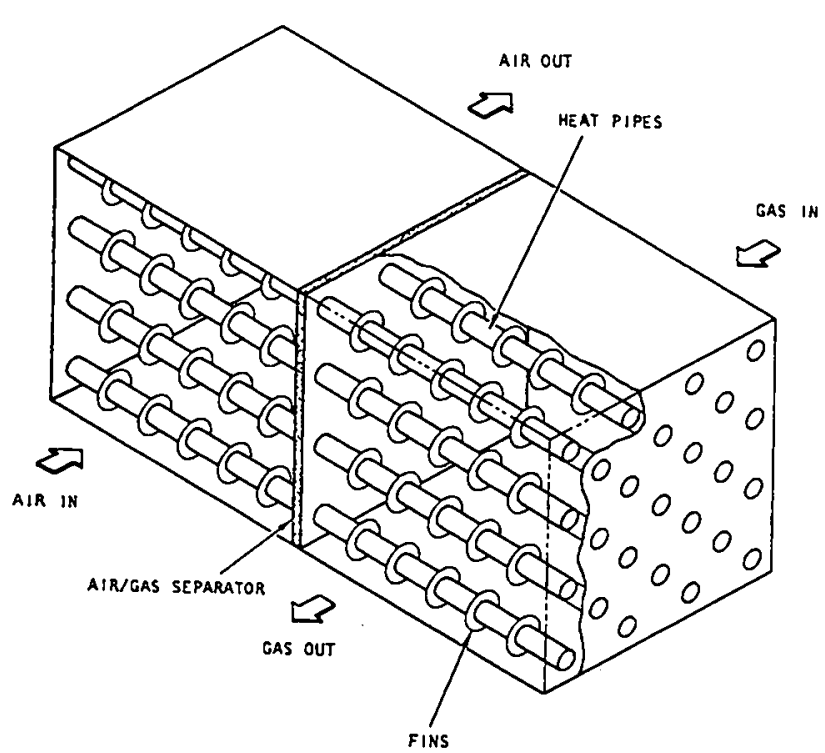

Fig. 64. Crossflow plate-fin heat exchanger construction. 
TABLE XVIII

COST SUMMARY FOR CERAMIC HEAT PIPE SYSTEMS (\$)

Item
Ceramic heat pipes
Ceramic end supports and
central baffle
Metallic recuperator
Assembly labor
Heat pipes
Metallic recuperator
Transition ducting
Insulation
Support structure
Fans
Additional items
Subtotal
A\&E fee
Total cost

$1600^{\circ} \mathrm{F}$ Stee 1 Soaking Pit

53,000

6,800

8,100

1,600

700

7,700

3,100

13,700

9,600

56,000

160,300

24,000

184,300
1600\% Aluminum

Remelt Furnace

$$
51.800
$$

6.700

8,700

1,600
700

6,600

2,600

12,600

49,600

67,300

208,200

31,200

239,400 $2000^{\circ} \mathrm{F}$ Glass

Melting Furnace

64,700

8.300

4,900

2,000

700

6,600

3,300

12,600

17,800

46,400

167,200

25,700

192,300
4. Practical heat pipe geometry for all three furnace applications consisted of $25.4 \mathrm{~mm}$ o.d. tubes with a $3.18 \mathrm{~mm}$ thick wall, $2.44 \mathrm{~m}$ long and having 2 circular fins to the $\mathrm{cm}$. Fins having an average thickness of $1.91 \mathrm{~mm}$ and a height of 6.35 im were used. The tubes were configured in a rectangular bundle on equilateral triangular centers. A transverse spacing (normal to the flow) of $40 \mathrm{~mm}$ and a longitudinal spacing of $35 \mathrm{~mm}$ were used. These tube dimensions are within the present range of manufacturing capability.

5. Potential fuel savings using the waste heat recovery system (summarized in Table $X I X)$ were $43.8 \%$ for the steel soaking pit, $43.4 \%$ for the aluminum remeit furnace, and $57.1 \%$ for the glass melting furnace.

6. The simple payback periods, based on potential fuel cost savings and estimated system costs, were less than six months for all designs, exclusive of specific furnace retrofitting and high temperature burner costs. Payback periods are summarided in Table $X X$. Final configuration for the glass furnace recuperator is shown in Fig. 65.
C. Heat Pipe Engineering (F. C. Prenger and J. E. Kemme, Q-13)

Performance tests were completed on a $0.8-\mathrm{m}$, gravity-assist heat pipe. The test parameters investigated were volume of the working fluid and tilt angle. Two limits have been identified, an entrainment limit which results in overheating of the evaporator wall near its midpoint and a pressure drop limit resulting in overheating at the base of the evaporator. The former is a function of the vapor flow characteristics and was observed to be independent of the liquid volume and tilt angle; whereas the latter is related to the liquid behavior and is strongly related to both the tilt angle and the liquid inventory in the heat pipe.

A schematic of the heat pipe tested is shown in Fig. 66. The outer wall is $25.4 \mathrm{~mm}$ in diam and $1.65 \mathrm{~mm}$ thick. The evaporator is $0.5 \mathrm{~m}$ long and contains 12 thermocouples, ten of wich are 10cated along the bottom of the heat pipe. The condenser is $0.3 \mathrm{~m}$ long and attached directiy to it is a 2-pass, water cooling jacket. The heat pipe wick is composed of 2 layers of 50 mesh screen with a wire diameter of $0.066 \mathrm{~mm}$. Alt materials were stainless steel. Heat was supplied by induction heating of the evaporator wall, and the power transported by the heat pipe was determined using the flowrate and temperature rise of the condenser cooling water. 
Furnace Application

$1600^{\circ} \mathrm{F}$ steel soaking pit

$1600^{\circ} \mathrm{F}$ aluminum remelt furnace

$2000^{\circ} \mathrm{F}$ glass melting furnace
Natural gas

(\$3.20/709 joule)

455,600

539,300

648,300
(\$3.18/70 joule)

451,600

534,500

642,500

TABLE $X X$

1984 SIMPLE PAYBACK PERIOD (YEARS)

Furnace Application

$1600^{\circ} \mathrm{F}$ steel soaking pit

$1600^{\circ} \mathrm{F}$ aluminum remelt furnace

$2000^{\circ} \mathrm{F}$ glass melting furnace
Natural gas

0.40

0.44

0.30

이

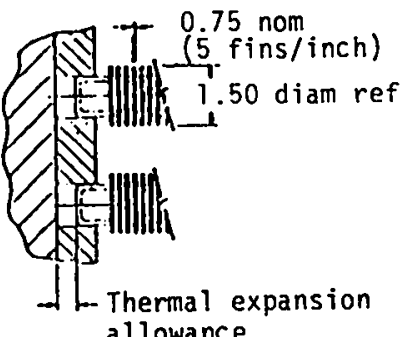

View 0
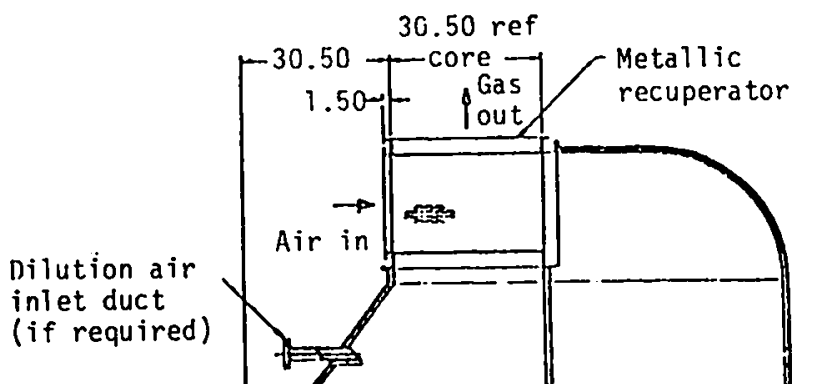

Castable refractory and/or firebrick containment

Furnace interface configuration T.B.D.

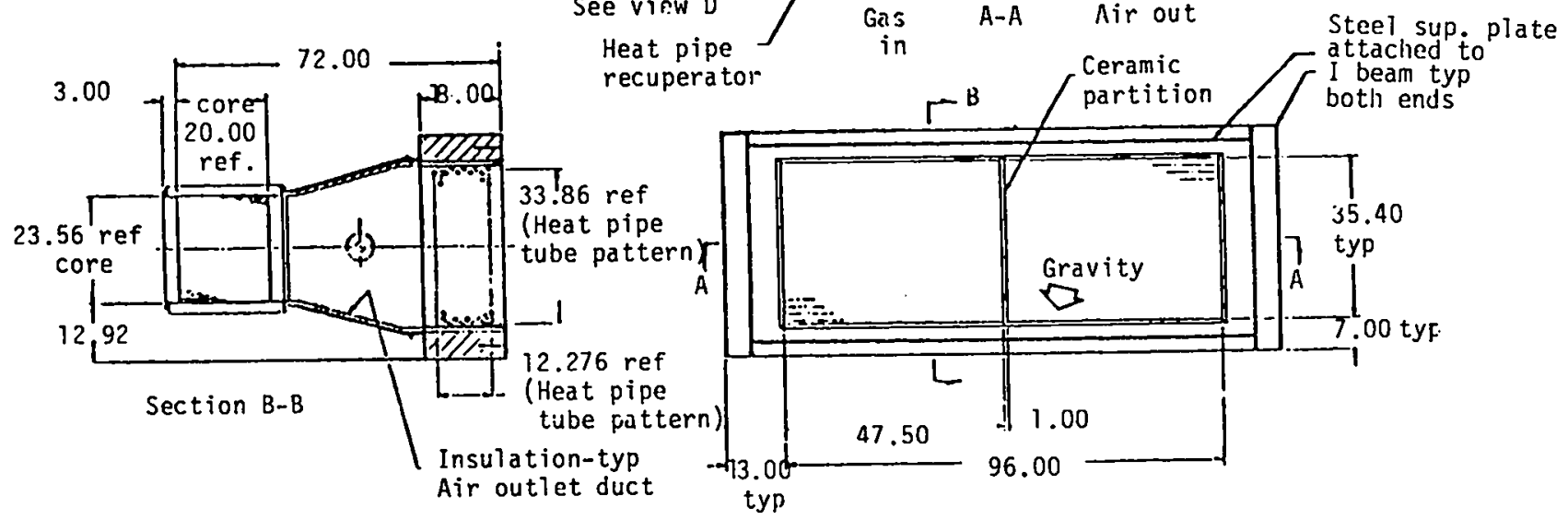

Fig. 65. Ceramic recuperator design concept - glass furnace. 


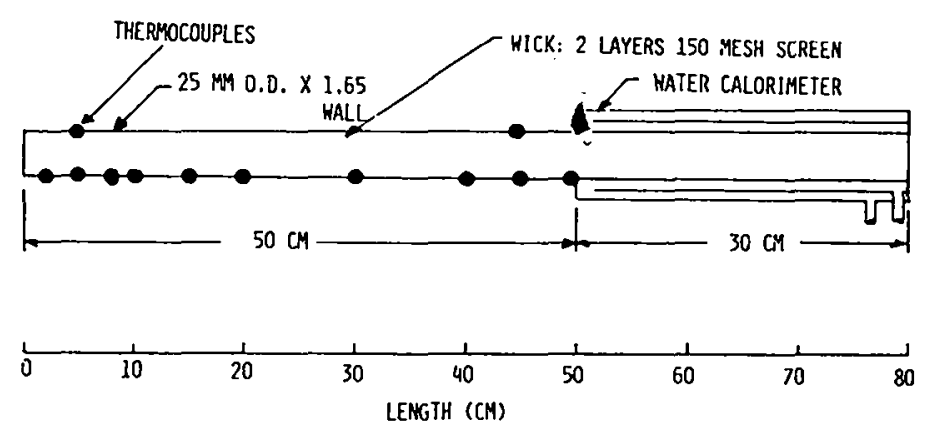

Fig. 66. BES4 heat pipe schematic.

The heat pipe was mounted on a stand with provision to vary the tilt angle between 0 and 90 degrees. Additional working fluid was added between runs at ambient temperature when the heat pipe internal pressure was below atmospheric pressure. Performance 1 imits were obtained by increasing the input power until overheating of the evaporator wall was observed. Two distinct patterns of dryout were observed. At low liquid inventories the bottom of the evaporator would overheat, which was an indication of insufficient circulation of the working fluid. This limit could be increased by adding more working fluid or by changing the tilt angle. The second overheating pattern occurred near the midpoint of the evaporator wall and at much higher liquid inventories. It is believed that this limit results from entrainment of the returning liquid by the vapor strean causing dryout along the evaporator wall. Although there is still sufficient working fluid to form a liquid pool in the evaporator, the vapor-liquid interaction limits the circulation of working fluid in this case.

Three working fluids were investigated at various fill volumes and at various tilt angles. Two of the fluids were organic (toluene and methanol), and the third was inorganic (water). The highest performance was obtained with water; whereas the easiest startup was achieved with methanol. Toulene had the highest operating temperature and extended the temperature range of the test data.

Figure 67 shows the performance data for methanol as a function of tilt angle and working fluid inventory. The volume of the heat pipe exclusive of the wick is $292 \mathrm{~cm}^{3}$. The wick holds an additional $9.5 \mathrm{~cm}^{3}$; therefore, liquid volumes of
106, 155, and $203 \mathrm{~cm}^{3}$ represent approximately one-third, one-half, and two-thirds overfill, respectively. The data indicate improved performance, with a strong maximum at $40^{\circ}$ tilt, with increasing liquid inventory. At a liquid volume of $13 \mathrm{~cm}^{3}$ the maximum performance remains constant but the performance at both low and high tilt angles continues to increase with additional working fluid. At $38 \mathrm{~cm}^{3}$ of working fluid the limit becomes independent of tilt angle but continues to be a weak function of liquid volume. Dryout of the evaporator occurs at its midpoint and the limit is vapor dependent. A similar behavior is observed for water and toulene, Figs. 68 and 69 . For water, however, the entrainment limit begins to decrease at the higher fill levels due to the lower vapor density and, hence, higher velocity required at a given power level.

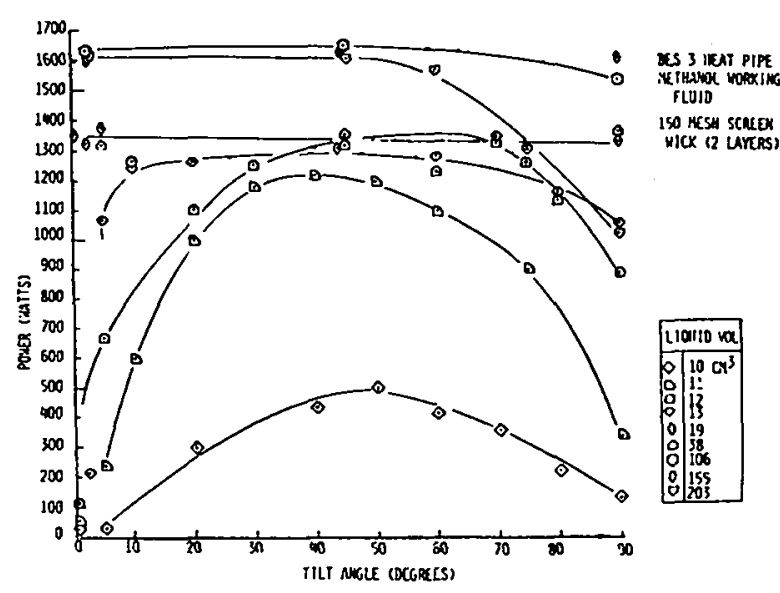

Fig. 67. Heat pipe performance for methanol working fluid. 


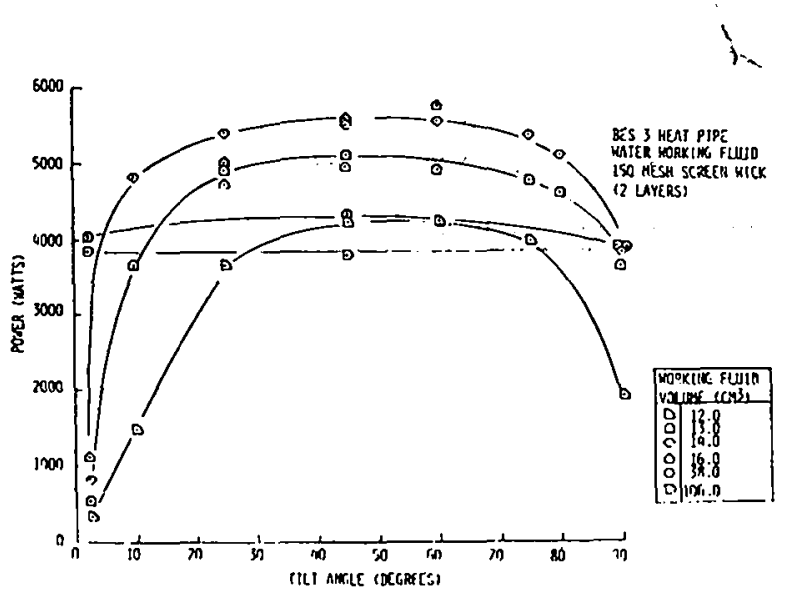

Fig. 68. Heat pipe performance for water working fluid.

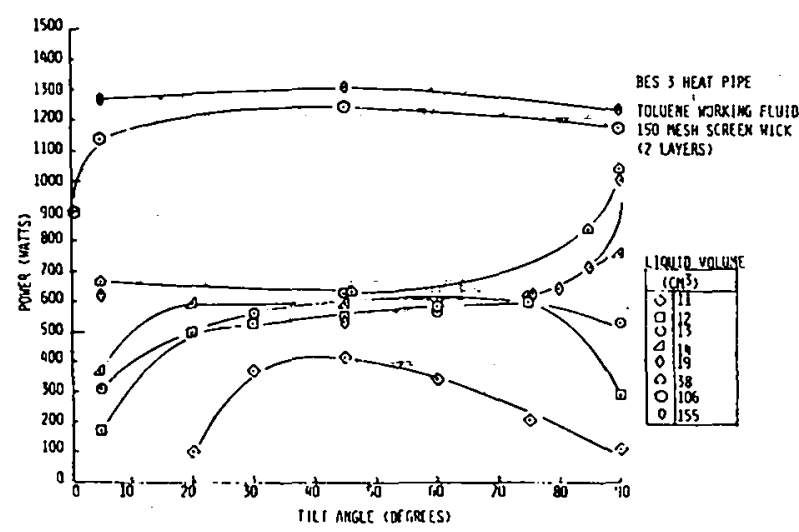

Fig. 69. Heat pipe performance for toulene working fluid.
The data for all working fluids display a maximum near a $45^{\circ}$ tilt angle at low liquid inventories. The increase in performance up to $45^{\circ}$ tilt is expected since the influence of gravity on the liquid return is increasing. However, the decrease in performance at higher tilt angles is unexpected and may be caused by a change in the liquid flow pattern. At low tilt angles the excess liquid may return in a puddle or trough; whereas at higher tilt angles the liquid may distribute itself around the inside of the wick and fall as a thin film. The accompanying large increase in surface area allows for a stronger frictional interaction with both the wick and the counterflowing vapor. This would reduce the liquid flow and also the performance. The tilt angle at which this transition occurs may also be a function of the wick structure.

Some of the data for toulene at low fill levels exhibit contrary behavior. The performance limit increases instead of decreasing at the higher tilt angles. The toulene behavior is similar to both water and methanol at the very low and high liquid volumes but at volumes of 14,19 , and $38 \mathrm{~cm}^{3}$ the opposite trend occurs. Additional tests with the toutene may be required to understand this phenomena.

More tests are planned with liquid metal working fluids and with different wick structures which include knurls and threads. Testing of a 3-m mercury heat pipe with internal threads is currently in progress. Data from this test are expected during the next reporting period. Results from this task, which include the heat pipe computer code, HTPIPE, continue to be used in support of other DOE funded programs. Both pretest and post-test analyses of heat pipes for the SPAR program are accomplished using results from this task. 
V. NUCLEAR CRITICALITY EXPERIMENTS AND SAFETY

A. Executive Summary (E. A. Plassmann, Q-14)

The nanosecond pulsing system has been installed on the Cockcroft-Walton accelerator and is now being tested. When operational, we will have a time-of-flight capability for neutron spectroscopy experiments.

Uranium fuel rings for the Godiva IV burst machine have been aluminum-ion plated in preparation for experiments at the PHERMEX Facility where we hope to measure neutron multiplication in a. dynamic subcritical system. We are evaluating several neutron detectors for this application. A large Hornyak button or a NE102 detector appears to exhibit satisfactory properties.

Preliminary measurements of the reactivity worth of hydrogen in the space reactor, SPAR, mockup have been made. The results will be used to evaluate the criticality hazard of flooding the reactor with water.

Intrinsic radiation measurements are continuing on the 861-3 InRad Unit and we are preparing to look at the 180 InRad Unit inside a Navy Tomahawk missile to verify predictions satisfying military characteristics for the system.

We have completed our measurements of the degradation of radiation attenuation factors for several materials proposed by the Sandia Laboratory for spent-fuel shipping casks. The mockup cask covers had been subjected to design basis accident exposures.

B. Nuclear Criticality Safety

1. Genera) (D. R. Smith, T. P. McLaughlin, E. A. Plassmann, Q-14). Groups CMB-6 and CMB-14 were reviewed for criticality safety procedures. This annual documentation is required by the LASL - Nuclear Safety Committee. No recomnendations were made. During a similar review of the Group CMB-11 Chemical Processing Section, we recommended that the recently activated slag and crucible disolver boxes be posted with fissile material limits and that solution limits on other drop boxes be revised. We also assisted ALO in its biennial criticality safety audits of Groups $M-1$, CMB-1, CMB-5, CMB-14, and the Shops Department. It was recommended that Group CMB-5 bring its internal training/retraining program up to date, and this has been done.
We sent a memorandum to ALO documenting the analysis of drop and fire tests performed by Group CMB 11 on $6 M$ and AL-M6 shipping containers. These are typically used for packaging plutonium dioxide, but for the tests they contained uranium dioxide and the resuits converted to plutonium equivalent. The results have demonstrated that this standard LASL shipping configuration is in compliance with the appropriate regulatory requirements for response to accidents.

Following discussion with Groups $\mathrm{H}-3$ and $0 \mathrm{~S}-2$ on the possible need for radiation alarms in SM-164, we recommended that upgrading a presently installed gamma level monitor was sufficient for this low risk area. SM-164 is adjacent to the former oralloy shop which had an approved criticality alarm system, now deactivated since fissile material operations have been relocated to the Group CMB-6 fissile material machining area.

Plutonium solution limitations were defined for gloveboxes (439 and 440 in room 429, PF-4) used in Group CMB-11 for cleaning plutonium metal pieces and contaminated hardware. The limits generally assure criticality safety for a number of possible operations. Guidance was also provided for current ${ }^{242} \mathrm{Pu}$ recovery procedures.

The one-time use of a crushing and screening dry box at Group CMB-6 for cross-blending UZrC containing up to a total of $3.5 \mathrm{~kg} \mathrm{U}(93)$ was assessed as involving no undue criticality hazard if performed in a specific stainless steel rod mill.

To satisfy requirements of DOE Manual Chapter 0530, we recertified 15 LASL group leaders as being familiar with Laboratory policies regarding nuclear criticality safety and knowledgeable of factors that influence criticality.

Guidance was provided to the DOE Las Vegas Office on general questions concerning the hand ling of weapon components at the Nevada Test Site.

A meeting was convened at LASL to discuss the ultimate disposition of accident debris material presently being stored at the Pantex Plant in Amarillo, TX. Besides the involved LASL personnel from Groups Q-2, Q-14, WX-D0, WX-1, WX-3, WX-5, and $H-D O$, the attendees also included people from the Oak Ridge National Laboratory, Pantex Plant, Rocky Flats Plant, Sandia Laboratories in 
Albuquerque, and DOE offices in Albuquerque and Amarillo. The discussions concerned methods of identification of the material, the criticality'. and radiation safety hazards associated with the present storage, and future action to be taken.

2. Criticality Safety Training (T.P. McLaughlin, D. R. Smith, E. A. Plassmann, Q-14; C. C. Byers, consultant). Two sessions of our twoday Nuclear Criticality Safety Training Course were given during this quarter. The attendees included nineteen LASL employees, two from Sandia Livermore, and one from DOE/ALO at the January 29-30 classes, and fifteen LASL and one from Oak Ridge Y-12 Plant at the March 18-19 session.

Nuclear criticality safety lectures were presented twice each to Groups CMB-11 and WX-3. These talks also satisfy DOE Manual chapter requirements.

3. Calculations of the Critical Mass of ${ }^{242} \mathrm{Pu}$ (T. P. McLaugh 1 in, G. E. Hansen, Q-14). In an effort to resolve differences between baresphere critical mass values for ${ }^{242} \mathrm{Pu}$ calculated by Groups T-2 and Q-14 using different multigroup cross section sets, which were each reduced from the same ENDF-B/V master file, we made hand corrections to the 4 th group values in our 16 group set. The fission threshold occurs in this energy group and due to the original collapsing scheme was suspected of contributing significantly to our differences. This was shown to be the case and we are now in agreement.

4. Review of Administrative Practices in Criticality Safety (D. R. Smith, Q-14). In support of this Nuclear Regulatory Commission funded activity, site visits were made to United Nuclear Corporation's New London, CT, and Wood River Jct, RI, operations; Texas Instrument's Attleboro, MA, plant, and the Savannah River Laboratories. Discussions centering on administrative practices and management philosophy regarding criticality safety as well as site tours were held. A draft document that may become an ANSI Standard was prepared and is being circulated for comments.

5. Weapons Program Support (D. R. Smith, T. P. McLaughlin, G. E, Hansen, E. A. Plassmann, M. B. Diaz, B. Wilson, Q-14). Nuclear safety memoranda were prepared for the Flora and Canfield and Huron King devices.
To aid in the assembly of the RABBIT components, two Group Q-14 members spent two days at the plutonium facility, TA-55, monitoring neutron multiplication and advising Group CMB-1I personnel during operations.

We provided guidance to Group $W X-5$ on several questions of criticality safety while handling Type 73 pits.

Benchmark critical experiments in support of the LASL 186 and Livermore 182 programs have undergone first-round definition and a trip to Livermore was made in this regard. Group CMB-11 will fabricate and assemble the parts and Group Q-14 with both financial and manpower support from Livermore will conduct the experiments. We will concurrently provide calculational analys is with support from Group X-6.

Most of the calculations and ancillary analytical effort have been completed in response to a request from the PANTEX plant for criticality guidance in the handling and storage of numerous, different weapon components containing fissile material. Documentation of this phase of the effort is underway.

C. Honeycomb Assembly

1. Machine Maintenance and Modification ( $R$. A. Pederson, T. P. McLaughlin, Q-14; R. G. Wagner, consultant). One of our operating procedures for critical assembly machines states that there must be at least two independent reactivity shutdown mechanisms. For Honeycomb, safety rod withdrawal and movement of the cart to separate the assembly into two halves satisfies this requirement. During a recent critical experiment with the SPAR mockup, the cart did not move when the SCRAM button was activated. Of course, there was no criticality safety problem since the two independent safety rods did withdraw to provide several dollars of shutdown reactivity. We subsequently determined that the hydraulic cylinder, which moves the cart, was stuck in its fully extended position.

After discussions with the group safety committee, we decided to rotate the cylinder endfor-end and modify the couplings so that now when it is in the fully extended position the cart is also in the SCRAMMED position. This is actually an added safety feature for the machine. The 
hydraulic cylinder was also taken apart and thoroughly cleaned and inspected.

While the machine was shut down for this work, we thought it was a good time to modify the control room operating panel. It is now obvious that only one control rod is being used for this Honeycomb configuration and we also removed several buttons that are no longer functional.

\section{Hydrogen Reactivity Worth in SPAR Space} Reactor Mockup Core (E. A. P lassmann, T. P. McLaughlin, T. F. Wimett, B. Pena, Q-14). A se ries of experiments are being performed to corroborate criticality safety calculations of the SPAR reactor under water flooding conditions.

The reactivity worth of hydrogen in the core of the Honeycomb mockup of the SPAR space reactor $c$ an be found by adding core-length (30.5-cm-long) threads of polyethylene into convenient voids between core materials. A diagram of the present configuration is drawn in Fig. 70. With the control rod fully inserted and no polyethylene in the assembly, i.e., the base loading, the configuration is supercritical and we observe a $10.7 \mathrm{~s}$ e-folding period for leakage neutron generation. Eight strands of polyethylene, weighing a total of $6.72 \mathrm{~g}$, are then added at the center. By measuring the resulting change in positive period, we

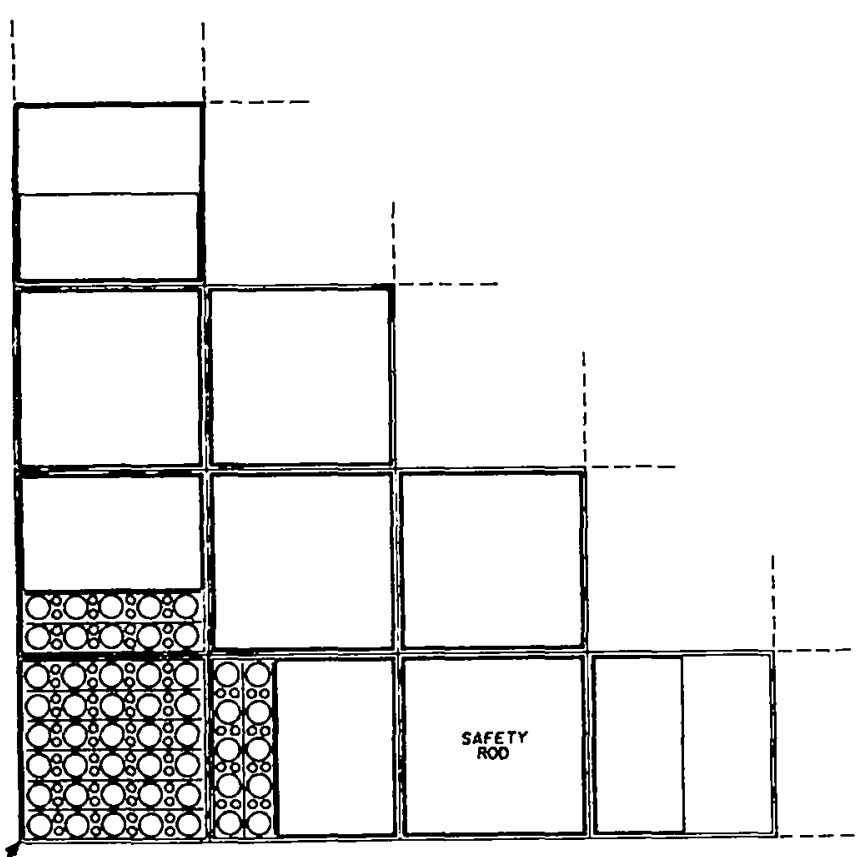
CEnter of core

Fig. 70. Quarter section of Honeycomb SPAR mockup. can infer the reactivity worth of polyethylene at that position. The measurement is then repeated with'the polyethylene inserted at other radial locations.

Our preliminary results are shown in Fig. 71 where the reactivity worth per gram of polyethy 1ene is plotted against radial positon in the core. To be precise, these data should be corrected for the relatively small effect of carbon to yield the reactivity coefficient for the hydrogen alone. The carbon measurements have not yet been made.

D. Godiva IV

1. Machine Maintenance and Modification (R. A. Pederson, T. F. Wimett, Q-14; R. G. Wagner, consultant). In preparation for the experiments at the PHERMEX Facility, the Godiva IV fuel disks, which include newly modified parts, have all been aluminum-ion plated, assembled, and tested for fit into the support clamps. The three central safety block fuel components have been separated from the ir mandrels and will be the next items that are aluminum plated.

We obtained a trailer for housing Godiva controls and it is being fitted with racks for installation of the necessary scram circuits. Control cables are ordered to run from this trailer to the reactor. We are trying to borrow large concrete blocks (about $1 \mathrm{~m}$ thick) from MP Division to assemble a shield house for the reactor at $T A-15$.

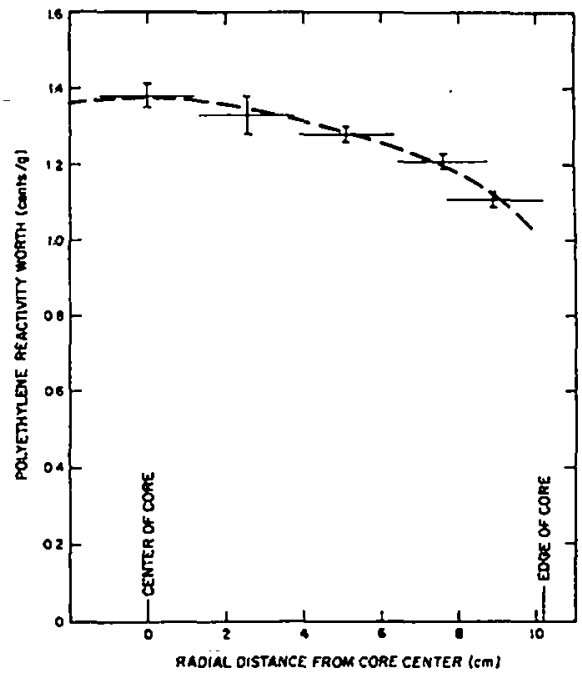

Fig. 71. Polyethylene reactivity in Honeycomb SPAR mockup. 
The new fuel stack has less uranium in order to tolerate the expected additional neutron ret flection from the close concrete walls in this shield house. To assure adequate reactivity control, we will check out Godiva inside the concrete vault of Kiva III to provide similar neutron reflection.

Finally, the assembly machine without the fuel will be connected to the trailer control cable and thoroughly tested before being loaded into the trailer for transport.

2. Detectors for Measurement of Integral Multiplication in Dynamic Subcritical Assemblies (A. E. Evans, R. E. Malenfant, Q-14). It has been proposed that neutrons from a Godiva burst be used to illuminate an exploding subcritical configuration and, by monitoring the neutron output, follow the time history of fission multiplication in the system. We plan to test this concept during a scheduled shot at the PHERMEX facility sometime this summer. Experiments to evaluate the radiological hardness of PHERMEX shielding to Godiva radiation and to determine the general feasibility of the proposed measurements are planned for this spring.

We have already shown that it is possible to measure neutron multiplication in subcritical assemblies when irradiated by Godiva bursts. For those measurements, ${ }^{1}$ fission neutrons were detected using a ${ }^{238} \mathrm{U}$ spiral fission chamber, a 2.5-cm-diam by 1.25-cm-thick Hornyak Button, and a thin NE102 plastic scintillator mounted on an Amperex XP2020 5-cm-diam photomultiplier. The latter assembly was loaned to us by Group J-12. In preparation for the forthcoming tests at PHERMEX, an experimental program is underway to study these and other neutron detectors to select the best one for the proposed application. The detector should have a high sensitivity to fast neutrons and a relatively low sensitivity to background thermal neutrons and to gamma radiation, only a portion of which is proportional to the fission multiplication. The detector also needs to be sufficiently sensitive that a statistically significant number of fast neutrons are detected during the time interval that is to be resolved.

During this reporting period, three detectors have been studied; a high-pressure $5-\mathrm{cm}$ by $10-\mathrm{cm}$
${ }^{4}$ He-recoil scintillator ${ }^{2}$ mounted on an Amperex XP-2000 photomultiplier, a 12.5-cm-diam by 1.25-cm-thick Hornyak Button on an RCA 4525, and a thin NE102 plastic scintillator mounted on an Amperex XP-2020. The latter of these is the "Photomultiplier" systern used in the preliminary measurements of Ref. 1. We can therefore predict the absolute output levels of the new detectors by comparison with the results given in Table 1 of the reference.

Our plan is to use the multiplication detectors in a current measuring mode, i.e., to observe the envelope of detector pulses as a single oscilloscope trace that will give us a direct measure of the neutron activity in the subcritical assembly. This is instrumentally a much simpler approach than to use ultrafast circuitry to detect and count individual pulses and a fast time analyzer or multichannel scaler to measure the time dependence of the counting rate. In keeping with the concept of current mode operation, the detectors were tested by measuring their dc anode currents under various steady-state conditions.

The detectors were operated with voltage dividers designed to provide high negative voltage at their cathodes, leaving the anodes at ground potential. This permitted direct connection to the input of a Keithly model 417 picoammeter to measure anode currents. Photomultiplier voltages were selected for optimum pulse-mode operation.

The detectors were tested under the following conditions:

(1) Dark current (no radiation present).

(2) $A{ }^{241} A m-B e$ neutron source with a strength of $2.2 \times 10^{5}$ neutrons/s directly against the front face of the detector.

(3) A $5-\mathrm{mCi}^{60} \mathrm{Co}$ source $30 \mathrm{~cm}$ from the front face of the detector, which gives a measured dose $50 \mathrm{mR} / \mathrm{h}$ rate at the detector.

Results listed in Table XXI indicate the ${ }^{4}$ He-recoil scintillator would be inferior to the NE102 scintillator for this application, but that the large Hornyak button is superior to both of these in neutron sensitivity and in relative neutron-to-gamma ray sensitivity ratio. We note that all of these detectors lose much of their 
TABLE XXI

DC RESPONSE OF SCINTILLATION NEUTTRON DETECTORS

\begin{tabular}{|c|c|c|c|}
\hline${ }^{4}$ He-recoil & Scintillator & 12.5-cm-Hornyak Button & 5-Cm NE102 \\
\hline Photomultíplier & $X P 2000$ & RCA4525 & XP2020 \\
\hline \multirow[t]{2}{*}{ Cathode Voltage (V) } & -1500 & -1300 & -2000 \\
\hline & \multicolumn{2}{|r|}{ Anode Current, (A) } & \\
\hline Dark Current & $0.20 \times 10^{-9}$ & $0.1 \times 10^{-8}$ & $0.05 \times 10^{-9}$ \\
\hline With Neutron Source & $0.46 \times 10^{-9}$ & $0.85 \times 10^{-7}$ & $0.12 \times 10^{-7}$ \\
\hline $\begin{array}{l}\text { With } 50 \mathrm{mR} / \mathrm{h}{ }^{60} \text { Co source } \\
\text { Net Current, Neutron Source }\end{array}$ & $\begin{array}{l}0.45 \times 10^{-8} \\
0.26 \times 10^{-9}\end{array}$ & $\begin{array}{l}0.18 \times 10^{-6} \\
0.84 \times 10^{-7}\end{array}$ & $\begin{array}{l}0.35 \times 10^{-1} \\
0.12 \times 10^{-7}\end{array}$ \\
\hline Net Current, Gamma Source & $0.43 \times 10^{-8}$ & $0.18 \times 10^{-6}$ & $0.35 \times 10^{-7}$ \\
\hline $\mathrm{n} /$ (relative) & 0.06 & 0.47 & 0.34 \\
\hline Relative Neutron Sensitivity & 0.02 & 7.0 & 1.00 ref. \\
\hline n/Dark Current & 21.5 & 85 & 240 \\
\hline Reference Godiva Burst Level (Ref 1) & & & $8 \times 10^{-3} \mathrm{~A}$ \\
\hline Predicted Level & $1.7 \times 10^{-4} \mathrm{~A}$ & $5 \times 10^{-2} A$ & \\
\hline
\end{tabular}

discrimination against gamma radiation when used in this manner. When one uses these detectors to count pulses from individual neutron or gamma-ray events, a discriminator can cut out the relatively low-amplitude gamma-induced pulses, thereby making the detectors virtually garma insensitive.

By employing the transient-digitizing equipment available at PHERMEX to measure the time dependence of the output pulse, either the large Hornyak Button or the NE102 should give satisfactory results for the planned fissionmultiplication time-dependence experiment.

3. Fission-Density Distribution Measurements with Godiva (A. E. Evans, R. E. Malenfant, Q-14). In our previous progress report, a proposed experiment was described which would apply fast-neutron hodoscope technology to the measurement of fission distribution in dynamic subcritical assemblies. The technique would involve the use of a multi-slot collimator to measure the time and spatial distribution of neutron output from the test device. A two-slot collimator, shown in Fig. 72, has been built for use in preliminary experiments. This collimator is now installed in the wall of the Kiva-III shielded instrumentation room.

A remotely operable precision movable table was constructed to permit simulation of fuel motion. This table, shown in Fig. 73, will be used to test system resolution by moving samples of fissionable material between successive bursts of Godiva. It was built from avallable components and is actuated by the existing stepping-motor controller that has been used with the scanning Hodoscope and fuel-motion actuators for the PARKA critical assembly.

We are planning to do some preliminary experiments to test our concept during the period when Godiva is being tested after reassembly. E. SKUA

Flux Trap Reactivity Considerations (T. F. Wimett, Q-14). Although the originally proposed applications for Skua were to provide short intense puises of thermal neutrons within the central flux trap, we also have the option of supplying intense bursts of fast neutrons in the large cavity ( $240 \mathrm{~mm}$ diam by $300 \mathrm{~mm}$ high) when the flux trap is removed. Operation under these conditions requires additional reactivity control. Consideration of this mode of operation has now been added to the reactor safety analysis.

To better estimate assembiy parameters with all or part of the flux trap removed, we made some neutron transport calculations that had the boral, cadmium, and uranium carbide liners in place but added various thicknesses of the moderator annuTus. Because of these thermal neutron absorbers, any neutron moderator inside the cavity was expected to behave as a reactivity poison. However, 


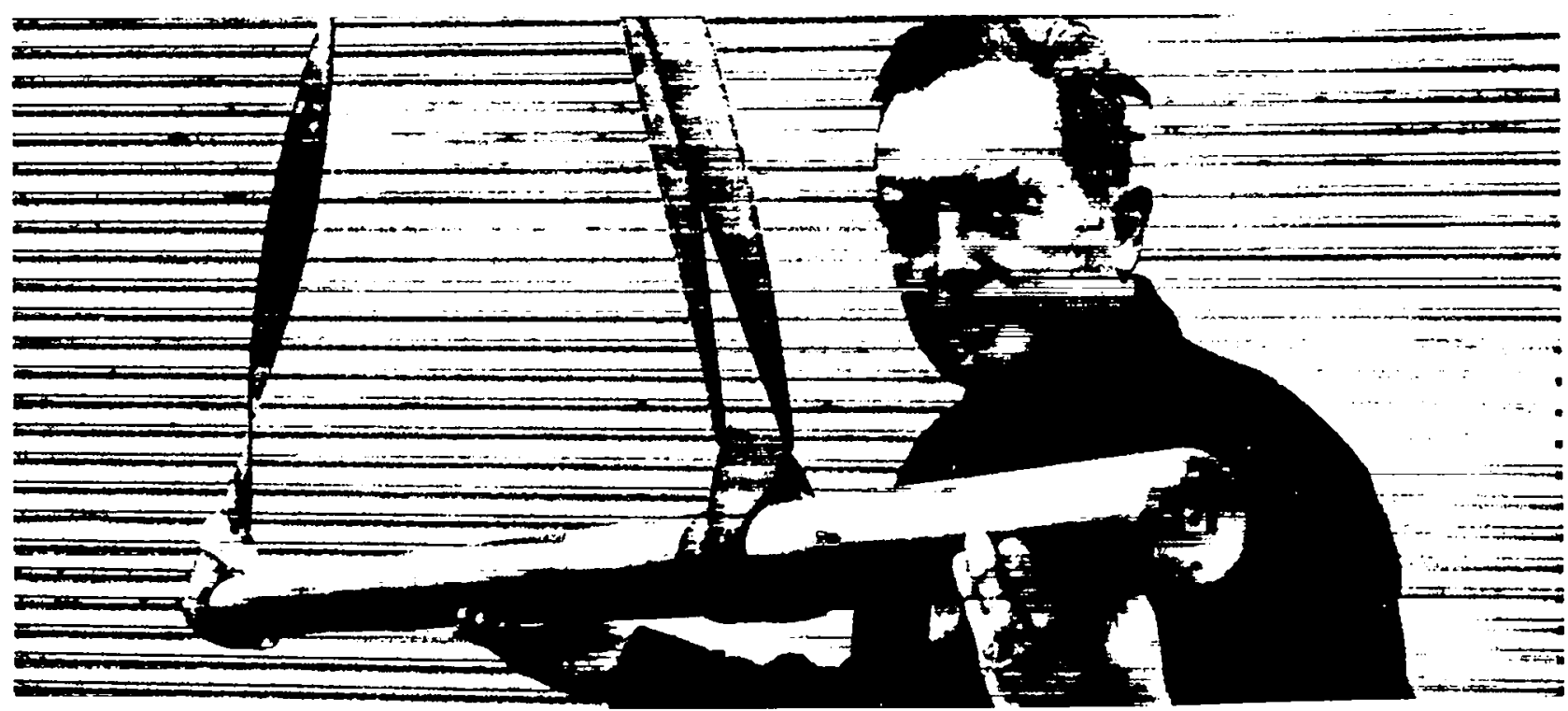

Fig. 72. Collimator for fission distribution measurements.

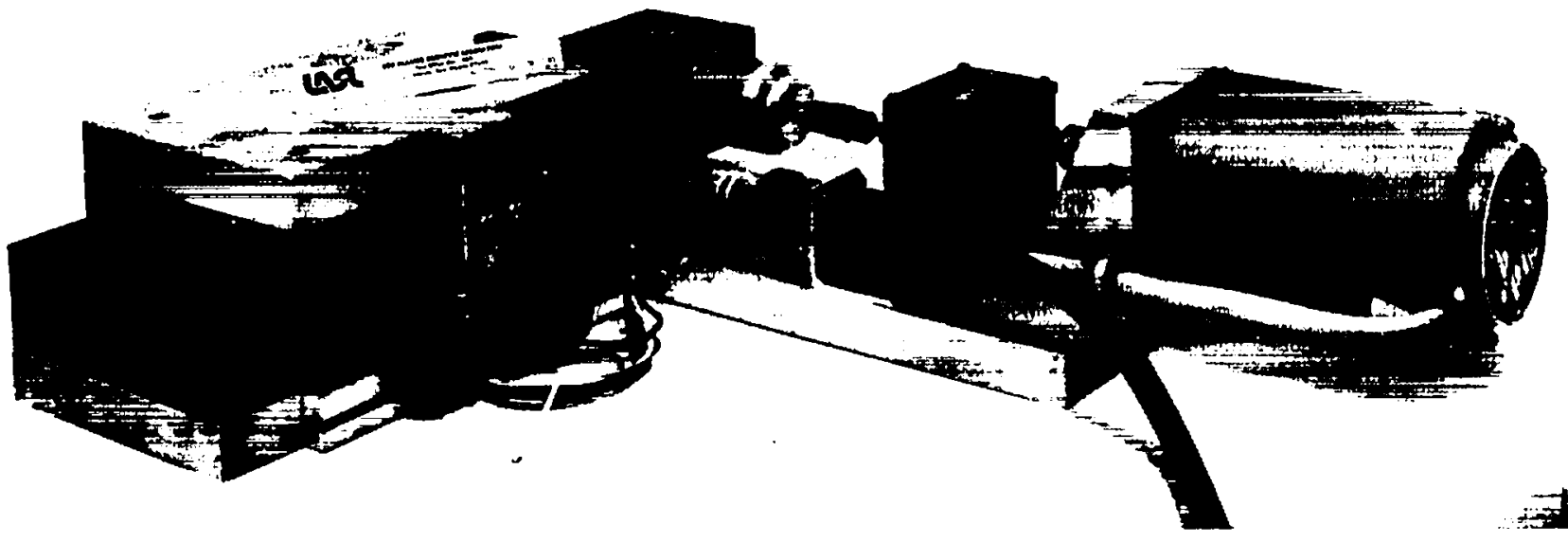

Fig. 73. Table for moving fissile sample by remote control.

results of the calculations indicate that this is not always the case, as illustrated in Fig. 74 where reactivity change is plotted against thickness of annular polyethylene moderator. Clearly, the first $5 \mathrm{~mm}$ increases reactivity owing to simple scattering of fast neutrons. The $14 \$$ increase in reactivity predicted for removal of the standard moderator (46 $\mathrm{mm}$ thickness) cannot be accommodated by existing control rods. Our early critical experiments have shown that such reactivity adjustment is readily accomplished by merely replacing a selected fuel disk by one of normal uranium.
A measure of the effect of polyethylene moderator in thermalizing the central neutron flux is illustrated in Fig. 75 which shows the abundance of neutrons in the "thermal" group (below $0.1 \mathrm{eV}$ ) plotted on a logarithmic scale as a function of polyethylene thickness.

F. Cockcroft-Walton Accelerator

Machine Modifications (A. E. Evans, A. R. Brown, M. B. Diaz, $(-14)$. We are endeavoring to reactivate a nanosecond pulsing system on the accelerator that will give us a time-of-flight capability for neutron spectroscopy. This system has now been completely renovated and reinstalled 


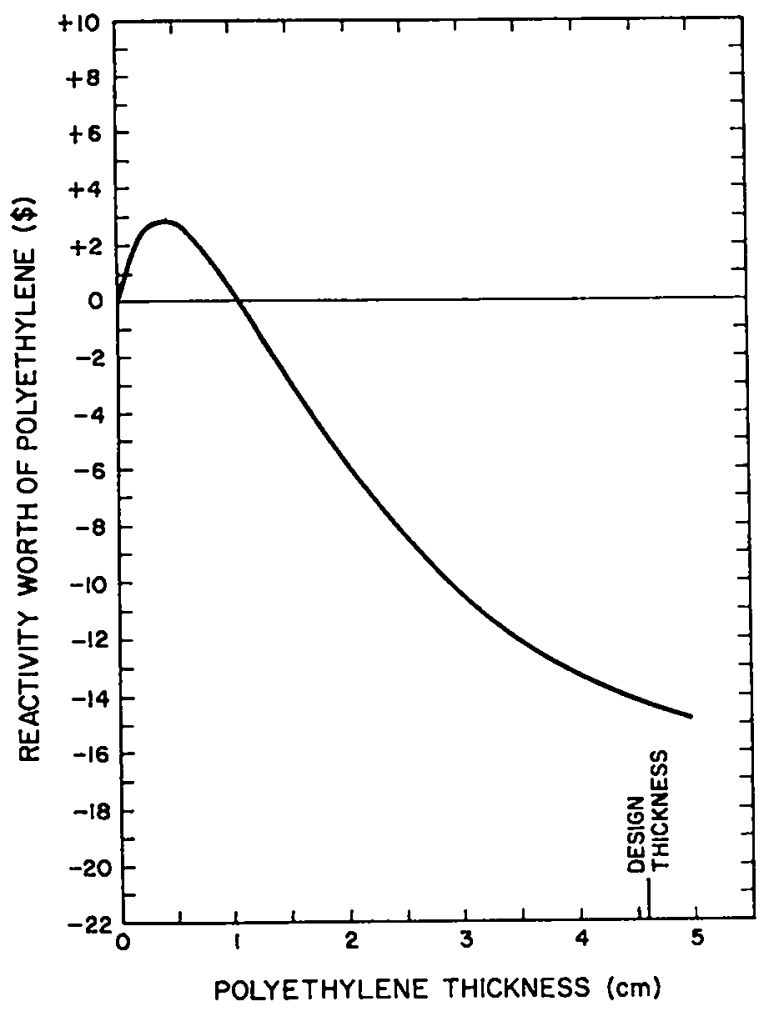

Fig. 74. Polyethylene effectiveness in Skua flux trap.

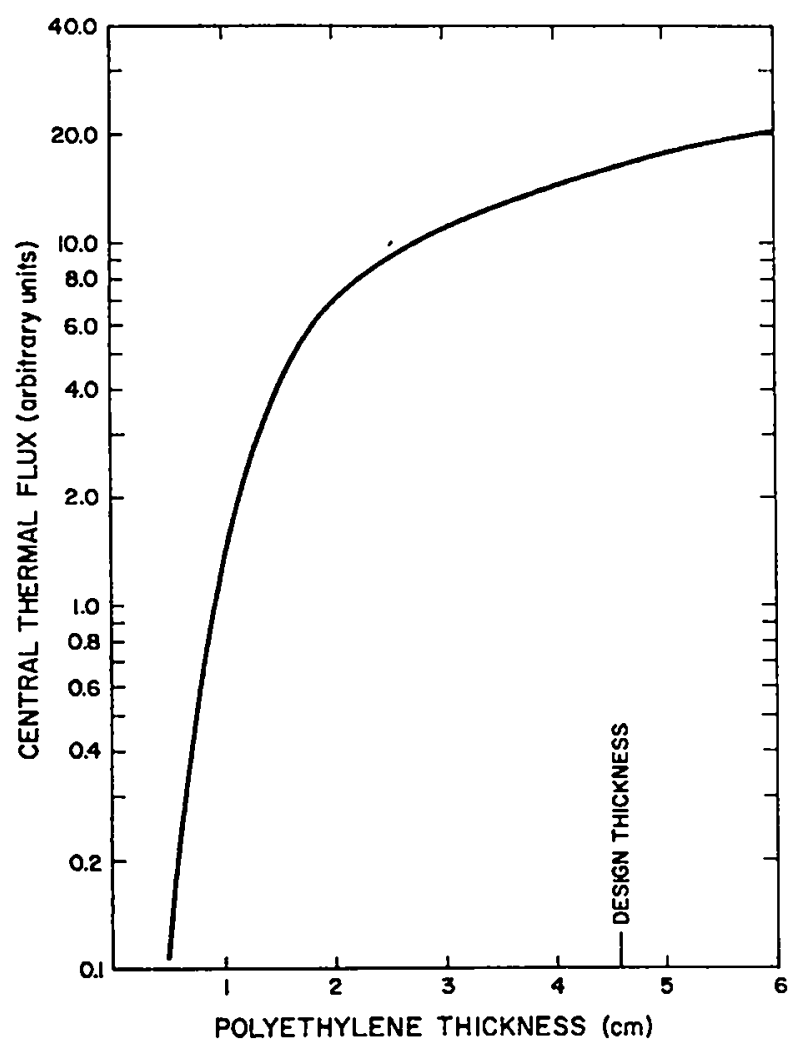

Fig. 75. Thermal neutron flux in Skua cavity. in the terminal of the machine. Prior to installation, when the electronic circuitry was being bench-tested we found unwanted self-oscillation in the high-voltage pulser that drives the preacceleration deflection plates. This problem was corrected by relocating the input connector to eliminate feedback from the output of the chassis. To improve reliability the type 866 mercury-vapor rectifiers that had been used in the 2500-V final-stage plate supply for the pulser were replaced with solid-state rectifiers. Considerable work was also required to rebuild mountings for the pulsing system, all of which floats at the potential of the beam extractor, some 15-30 $k V$ below the base voltage of the accelerator terminal in which it is housed.

Preliminary tests of the terminal nanosecond pulser indicate that it is working, but we currently lack instrumentation to observe the 10-nswide beam pulses with good fidelity in the control room. Operating at a pulse repetition rate of $15.6 \mathrm{kHz}$ should give us an average beam current on target of about $1.6 \times 10^{-4}$ of the peak beam current. Tests were run using 200 ua of beam current measured on target with the accelerator operating in the dc mode. When the pulsing system was actuated, we measured a target current of on 1 y 3 $\mathrm{nA}$, or $1.5 \times 10^{-5}$ of the peak current, indicating that $90 \%$ of the beam that should have been available in the pulse was being lost. Further testing will be necessary to resolve this problem before proceeding to the next step; installation of a fiber optic external control for the terminal pulser and integration of the post-acceleration buncher into the system.

G. "INRAD" Measurements of LASL Weapons

1. B61-3 INRAD Unit (R. A. Pederson, E. A. Plassmann, B. Pena, Q-14). Preliminary values of the intrinsic radiation from the B61-3 InRad Unit are reported as a maximum of $0.52 \mathrm{mrem} / \mathrm{h}$ neutron and $0.44 \mathrm{mR} / \mathrm{h}$ garmma dose rates. These were measured with our previously used ${ }^{(3)}$ radiationinduced pulse counting systems at $61 \mathrm{~cm}(2 \mathrm{ft})$ from the center of the pit perpendicular to the axis of the unit. The gamma dose rate is somewhat lower than that inferred from the unfolded photon 
spectrum obtained with the Group P-2 NaI spectrometer. We are repeating the measurements in an, attempt to reconcile the differences.

2. W80 InRad Unit in Tomahawk Missile (E. A. Plassmann, Q-14). Preparations are underway to obtain a complete Tomahawk Missile into which we can insert the W80 InRad Unit for intrinsic radiation dose rate measurements. With the warhead inside the missile, the surrounding structure and rocket fuel is expected to significantly reduce the external dose rates. Our purpose is to evaluate this attenuation and verify predictions that would satisfy the military characteristics (MC's) specified for the system.

H. Sandia Shipping Cask Evaluation

Attenuation Factor Degradation from Simulated Accident Exposures (R. A. Pederson, E. A. Plassmann, $Q-14$ ). Our evaluation of the several materials proposed by the Albuquerque Sandia Laboratory (SLA) for their Breeder Reactor SpentFuel Shipping Cask Program is continuing. We previously reported ${ }^{(4)}$ neutron and gamma-ray attenuation factors for four covers each of three different materials (twelve covers total) for an experimental mockup cask. Several of the covers were returned to SLA and subjected to design basis accident environments. Two of these had been sent back to us for remeasurement, and the degradation in their attenuation properties because of the simulated accident exposure were subsequentiy reported. (5)

We finaliy received four others of the exposed covers and our measurements of their attenuation factors is now complete. In order to correlate these with the original results, our experimental procedure has remained unchanged. A strong ${ }^{252} \mathrm{Cf}$ source is centered inside the cask mockup and then we measure the dose rates at several distances both for the cask open and with the cover in place. Figure 76 is a photograph of the experimental setup in the experimental bay of Building 127 (TA-18) and shows the recently fabricated linear track for automatically positioning the detectors at the proper distances in front of the cask covers.

The dose rates measured for the four shield covers both before and after the simulated accident exposures are listed in Table XII. The "letter" designations correspond to the listings in Ref. 4. The present data is corrected for source decay back to November 5, 1978, which is the reference date for the previous results.

Attenuation factors obtained from these data are shown in Table XXIII, which also gives values obtained before the exposure and the degradation ratio to show how badly the covers were damaged.

The boron-silicone cover " $A$ " is noted to be the most severely effected by the "accident." Its ability to shield neutrons was degraded by $90 \%$. The damage is clearly evident in Fig. 77 which is a photograph of this cover after its fire exposure.

The covers borated beechwood " $D$ " and NS-I " $\mathrm{J}$ " were also severely damaged, each losing about $80 \%$ in neutron shielding. The photograph of Fig. 78 shows that the borated beechwood at least maintained its general integrity during the "accident."

Best preserved was the boro-silicone cover " $H$ " shown in Fig. 79 seated in the mockup shipping cask. This cover was only degraded to $2 / 3$ rds of its original neutron and gama attenuation factor. The simulated accident for this cover was not as severe as the similar material cover " $A$ " received.

\section{PUBLICATIONS}

LA Report

H. C. Paxton, "Experimental Criticality Specifications, Update through 1979." Los Alamos Scient if ic Laboratory report LA-7170-MS, Supp 1. (February 1980).

\section{Journal Publication}

A. E. Evans, "Garma-Ray Response of a 38-mm Bismuth Germinate Scintillator," IEEE Transactions on Nuclear Science, NS-27, No. 1, pp 172-175 (February 1980).

\section{REFERENCES}

1. Q-14-78-900, Group Q-14 Quarter ly Progress Report October 1-December 31, 1978, "Evaluation of the Godiva Burst Reactor for Use in PHERMEX," R. E. Malenfant, R. A. Pederson, T. F. Wimett, R. G. Wagner, Albert E. Evans, pp 10-11.

2. A. E. Evans and J. J. Malanify, "4he Gas Scintillator for Prompt-Neutron Fissile Assay of Small Samples," Nuclear Analysis Research and Development Program Status Report September-December 1974, report LA-5889-PR (ApriT 1975) p.23. 
3. Q-14-305, Group Q-14 Quarterly Progress Report October 1-December 30, 1977, "InRad

Measurements on the W76," E. A. Plassmann, A. E. Evans, R. A. Pederson, and C. H. Reed, pp 8-12.

4. 0-14-79-116, Group 0-14 Quarter ly Progress Report January 1-March 31, 1979, "Measurement of Attenuation Factors," R. A. Pederson and E. A. Plassmann, pp 29-35
5. Q-14-79-308, Group Q-14 Quarter 1y Progress Report July 1-September 30, 1979, "Degradation fof Attenuation Factors from Simulated Accident Exposure," R. A. Pederson, E. A. Plassmann, R. E. Malenfant, A. R. Brown, B. G. Pena, pp 31-33.

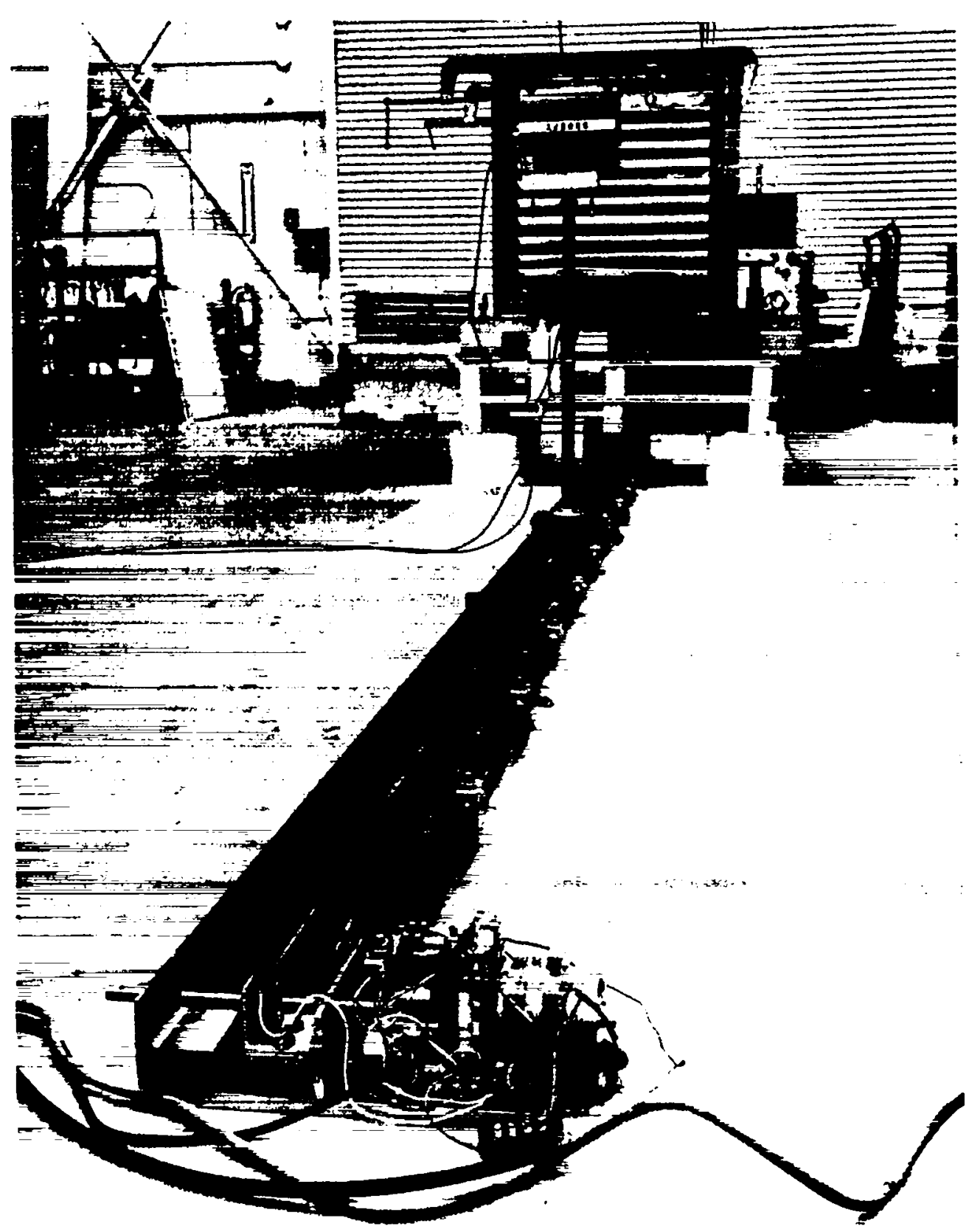

Fig. 76. Automatic linear positioning system for radiation detectors. 


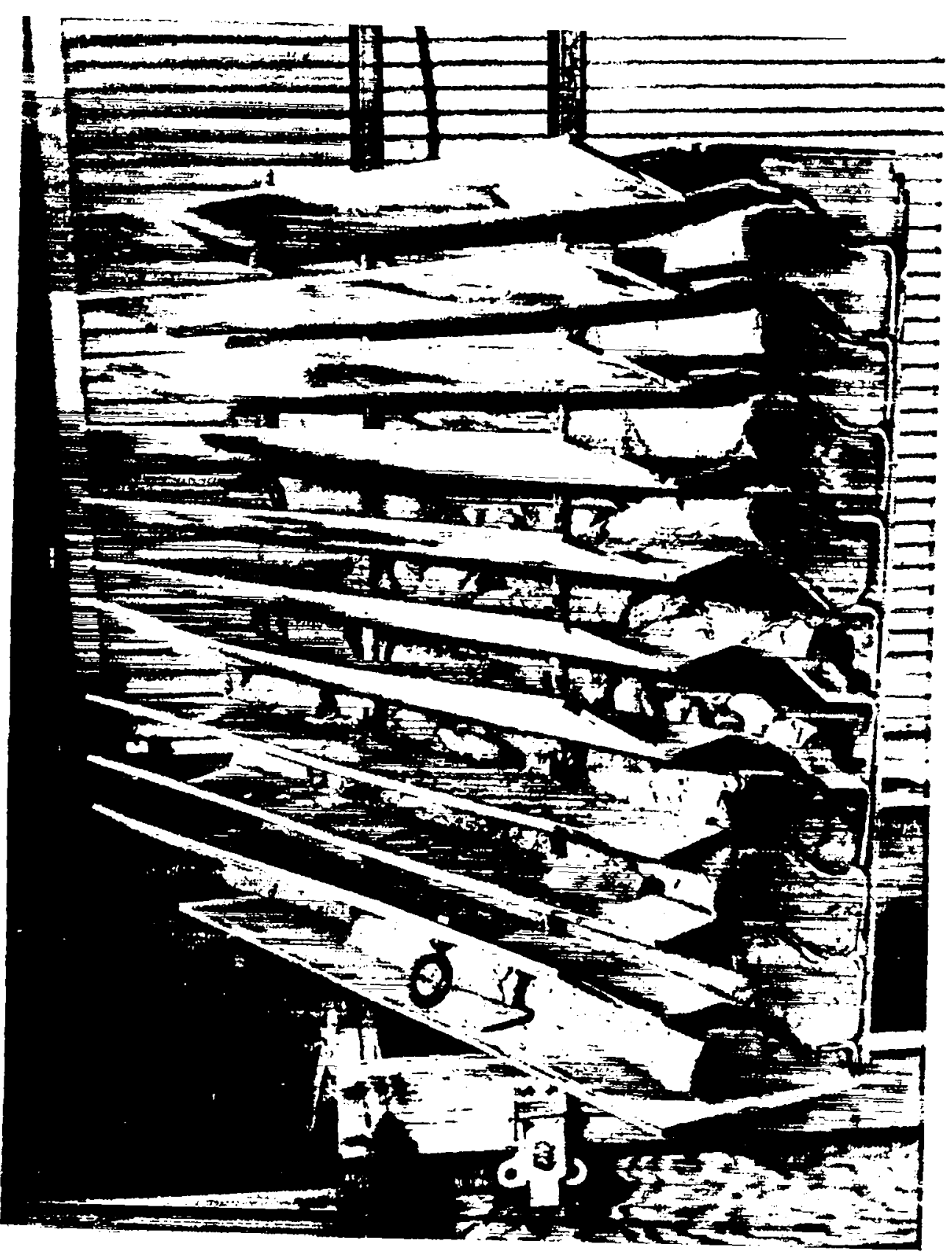

Fig. 77. Boro-silicone cask cover "A" after exposure. 
TABLE XXII

$$
\begin{aligned}
& \text { SANDIA CASK ATTENUATION FACTORS } \\
& 253 \mathrm{c}, \mathrm{f}\left(\mathrm{Q}=1.668 \times 10^{8} \mathrm{~N} / \mathrm{s}\right. \text {, on 2-28-80) }
\end{aligned}
$$

\begin{tabular}{|c|c|c|c|c|c|c|c|c|c|c|c|c|c|c|c|}
\hline \multirow[b]{2}{*}{ Materíal } & \multicolumn{3}{|c|}{$100 \mathrm{~cm}$} & \multicolumn{3}{|c|}{$200 \mathrm{~cm}$} & \multicolumn{3}{|c|}{$300 \mathrm{~cm}$} & \multicolumn{3}{|c|}{$400 \mathrm{~cm}$} & \multicolumn{3}{|c|}{$500 \mathrm{~cd}$} \\
\hline & N & $\gamma$ & $N+\gamma$ & N & $\gamma$ & $N+\gamma$ & N & $r$ & $H+\gamma$ & N & $\gamma$ & $N+\gamma$ & N & $\gamma$ & N+ \\
\hline \multicolumn{16}{|l|}{ Boro-Silcone (A) } \\
\hline Before Exposure & 18.5 & 3.8 & 22.3 & 4.4 & 1.0 & 5.4 & 1.9 & 0.46 & 2.36 & 1.1 & $(0.27)$ & 1.4 & $(0.71)$ & $(0.17)$ & 0.9 \\
\hline After Exposure & 164.25 & 5.6 & 169.85 & 37.2 & 1.4 & 38.6 & 15.9 & 0.67 & 16.6 & 8.8 & 0.39 & 9.2 & 5.8 & 0.27 & 6.1 \\
\hline \multicolumn{16}{|l|}{ Boro Sllicone (H). } \\
\hline Before Exposure & 17.3 & 3.5 & 20.8 & 3.8 & 0.89 & 4.7 & (1.8) & $(0.42)$ & 2.2 & 1.1 & 0.24 & 1.3 & $(0.65)$ & $(0.15)$ & 0.8 \\
\hline After Exposure & 28.1 & 4.2 & 32.3 & 6.1 & 1.07 & $7 . ?$ & 2.8 & 0.50 & 3.3 & 1.6 & 0.28 & 1.9 & 1.1 & 0.19 & 1.3 \\
\hline \multicolumn{16}{|l|}{ Borated Beechwond $(0)$} \\
\hline Before Exposure & 18.1 & 4.4 & 22.5 & 4.3 & 1.3 & 5.6 & 1.9 & 0.53 & 2.4 & 1.1 & $(0.32)$ & 1.4 & $(0.67)$ & $(0.20)$ & 0.9 \\
\hline After Exposure & 76.6 & 6.3 & 82.9 & 17.2 & 1.7 & 18.9 & 7.7 & 0.78 & 8.5 & 4.5 & 0.46 & 5.0 & 3.0 & 0.28 & 3.3 \\
\hline K5-1 & & & & & & & & & & & & & & & \\
\hline Before Exposure & 27.8 & 3.5 & 31.3 & 5.7 & 1.0 & 6.70 & 2.5 & 0.45 & 3.0 & 1.5 & 0.26 & 1.8 & $(0.88)$ & $(0.17)$ & 1.1 \\
\hline After Exposure & 130.1 & 7.1 & 137.2 & 19.0 & 1.9 & 25.9 & 12.4 & 0.88 & 13.3 & 7.1 & 0.54 & 7.6 & 4.9 & 0.35 & 5.2 \\
\hline
\end{tabular}

TABLE XXIII

MEASURED DOSE RATES FOR SANDIA SHIPPING CASK COVERS

NEUTRON \& GAMMA (mrem/hr)

\begin{tabular}{|c|c|c|c|c|c|c|c|c|c|c|c|c|c|c|c|}
\hline \multirow[b]{2}{*}{ Material } & \multicolumn{3}{|c|}{$100 \mathrm{~cm}$} & \multicolumn{3}{|c|}{$200 \mathrm{~cm}$} & \multicolumn{3}{|c|}{$300 \mathrm{ct}$} & \multicolumn{3}{|c|}{$400 \mathrm{~cm}$} & \multicolumn{3}{|c|}{ Average } \\
\hline & $x$ & $r$ & $N+Y$ & N & $Y$ & $M+Y$ & $N$ & $y$ & $n+\gamma$ & N & $\gamma$ & $\boldsymbol{N}+\boldsymbol{Y}$ & $n$ & $\gamma$ & $\mathrm{M}+\mathrm{Y}$ \\
\hline \multicolumn{16}{|l|}{ Boro-Stilicone (A) } \\
\hline Before Exposure & 15.4 & 5.5 & 13.7 & 16.8 & 5.7 & 14.7 & 18.0 & 5.6 & 15.6 & 18.4 & 6.0 & 15.6 & & & \\
\hline After Exposure & 1.6 & 3.6 & 1.8 & 1.8 & 3.5 & 2.1 & 1.9 & 3.3 & 2.2 & 2.0 & 3.4 & 2.4 & & & \\
\hline Ratio After/Before & 0.10 & 0.54 & 0.13 & 0.11 & 0.61 & 0.14 & 0.08 & 0.60 & 0.14 & 0.09 & 0.57 & 0.15 & 0.10 & 0.56 & 0.14 \\
\hline \multicolumn{16}{|l|}{ Boro-Silcone $\quad(H)$} \\
\hline Before Exponsure & 16.5 & 6.0 & 14.7 & 19.4 & 6.9 & 16.9 & 19.0 & 6.1 & 16.7 & 18.4 & 6.7 & 16.8. & & & \\
\hline After Exposure & 9.5 & 4.8 & 9.5 & 11.1 & 4.6 & 11.1 & 11.1 & 4.2 & 11.2 & 11.0 & 4.7 & 11.5 & & & \\
\hline Rat in After/Before & 0.57 & 0.80 & 0.54 & 0.57 & 0.72 & 0.65 & 0.58 & 0.69 & 0.67 & 0.60 & 0.70 & 0.68 & 0.58 & 0.73 & $0 . € 6$ \\
\hline \multicolumn{16}{|l|}{ Borated Beechwood (0) } \\
\hline Before Exposure & 15.8 & 4.8 & 13.6 & 17.2 & 4.4 & 14.2 & 18.0 & 4.8 & 15.4 & 18.4 & 5.1 & 15.6 & & & \\
\hline After Exposure & 3.5 & 3.2 & 3.7 & 4.0 & 2.0 & 4.2 & 4.0 & 2.8 & 4.3 & 4.1 & 2.9 & 4.4 & & & \\
\hline Rat io After/Before & 0.22 & 0.67 & 0.27 & 0.23 & 0.68 & 0.30 & 0.22 & 0.58 & 0.28 & 0.22 & 0.57 & 0.28 & 0.22 & 0.63 & 0.28 \\
\hline \multicolumn{16}{|l|}{$K 2-1 \quad(2)$} \\
\hline Before Exposure & 10.3 & 6.0 & 9.8 & 13.0 & 5.7 & 11.9 & 13.7 & 5.7 & 12.3 & 13.5 & 6.2 & 12.1 & & & \\
\hline After Exposure & 2.0 & 2.8 & 2.2 & 2.1 & 2.6 & 3.1 & 2.5 & 2.5 & 1.8 & 2.5 & 2.4 & 2.9 & & & \\
\hline Rat in After/Bnfore & 0.19 & 0.47 & 0.23 & 0.18 & 0.16 & 0.26 & 0.18 & 0.44 & 0.15 & 0.18 & 0.29 & 0.24 & 0.18 & 0.44 & 0.22 \\
\hline
\end{tabular}

$$
\begin{aligned}
{ }^{252} \mathrm{Cf}(Q & \left.=1.668 \times 10^{8} \mathrm{~N} / \mathrm{s} \text { on } 2-26-80\right) \\
(Q & \left.=2.237 \times 10^{8} \mathrm{~N} / \mathrm{s} \text { on } 11-5-78\right)
\end{aligned}
$$




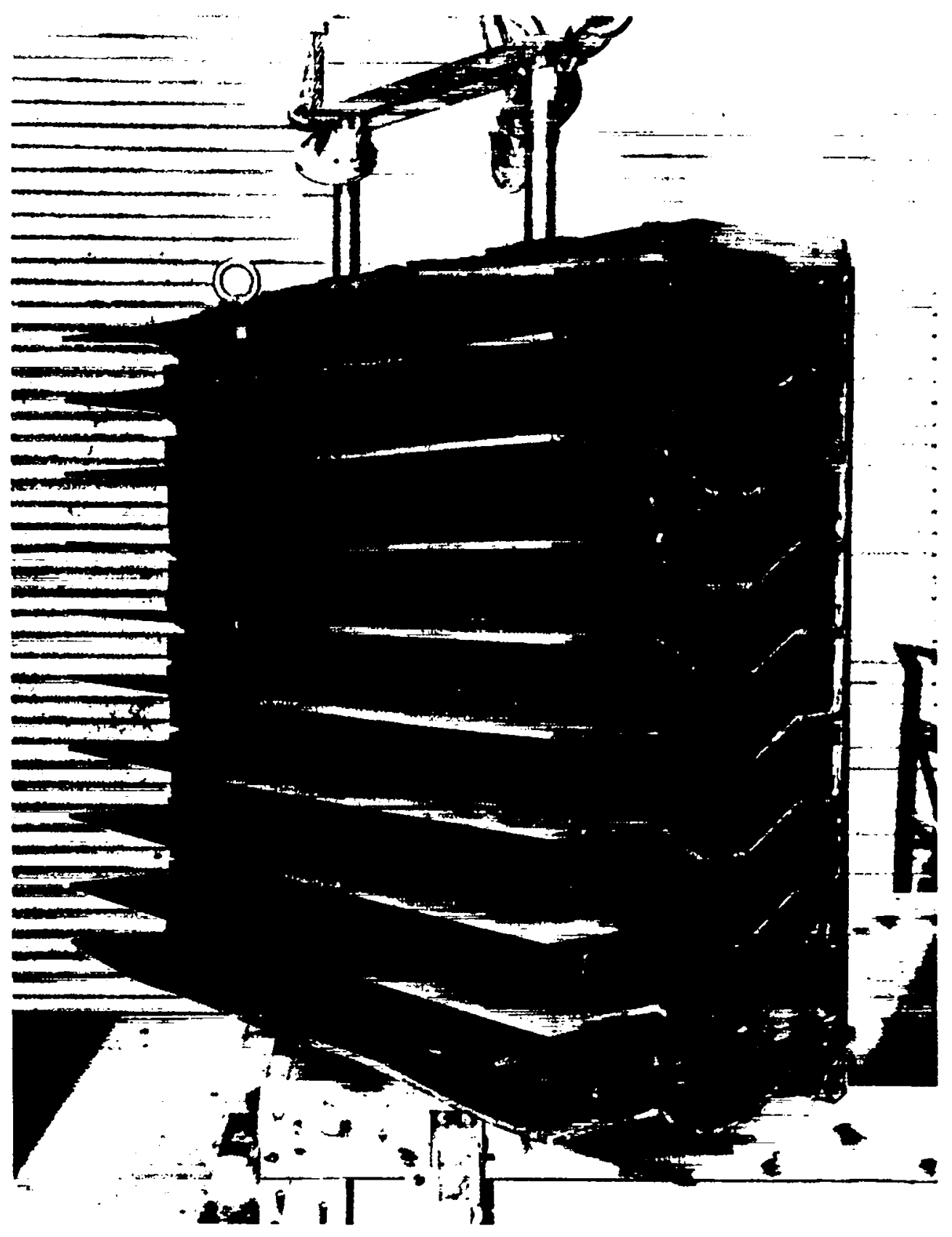

Fig. 78. Borated beechwood cask cover "D." 


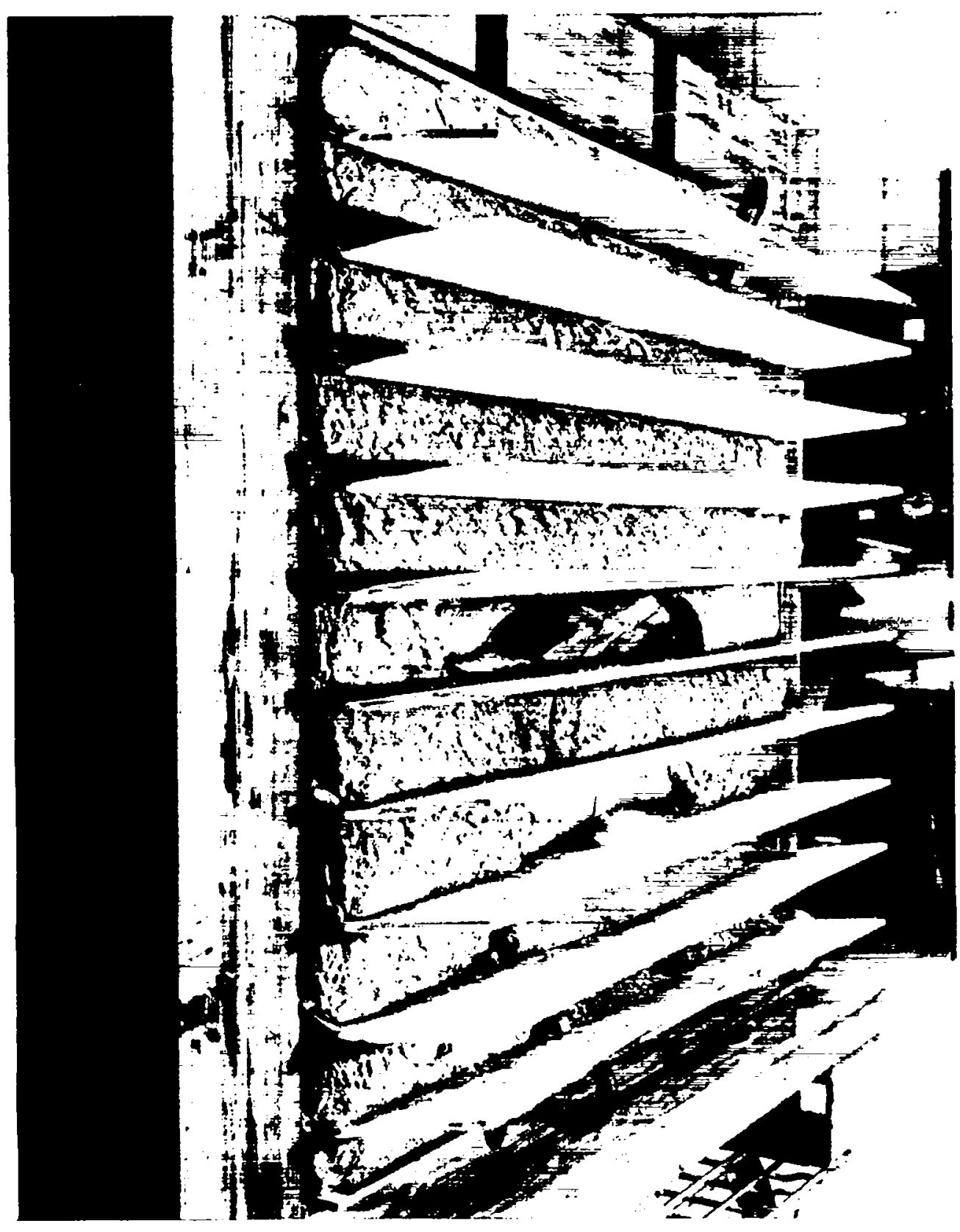

Fig. 79. Boro-silicone cover " $H$ " in mockup shipping cask. 
Frinted in the Unitud Statex of Amcrica. Avaitible from National Technical Information Service

tiS Deportnient of Commerie

5285 Purt Royal Road

Springfeld. VA 22161

Miczoriche $\$ 3.00$

$\begin{array}{llllllllll}001.025 & 4.00 & 126-130 & 7.25 & 251-275 & 10.75 & 376-400 & 13.00 & 501-525 & 15.25 \\ 026.050 & 4.50 & 151-175 & 8.00 & 276.300 & 11.00 & 401425 & 13.25 & 556-550 & 15.50 \\ 051075 & 5.25 & 176-200 & 9.00 & 301.325 & 11.75 & 426450 & 14.00 & 551-575 & 16.25 \\ 076.100 & 6.00 & 201.225 & 9.25 & 326.350 & 12.00 & 451-475 & 14.50 & 576-00 & 16.50 \\ 101-125 & 6.50 & 226.250 & 9.50 & .151-375 & 12.50 & 476-500 & 15.00 & 601-4 p & \end{array}$

Note: Add \$2.50 for sach duditionsl th0-rape inctenent from 601 puges up. 